\title{
ECONOMICS
}

\section{IMPORT PENETRATION AND CONSUMPTION OF DOMESTIC AND FOREIGN VARIETIES}

\author{
by
}

Kenneth W. Clements

Economics Discipline, Business School, University of Western Australia

\section{Long Vo}

Economics Discipline, Business School, University of Western Australia

and

Marc Jim Mariano

KPMG Economics 


\title{
IMPORT PENETRATION AND CONSUMPTION OF DOMESTIC AND FOREIGN VARIETIES*
}

\author{
by \\ Kenneth W. Clements ${ }^{\mathrm{a}}$, Long $\mathrm{Vo}^{\mathrm{a}}$ and Marc Jim Mariano ${ }^{\mathrm{b}}$
}

\begin{abstract}
This paper analyses import penetration with a consumer demand approach that distinguishes domestically and foreign-produced varieties. Consistent aggregation leads to a macro-level import demand equation that faithfully reflects the underlying micro demands for foreign varieties. The approach avoids restrictive assumptions such as homotheticity and permits an array of hypothesis tests of functional form. We show how to estimate the model with a relative short time series -- important for countries with limited data -- and as an illustrative example, apply it to Australia. We find that income growth is largely responsible for the recent surge in imports into that country.
\end{abstract}

Keywords: Disaggregated import demand; Consumer demand; Estimating demand equations; Bootstrap simulation

JEL classifications: D12, F41

\footnotetext{
* Acknowledgements: For helpful discussions, we thank George Verikios. All remaining errors are ours. Corresponding: ken.clements@uwa.edu.au

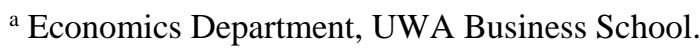

${ }^{\mathrm{b}}$ KPMG Economics.
} 


\section{Introduction}

Over the last two decades, import penetration in Australia has risen substantially. Panel A of Figure 1.1 shows the evolution of the share of sales of food and agricultural products in Australia coming from imported sources. As can be seen, the share has increased from about 6 percent in 1996 to a little under 12 percent in 2017, so it has almost doubled over two decades. Similar large increases occur in the other seven groups in the figure, and imports in total have risen by more than 12 percentage points (panel I).

In this paper we use a consumer demand system for domestic and foreign varieties of a number of goods to analyse changes in import penetration. The paper extends prior research in several ways. A prominent approach is to break-up the problem into two steps - first allocate total expenditure to the broad groups and then, given that decision, split spending on each into domestic and foreign components. Our paper proposes an alternative one-step approach that treats both varieties for all goods simultaneously. This avoids issues related to endogeneity of group expenditures and the restrictive assumption of homotheticity. We show how our framework can be implemented with a short span of data, important for countries with limited data endowments, and how it permits an array of hypothesis tests pertaining to functional form. The paper also demonstrates how consistent aggregation over demand equations leads to a subsystem for each good, which is a convenient mechanism to study import penetration. Additionally, aggregating equations leads to a macro-level total demand for imports, reflecting the underlying micro demands for foreign varieties in a satisfactory manner. Thus, the elasticities of total imports are weighted averages of their micro counterparts. Finally, we show how our approach can be used for counter-factual simulations that isolate factors responsible for the rapid import growth.

There are two broad streams of literature dealing with import penetration. The first generation research starts directly with an import demand equation such as 


$$
\log q=\lambda_{0}+\lambda_{1} \log \frac{p}{P}+\lambda_{2} \log y+\text { controls. }
$$

Here, $q$ is the volume of imports, $\frac{p}{P}$ the relative price, $y$ real income, $\lambda_{1}<0$ the price elasticity and $\lambda_{2}>0$ the income elasticity. Regarding imports as the excess demand for the good, $q=$ $q^{d}-q^{s}$, where $q^{d}\left(q^{s}\right)$ is domestic demand (supply), and the price elasticity of imports is a simple function of the elasticity of domestic demand $\left(\eta^{d}<0\right)$ and supply $\left(\eta^{s}>0\right)$, that is, $\lambda_{1}=\omega \eta^{d}+(1-\omega) \eta^{s}$, where $\omega=q^{d} / q$. There is an extensive literature on this approach and surveys are available by, for example, Goldstein and Khan (1985), Hooper et al. (2000), Magee (1975), Marquez (1990, 1999, 2002) and Stern et al. (1976). A particularly influential paper in this stream is Houthakker and Magee (1969).

Second-generation research treats domestic and imported varieties of each good as two distinct goods, so rather than imports being the excess demand, now there is a separate demand function for these, as well as one for the domestically produced good. This approach makes explicit the substitution between the imported and domestic goods. As there are domestic and foreign varieties of each good, the number of demand equations equals twice the number of goods separately identified, which can be large even for only a modest number of goods. A common practice is to simplify the problem by dividing it into two steps. The first considers spending on each good from both foreign and domestic sources. Typically, this involves the split of total expenditure into spending on the broad aggregates such as food, clothing, housing, etc. This might be governed by a demand model such as the linear expenditure system (LES, Stone, 1954). The second step of this approach deals with the split of expenditure into domestic and foreign components. A popular choice for this purpose is the constant elasticity of substitution expenditure (CES) system.

The attractive features of the two-step approach include its comprehensive nature with the extensive commodity detail, as well as the clean analytic interpretation of the parameters of the LES and CES. There is also the key advantage of the reduced dimensionality of the 
problem. With $G$ broadly-defined groups of goods, there are $2 G$ demands with a $2 G \times 2 G$ substitution matrix. This matrix contains $4 G^{2}$ elements, which for $G=10$, for example, is 400 . This matrix is restricted to be symmetric negative semidefinite, but even then the number of free elements is still huge at $G(2 G+1)$, or 210 for $G=10$. The LES involves $2 G-1$ free parameters ( $G$ subsistence parameters and $G-1$ marginal shares), while the CES has $2 G$ ( $G$ distribution parameters and $G$ elasticities of substitution), a total of $4 G-1$ parameters. Reducing the $G(2 G+1)$ elements of the matrix to $4 G-1$ more basic parameters represents a major advantage; in fact, this reductions is crucial in making the approach computationally feasible.

Empirical research on the second approach described above was initiated by Armington (1969). The substitutability between domestic and foreign goods (or the so-called “Armington elasticity”) is one of the key parameters in much of computable general equilibrium (CGE) modelling. In a survey, Lloyd and Zhang (2006) identify a number of CGE models that use Armington elasticities, and they go so far as to emphasise that the Armington framework dominates CGE modelling of trade policy issues. ${ }^{2}$ Contemporary major users of the Armington approach include the MONASH model (Dixon and Rimmer, 2002), the models of the Centre for International Economics (Stoeckel et al., 1990) and the Global Trade Analysis Project (GTAP, Hertel, 1997). It should also be noted that the Armington model plays a prominent role in modern numerical trade theory (Costinot and Rodríguez-Clare, 2014).

The LES is also used in several leading CGE models for the allocation of expenditure to the broad groups in the first step. There are some disadvantages of the LES-CES combination, however. The first is that these are based on separability. LES is derived from the

\footnotetext{
${ }^{2}$ Early examples include Sato (1968), Miller and Spencer (1977), Lloyd (1979a, 1979b), Deardorff and Stern (1981), Dixon et al. (1982) and Shoven and Whalley (1984).
} 
Stone-Geary utility function which is additive with no interactions among groups, the strongest form of separability. The CES utility function is also separable, but not additive. When applied to domestic and foreign varieties of the same group, separability may not be too unreasonable when broad aggregates are used, as these are likely to exhibit limited utility interactions. The more serious issue with CES is that it is homothetic (income elasticities are all unitary). Suppose the foreign variety is more luxurious than the domestic counterpart (think: imported French champagne versus locally produced sparklingly wine). With the income elasticity of both varieties constrained to unity, CES cannot account for the frequently occurring phenomenon of surging imports of imported varieties when income rises. The two-step procedure can itself be another disadvantage. This decision hierarchy is usually justified by separability, but there can still be the problem of endogeneity of group expenditure in the allocation of the second step. "Fortunately", as the income (that is, expenditure) elasticities of the CES are constrained to unity, the possibility of biased estimates is sidestepped. ${ }^{3}$

Two studies are more closely related to ours. Berner (1977) considers the demand for five groups of goods, each coming from three sources, domestic, the European Economic Community (EEC) and the rest of the world. Goods belonging to the same group, such as domestically produced food items and those imported from the EEC, are allowed to interact fully in generating utility. On the other hand, between-group interactions are more limited. For the allocation to groups, Berner uses two demand models, the S-branch system (Brown and

\footnotetext{
${ }^{3}$ There is a related matter due to Gorman (1959), who considered the conditions required for a two-step approach to result in expenditure equations of the first step that contain well-defined indexes of the prices of the groups of goods. He showed this requires either separability or a stringent homogeneity condition on the group sub-utility functions, a condition satisfied by the CES as it is homothetic. Accordingly, while the CES is rigid because of its unitary expenditure elasticities, this very limitation gives it immunity from endogeneity and Gorman-type problems.
} 
Heien, 1972) and the Rotterdam model (Barten, 1964; Theil, 1965). The estimates of the Rotterdam model seem to be more successful than those of the S-branch. The sample period (1954-70) was a time of relative economic tranquillity with limited variability of the data, possibly leading to imprecise estimates of the model. Although not clear from the paper, that could have been the reason for employing the mixed estimation procedure (that merges subjective prior distributions on the parameters with sample evidence) for the Rotterdam. Detailed results are presented for Germany only, but Berner notes that for two other countries, the Rotterdam sample estimates were not satisfactory.

The second closely related paper is Marquez (1993) who considers the demand for imports from several countries, as well as the demand for domestic goods. Thus, if there are $n$ countries, there is a system of $n$ demand equations for each country, $n-1$ imports plus the demand for domestic goods. While Marquez also uses the Rotterdam model, in contrast to Berner, all types of imports from a given country are aggregated into one good. Marquez considers $n=5$ countries of origin and estimates the model for each destination country, Canada, Japan and the US. All but one of the own-price effects are negative, but many of the cross-price effects are small and insignificant, and the substitution matrix is not negative semidefinite for Japan and the US. ${ }^{4}$

\footnotetext{
${ }^{4}$ Both Berner (1977) and Marquez (1993) use the Rotterdam model, but there is a difference in the form of the model. Berner uses the "relative price version" (which holds constant the marginal utility of income), while Marquez uses the "absolute price version" (real income constant). The price responses of the absolute version combine the specific and general substitution effects; these responses are of the nature of reduced-form coefficients and cannot be used to identify utility interactions among goods. In another paper, Marquez (1999) estimates an import demand equation for Canada, Japan and the US. He uses the Rotterdam functional form again, but rather than an equation system, the demand for imports from all sources is treated as a single equation for each country.
} 
Finally, there is related research that advocates disaggregation in import demand estimation. Estimating elasticities with disaggregated data and then aggregating up typically leads to substantial larger elasticities, as compared to those estimated directly with aggregated data. This work includes Freenstra et al. (2018), Imbs and Méjean (2015), Kee et al. (2008); see also Hummels and Lee (2018).

The remainder of this paper is structured as follows. Section 2 sets out the details of the demand system to be used, while Section 3 introduces a method of estimation that can be employed with modest-sized samples. The model is applied in Section 4 to Australian data of the last two decades with $G=8$ groups, each with domestic and foreign varieties. A novel twodimensional aggregation scheme is used in Section 5: (i) The demand equations are aggregated over the two varieties to give sub-models for each group that can be used for market analysis. (ii) The foreign-variety demands are aggregated over the 8 groups to give the demand for total imports. Surprisingly, Section 6 shows that the primary driver of the higher import penetration in Australia was not the lower prices of foreign goods associated with trade liberalisation. Many of these prices did indeed fall but when combined with low price elasticities, this was insufficient to account for the increased penetration. Higher incomes are shown to have been responsible for the increased imports -- higher incomes meant more spending on superiorquality varieties, and these were typically imported. Concluding comments are contained in Section 7.

\section{Demand Equations}

Let there be $n$ goods purchased by the consumer in quantities $q_{1}, \cdots, q_{n}$, at prices $p_{1}, \cdots, p_{n}$. Spending on good $i$ is $p_{i} q_{i}$, and so total expenditure is $\sum_{i=1}^{n} p_{i} q_{i}$, which plays the role of the budget constraint:

(2.1) $\quad \sum_{i=1}^{n} p_{i} q_{i}=M$. 
This $M$ is total expenditure, but as an abbreviation, it will be referred to as "income". The share of income devoted to good $i$ is $w_{i}=\frac{p_{i} q_{i}}{M}$, which is known as the budget share. Suppose we have annual observations indexed by $t=0,1, \cdots, T$. Define $\bar{w}_{i t}=1 / 2\left(w_{i t}+w_{i, t-1}\right)$ as the arithmetic average of the $i^{t h}$ budget share in years $t$ and $t-1$ and $D q_{i t}=\log q_{i t}-\log q_{i, t-1}$ as the $i^{t h}$ quantity log-change. The Divisia volume index is then

$$
D Q_{t}=\sum_{i=1}^{n} \bar{w}_{i t} D q_{i t}
$$

This is a budget-share-weighted average of the growth in the $n$ quantities consumed and is an index of the change in the consumer's real income.

Next, define $\theta_{i}=\frac{\partial\left(p_{i} q_{i}\right)}{\partial M}$ as the $i^{t h}$ marginal share, the impact on spending on good $i$ following a \$1-rise in income. As the increase in income is totally spent, these shares have a unit sum:

$$
\text { (2.3) } \quad \sum_{i=1}^{n} \theta_{i}=1 \text {. }
$$

The Frisch price index is a marginal-share weighted average of the changes in prices:

$$
D P_{t}^{\prime}=\sum_{i=1}^{n} \theta_{i} D p_{i t}
$$

where $D p_{i t}=\log p_{i t}-\log p_{i, t-1}$. These indexes are used in the Rotterdam model (Barten, 1964, Theil, 1965), which takes the form

$$
\bar{w}_{i t} D q_{i t}=\theta_{i} D Q_{t}+\sum_{j=1}^{n} v_{i j}\left(D p_{j t}-D P_{t}^{\prime}\right)+\varepsilon_{i t}, \quad i=1, \cdots, n
$$

The term on the left-hand side is $\bar{w}_{i t} D q_{i t}$, the change in the quantity demanded of good $i$ weighted by its (average) budget share. As $\Delta w_{i} \approx \bar{w}_{i t} D p_{i t}+\bar{w}_{i t} D q_{i t}-\bar{w}_{i t} D M_{t}$, where $D M_{t}=$ $\log M_{t}-\log M_{t-1}$, the variable on the left of (2.5) is interpreted as the quantity component of the change in the $i^{\text {th }}$ budget share, the endogenous part of the change. The first term on the right measures the effect of income changes and is the Divisia volume index, $D Q_{t}$, with coefficient $\theta_{i}$, the marginal share of $i$. It is to be noted that $D Q_{t}$ is the sum over $i=1, \cdots, n$ of the variable on the left of (2.5). 
The second term on the right of (2.5), $\sum_{j=1}^{n} v_{i j}\left(D p_{j t}-D P_{t}^{\prime}\right)$, is a weighted sum of $n$ relative price changes, which measures the substitution effects of price changes. These are relative price changes with the change in each nominal price, $D p_{j t}$, deflated by the Frisch price index $D P_{t}^{\prime}$. The price coefficients, $v_{i j}$, are symmetric in $i$ and $j$ :

$$
v_{i j}=v_{j i}, \quad i, j=1, \cdots, n,
$$

and satisfy

$$
\sum_{j=1}^{n} v_{i j}=\phi \theta_{i}, \quad i=1, \cdots, n,
$$

where $\phi<0$ is the income flexibility, the reciprocal of the income elasticity of the marginal utility of income. Constraints (2.3) and (2.7) imply $\sum_{i=1}^{n} \sum_{j=1}^{n} v_{i j}=\phi$. The final term on the right of model (2.5) is the random disturbance $\varepsilon_{i t}$, assumed to be zero mean and serially uncorrelated. Dividing both sides of (2.5) by $\bar{w}_{i t}$, it can be seen that $\eta_{i}=\frac{\theta_{i}}{\bar{w}_{i t}}$ is the income elasticity of good $i$ and that $F_{i j}=\frac{v_{i j}}{\bar{w}_{i t}}$ is the $(i, j)^{t h}$ Frisch price elasticity, the elasticity of demand for $i$ with respect to the Frisch-deflated price of $j$, which holds constant the marginal utility of income.

Equation (2.5) is the relative price version of the model. Substitution of (2.4) into (2.5) and using (2.7), gives the absolute-price version:

$$
\bar{w}_{i t} D q_{i t}=\theta_{i} D Q_{t}+\sum_{j=1}^{n} \pi_{i j} D p_{j t}+\varepsilon_{i t}
$$

where $\pi_{i j}=v_{i j}-\phi \theta_{i} \theta_{j}$ is a Slutsky coefficient. These coefficients measure the total substitution effects and satisfy symmetry, $\pi_{i j}=\pi_{j i}, i, j=1, \cdots, n$, and homogeneity, $\sum_{j=1}^{n} \pi_{i j}=0, i=1, \cdots, n$. The $(i, j)^{t h}$ Slutsky elasticity is $S_{i j}=F_{i j}-\phi \eta_{i} \theta_{j}$, while the corresponding Marshallian elasticity (measuring the income and substitution effects combined) is $M_{i j}=S_{i j}-\eta_{i} \bar{w}_{j t}$. 
Model (2.8) can be derived from the familiar Marshallian demand equation, $q_{i}=$ $q_{i}\left(M, p_{1}, \cdots, p_{n}\right)$, in differential form. Thus, $d q_{i}=\frac{\partial q_{i}}{\partial M} d M+\sum_{j=1}^{n} \frac{\partial q_{i}}{\partial p_{j}} d p_{j}$, or using $\frac{d x}{x}=$ $d \log x$ and multiplying through by $w_{i}, w_{i} d \log q_{i}=\frac{\partial p_{i} q_{i}}{\partial M} d \log M+\sum_{j=1}^{n} \frac{p_{i} p_{j}}{M} \frac{\partial q_{i}}{\partial p_{j}} d \log p_{j}$. Using the Slutsky decomposition, $\frac{\partial q_{i}}{\partial p_{j}}=s_{i j}^{*}-q_{j} \frac{\partial q_{i}}{\partial M^{\prime}}$, where $s_{i j}^{*}$ is the (symmetric) substitution effect, we have

$$
w_{i} d \log q_{i}=\left(\frac{\partial p_{i} q_{i}}{\partial M}\right) d \log Q+\sum_{j=1}^{n}\left(\frac{p_{i} p_{j} s_{i j}^{*}}{M}\right) d \log p_{j}
$$

where $d \log M-\sum_{j=1}^{n} w_{j} d \log p_{j}=\sum_{j=1}^{n} w_{j} d \log q_{j}$, which follows from the total differential of (2.1). The absolute price version (2.8) is a finite-change version of (2.9) with $\theta_{i}=\frac{\partial\left(p_{i} q_{i}\right)}{\partial M}$ and $\pi_{i j}=\frac{p_{i} p_{j} s_{i j}^{*}}{M}$. Using $\pi_{i j}+\phi \theta_{i} \theta_{j}=v_{i j}$, the relative price version (2.5) can be obtained from (2.8).

To deal with domestic and foreign varieties, divide the $n$ goods into $G<n$ groups denoted by $\boldsymbol{S}_{1}, \cdots, \boldsymbol{S}_{G}$, such that each good belongs to one group only. Goods within each group are taken to be reasonably close substitutes, while there is limited substitution between varieties belonging to different groups. If groups are strongly separable, then the utility function is of the form $\sum_{g=1}^{G} u_{g}\left(\boldsymbol{q}_{g}\right)$, where $u_{g}\left(\boldsymbol{q}_{g}\right)$ is the sub-utility function for $g$ and $\boldsymbol{q}_{g}$ are the quantities belonging to $\boldsymbol{S}_{g}$. This implies the following restrictions on the price coefficients of model (2.5):

$$
v_{i j} \begin{cases}\neq 0 & i, j \in S_{g}, \quad g=1, \cdots, G \\ =0 & i \in S_{g}, j \in S_{h}, \quad g \neq h, g, h=1, \cdots, G,\end{cases}
$$

so that the demand for $i \in S_{g}$ is

$$
\bar{w}_{i t} D q_{i t}=\theta_{i} D Q_{t}+\sum_{j \in S_{g}} v_{i j}\left(D p_{j t}-D P_{t}^{\prime}\right)+\varepsilon_{i t}
$$

Now the prices affecting the consumption of good $i$ are only those of goods belonging to the same group as the good in question, so there is an appealing unification between the structure of the utility function and the demand equations. 
Suppose there are two varieties of each good, those from domestic and foreign sources, and the two varieties of each good form a separable group. Thus, we shall denote varieties by the subscript $i$, with $i=1,2$ for domestic and foreign varieties, and indicate the group by the superscript $g$, as set out in Table 2.1. With this notation system, the demands for the domestic and foreign varieties are

$$
\bar{w}_{i t}^{g} D q_{i t}^{g}=\theta_{i}^{g} D Q_{t}+\sum_{j=1}^{2} v_{i j}^{g}\left(D p_{j t}^{g}-D P_{t}^{\prime}\right)+\varepsilon_{i t}^{g}, i=1,2 ; g=1, \cdots, G .
$$

Here, $D Q_{t}=\sum_{g=1}^{G} \sum_{i=1}^{2} \bar{w}_{i t}^{g} D q_{i t}^{g}$ and $D P_{t}^{\prime}=\sum_{g=1}^{G} \sum_{i=1}^{2} \theta_{i}^{g} D p_{i t}^{g}$.

According to Equation (2.11), the demand for the domestically (foreign) produced variety of a good in group $g$ is affected by income, its own relative price and that of the foreign (domestic) variety. From (2.6) and (2.7), the price coefficients now satisfy

$$
\begin{aligned}
& v_{12}^{g}=v_{21}^{g}, g=1, \cdots, G \\
& \sum_{j=1}^{2} v_{i j}^{g}=\phi \theta_{i}^{g}, i=1,2, g=1, \cdots, G
\end{aligned}
$$

For $g, h=1, \cdots, G$, the $(i, j)^{t h}$ Frisch, Slutsky and Marshallian price elasticities are, respectively, $F_{i j}^{g h}=\delta_{g h} \frac{v_{i j}^{g}}{\bar{w}_{i t}^{g}}$, where $\delta_{g h}$ is the Kronecker delta; $S_{i j}^{g h}=F_{i j}^{g h}-\phi \eta_{i}^{g} \theta_{j}^{h}$, where $\eta_{i}^{g}=\frac{\theta_{i}^{g}}{\bar{w}_{i t}^{g}}$ is the income elasticity of $i \in \boldsymbol{S}_{g}$; and $M_{i j}^{g h}=S_{i j}^{g h}-\eta_{i}^{g} \bar{w}_{j t}^{h}$.

\section{Estimation}

To estimate model (2.11) subject to constraints (2.12) and (2.13), several complexities need to be addressed.

\section{The Constraints and Dimensionality}

The constraints can be substituted out in the manner suggested by Theil (1975/76). For each group $g$, constraint (2.13) can be used to eliminate the diagonal elements of the $2 \times 2$ matrix of price coefficients $\left[v_{i j}^{g}\right]$. Define $A_{i t}^{g}(\boldsymbol{\theta})=\theta_{i}^{g}\left(D p_{i t}^{g}-\sum_{g=1}^{G} \sum_{k=1}^{2} \theta_{k}^{g} D p_{k t}^{g}\right)$, with $\boldsymbol{\theta}=$ $\left[\theta_{k}^{g}\right]$, a vector of all the marginal shares, and the price difference $\Delta p_{i j, t}^{g}=D p_{i t}^{g}-D p_{j t}^{g}, i \neq j$, 
which satisfies $\Delta p_{i j, t}^{g}=-\Delta p_{j i, t}^{g}$. Then, using symmetry, $v_{21}^{g}=v_{12}^{g}$, the price term of (2.11) can be written for $i=1,2$ as:

$$
\left[\begin{array}{c}
\sum_{j=1}^{2} v_{1 j}^{g}\left(D p_{j t}^{g}-D P_{t}^{\prime}\right) \\
\sum_{j=1}^{2} v_{2 j}^{g}\left(D p_{j t}^{g}-D P_{t}^{\prime}\right)
\end{array}\right]=\left[\begin{array}{cc}
A_{1 t}^{g}(\boldsymbol{\theta}) & \Delta p_{21, t}^{g} \\
A_{2 t}^{g}(\boldsymbol{\theta}) & -\Delta p_{21, t}^{g}
\end{array}\right]\left[\begin{array}{c}
\phi \\
\\
v_{12}^{g}
\end{array}\right] .
$$

This vector form highlights the cross-equation constraints. Thus, model (2.11) becomes

$$
\bar{w}_{i t}^{g} D q_{i t}^{g}=\theta_{i}^{g} D Q_{t}+\phi A_{i t}^{g}(\boldsymbol{\theta})+v_{12}^{g}[2 \gamma(i)-1] \Delta p_{21, t}^{g}+\varepsilon_{i t}^{g} ; i=1,2 ; g=1, \cdots, G,
$$

where $\gamma(i)$ denotes an indicator variable that equals 1 when $i=1$ and zero when $i=2$.

For each group, now there are 2 marginal shares and one off-diagonal price coefficient and with $G$ groups, the total number of free parameters is $3 G$. There is also the income flexibility $\phi$, which is common to each equation. As the marginal shares have a unit sum, one of these is constrained, leaving the number of free parameters for the system at $3 G$. There are two item indexes in system (3.1), $i=1,2$ for the domestic and foreign varieties of goods within a group, and $g=1, \cdots, G$ for groups. It is convenient to provisionally consolidate the two indexes into one, $k=1, \cdots, 2 G$, and express (3.1) as

$$
\bar{w}_{k t} D q_{k t}=\theta_{k} D Q_{t}+\text { price terms }+\varepsilon_{k t} ; k=1, \cdots, 2 G
$$

The disturbance terms, $\varepsilon_{k t}$, are assumed to have zero means with variances and covariances denoted by $\sigma_{k l}=E\left(\varepsilon_{k t} \varepsilon_{l t}\right)$. The $2 G \times 2 G$ covariance matrix $\left[\sigma_{k l}\right]$ contains $G(2 G+1)$ distinct elements, which for $G=8$ amounts to 136 . Our data with $T=22$ years (see below) are insufficient to estimate with any precision these 136 elements together with the $3 G=24$ coefficients. $^{5}$

\footnotetext{
${ }^{5}$ On the problems of estimating systems when the sample size is small relative to the number of goods, see Appendix A2.
} 


\section{The Covariance Matrix}

To make the problem tractable, we initially ignore the dependence of $A_{i t}^{g}(\boldsymbol{\theta})$ on $\boldsymbol{\theta}$ by treating the term as known, and assume $\sigma_{k l}=\sigma^{2} w_{k}\left(\delta_{k l}-w_{l}\right)$, where $w_{k}$ is now interpreted as the sample mean of $\bar{w}_{k t}$. This is the covariance structure associated with the multinomial distribution with probabilities $w_{1}, \cdots, w_{2 G}$. We write Equation (3.1) for a given year $t$ in vector form by stacking each commodity one on top of the other to give $\boldsymbol{y}_{t}=\boldsymbol{X}_{t} \boldsymbol{\beta}+\boldsymbol{\varepsilon}_{t}$. The $2 G \times$ $2 G$ disturbance covariance matrix $\mathrm{E}\left(\boldsymbol{\varepsilon}_{t} \boldsymbol{\varepsilon}_{t}^{\prime}\right)$ takes the form $\boldsymbol{\Sigma}=\sigma^{2}\left(\boldsymbol{W}-\boldsymbol{w} \boldsymbol{w}^{\prime}\right)$, where $\boldsymbol{W}=$ $\operatorname{diag}[\boldsymbol{w}]$ and $\boldsymbol{w}=\left[w_{1}, \cdots, w_{2 G}\right]$. This matrix is singular $\left(\boldsymbol{\Sigma} \boldsymbol{\iota}=\mathbf{0}\right.$, as $\boldsymbol{w}^{\prime} \boldsymbol{\iota}=1$ where $\boldsymbol{\iota}$ is a vector of unit elements) since model (3.1) is a budget allocation system, implying $\boldsymbol{\varepsilon}_{t}^{\prime} \boldsymbol{\iota}=0$. One equation is redundant and the solution is to drop one and the results are invariant to which equation is chosen (Barten, 1969). Delete the last equation and define $\widetilde{\boldsymbol{\Sigma}}=\sigma^{2}\left(\widetilde{\boldsymbol{W}}-\widetilde{\boldsymbol{w}} \widetilde{\boldsymbol{w}}^{\prime}\right)$ as the covariance matrix of the reduced system, where $\widetilde{\boldsymbol{W}}=\operatorname{diag}[\widetilde{\boldsymbol{w}}]$ with $\widetilde{\boldsymbol{w}}$ the vector of the remaining $2 G-1$ budget shares. Then, the inverse of this covariance matrix is

$$
\widetilde{\boldsymbol{\Sigma}}^{-1}=\frac{1}{\sigma^{2}}\left(\widetilde{\boldsymbol{W}}^{-1}+\frac{1}{w_{2 G}} \boldsymbol{\iota}^{\prime}\right)
$$

where $w_{2 G}$ is the share of the omitted good. ${ }^{6}$

Let $\boldsymbol{e}_{t}=\left[e_{1 t}, \cdots, e_{2 G-1, t}, e_{2 G, t}\right]^{\prime}$ be the vector of the $2 G$ residuals of the full system and $\tilde{\boldsymbol{e}}_{t}=\left[\tilde{e}_{1 t}, \cdots, \tilde{e}_{2 G-1, t}\right]^{\prime}$ be the vector of the $2 G-1$ residuals of the reduced system. It follows from $\boldsymbol{\varepsilon}_{t}^{\prime} \boldsymbol{\iota}=0$ that $\boldsymbol{e}_{t}^{\prime} \boldsymbol{\iota}=0$ and $\tilde{\boldsymbol{e}}_{t}^{\prime} \boldsymbol{\iota}=-e_{2 G, t}$. Using GLS, we minimise the sum over $t=$ $1, \cdots, T$ of the quadratic form of the latter residuals with weight matrix the inverse covariance matrix $\widetilde{\boldsymbol{\Sigma}}^{-1}$. It follows from Equation (3.3) that this sum is

$$
\sum_{t=1}^{T} \tilde{\boldsymbol{e}}_{t}^{\prime} \widetilde{\boldsymbol{\Sigma}}^{-1} \tilde{\boldsymbol{e}}_{t}=\frac{1}{\sigma^{2}} \sum_{t=1}^{T} \tilde{\boldsymbol{e}}_{t}^{\prime}\left(\widetilde{\boldsymbol{W}}^{-1}+\frac{1}{w_{2 G}} \boldsymbol{\iota}^{\prime}\right) \tilde{\boldsymbol{e}}_{t}=\frac{1}{\sigma^{2}} \sum_{k=1}^{2 G} \sum_{t=1}^{T}\left(\frac{e_{k t}}{\sqrt{w_{k}}}\right)^{2}
$$

\footnotetext{
${ }^{6}$ For more on the stacked form of the model, see Appendix A1. For a justification of the multinomial approach and further details of the above, see Appendix A2.
} 
where the second step is based on $\boldsymbol{\iota}^{\prime} \tilde{\boldsymbol{e}}_{t}=-e_{2 G, t}$. The quadratic form for the reduced system involves the weighted squares and cross-products of the residuals, but from the far-right side of (3.4), the counterpart for the full system has no cross-product terms. That is, the GLS criterion is equivalent to the weighted sum of squares of the full system with weights the reciprocals of the square roots of the budget shares. As commodities with larger budget shares tend to have a larger dispersion, this can be viewed as a variance-stabilising weighting scheme.

The multinomial approach transforms what would have been a large-scale SURE-type problem into a more-manageable single-equation one: After multiplying through by $\frac{1}{\sqrt{w_{k}}}$, Equation (3.2) -- the full model -- can be estimated as a single equation by OLS using all $2 G \times$ $T$ observations:

$$
\frac{\bar{w}_{k t} D q_{k t}}{\sqrt{w_{k}}}=\theta_{k} \frac{D Q_{t}}{\sqrt{w_{k}}}+\frac{\text { price terms }}{\sqrt{w_{k}}}+\frac{\varepsilon_{k t}}{\sqrt{w_{k}}}, k=1, \cdots, 2 G ; t=1, \cdots, T .
$$

This is a pooled OLS approach. Let $\sqrt{\boldsymbol{W}^{-1}}$ denote the $2 G \times 2 G$ diagonal matrix with the reciprocals of the square roots of the budget shares on the diagonal, and define the transforms $\boldsymbol{y}_{t}^{*}=\sqrt{\boldsymbol{W}^{-1}} \boldsymbol{y}_{t}, \boldsymbol{X}_{t}^{*}=\sqrt{\boldsymbol{W}^{-1}} \boldsymbol{X}_{t}, \boldsymbol{\varepsilon}_{t}^{*}=\sqrt{\boldsymbol{W}^{-1}} \boldsymbol{\varepsilon}_{\boldsymbol{t}}$. Multiplying both sides of $\boldsymbol{y}_{t}=\boldsymbol{X}_{t} \boldsymbol{\beta}+\boldsymbol{\varepsilon}_{t}$ by $\sqrt{\boldsymbol{W}^{-1}}$ gives $\boldsymbol{y}_{t}^{*}=\boldsymbol{X}_{t}^{*} \boldsymbol{\beta}+\boldsymbol{\varepsilon}_{t}^{*}$, and the BLU estimator of the coefficient vector $\boldsymbol{\beta}$ is $\widehat{\boldsymbol{\beta}}=$ $\left(\sum_{t=1}^{T} \boldsymbol{X}_{t}^{* \prime} \boldsymbol{X}_{t}^{*}\right)^{-1} \sum_{t=1}^{T} \boldsymbol{X}_{t}^{* \prime} \boldsymbol{y}_{t}^{*}$, which is equal to $\left(\sum_{t=1}^{T} \boldsymbol{X}_{t}^{\prime} \boldsymbol{\Sigma}^{-1} \boldsymbol{X}_{t}\right)^{-1} \sum_{t=1}^{T} \boldsymbol{X}_{t}^{\prime} \boldsymbol{\Sigma}^{-1} \boldsymbol{y}_{t}$.

The multinomial approach is somewhat restrictive, as all covariances are negative and do not allow for specific interdependencies between individual pairs of goods. But the approach avoids the problem of having to estimate a large number of elements of the unrestricted disturbance covariance matrix, and so leads to a considerable simplification of a complex estimation problem. Moreover, Monte Carlo studies point to the robust performance of this approach (Selvanathan, 1991; Theil, 1987).

There are two additional issues that need to be mentioned. First, model (3.1) is nonlinear in the parameters due to the term $A_{i t}^{g}(\boldsymbol{\theta})$, but this was ignored above by treating the vector of 
marginal shares, $\boldsymbol{\theta}$, as known. We deal with the nonlinearity with an iterative procedure. Secondly, to avoid relying on asymptotics, we use a bootstrap procedure for standard errors. Details of these procedures are provided in Appendix A3.

\section{Application}

We start with data for 20 sectors in Australia over the period 1996 - 2017 and then aggregate into $G=8$ broader groups, each with two varieties -- domestic and foreign. For details, see Appendix A4. The budget shares of Table 4.1 indicate the importance of food and energy, which between them more than 40 percent of the total. And in both cases, the domestic variety dominates. By contrast, several of the other groups have substantial foreign components - in the case of machinery and equipment, expenditure on the foreign variety exceeds the domestic counterpart. Figure 4.1 plots quantities against prices and in most instances, the regression line has a noticeable negative slope, giving informal support to the law of demand. ${ }^{7}$

We estimate model (3.1) using the approach described above and columns 4 - 6 of Table 4.2 contain the results. The marginal shares are all positive and the majority significant. All own-price coefficients are negative, but many imprecisely estimated with quite high standard errors. From the final row of this table, the estimate of the income flexibility is -0.506 , which is significant and agrees with prior estimates. ${ }^{8}$ A number of the cross-price coefficients appear insignificant - the only such coefficient more than twice its standard error is for "Wood and Paper Products". Looking at column 2 of panel B of Table 4.3, it can be seen that on the basis of univariate "t-tests", the hypothesis $H_{0}: v_{i j}^{g}=0, i \neq j$ cannot be rejected for any group. An "F-test” of the joint hypothesis of zero cross-price coefficients for all groups is

\footnotetext{
${ }^{7}$ Appendix A4 presents the Divisia moments, which reveal (i) for the majority of observations, quantities are more dispersed than prices; and (ii) the cross-commodity price-quantity correlations are negative. These results agree with prior studies as summarised by Clements (2019).

${ }^{8}$ For surveys, see Brown and Deaton (1972, p. 1206), Clements (2019) and Clements and Zhao (2009).
} 
rejected at the 5-percent level of significance, but not at the 1-percent, as shown in column 3 of row 1 of panel A. Could the domestic and foreign-produced varieties of the same good really be independent and not interact in the generation of utility? On the face of it, this would seem to stretch creditability, but there can be plausible explanations. Although all care has been exercised in constructing the data, it is still possible that the difficulty in matching varieties of some goods has led to measurement error. Alternatively, there could simply be insufficient price variation to precisely measure subtle interactions between varieties. A third explanation is that our tests could be faulty, although this would seem unlikely with the robust bootstrap approach used. ${ }^{9}$

In any event, on the basis of Occam's razor it is useful to examine the implications of reformulating the model in the simpler preference-independent form whereby all the crossprice coefficients are zero. Under preference independence (PI), model (2.11) becomes:

$$
\bar{w}_{i t}^{g} D q_{i t}^{g}=\theta_{i}^{g} D Q_{t}+v_{i i}^{g}\left(D p_{i t}^{g}-D P_{t}^{\prime}\right)+\varepsilon_{i t}^{g}, \quad i=1,2 ; g=1, \cdots, 8 .
$$

As shown in Appendix A10, the estimated marginal share for domestic "Wood and Paper Products” (hereafter, wood) is negative, which although insignificant, is inadmissible under PI. Interestingly, as noted above for the preference dependence model, wood was the only group for which the cross-price coefficient was more than twice its standard error. Therefore, it would seem appropriate to use the less-restricted version that allows this group to have interactions, that is, $v_{i j}^{5} \neq 0, i \neq j$. In a format similar to (3.1), this model can be expressed as:

$$
\bar{w}_{i t}^{g} D q_{i t}^{g}=\theta_{i}^{g} D Q_{t}+\phi A_{i t}^{g}(\boldsymbol{\theta})+\delta(g)[2 \gamma(i)-1] v_{12}^{g} \Delta p_{21, t}^{g}+\varepsilon_{i t}^{g}, i=1,2 ; g=1, \ldots 8,
$$

\footnotetext{
${ }^{9}$ As shown in Appendix A10, adding intercepts to the model (which allow for residual trends) does not change the estimates appreciably.
} 
where $\delta(g)$ is an indicator variable equal to 1 when $g=5$ (for wood) and zero when $g \neq 5$, and as before, $\gamma(i)$ is an indicator variable that equals 1 when $i=1$ and zero otherwise. This will be referred to as the "partial preference independence" (PPI) model.

We shall use model (4.2) subsequently as it is parsimonious and as shown in Table 4.4, all marginal shares are now positive. These estimates can be compared to those of the preference dependent model given in Table 4.2. First, the marginal shares, and their standard errors, are very similar. Second, regarding the domestic own-price coefficients, those of Table 4.4 are all absolutely lower (except for group 5, where the coefficient is slightly higher), and all their standard errors are lower. Third, the foreign own-price coefficients and their standard errors tend to fall. Fourth, the cross-price coefficient for wood is significantly positive and close to the Table 4.2 value; the positive value means the two varieties of the good are substitutes, which is plausible. Fifth, the changes in the price coefficients lead to a noticeable drop in the income flexibility from -0.51 to -0.36 , while its standard error falls by almost one-half. All in all, there is a reduced substitutability. From panel A, row 1, column 2 of Table 4.3, model (4.2) is acceptable at the 1-percent level, but not at the 1-percent level. ${ }^{10}$

There is considerable diversity among the income elasticities of column 7 of Table 4.4, and in all cases, the foreign-variety elasticity exceeds that of the domestic one. Foreign goods are evidently regarded as more luxurious than their domestic counterparts, agreeing with the idea that overseas-varieties tend to be more expensive and prized for their quality. From column 3 of panel B of Table 4.3, the hypothesis that the foreign income elasticities exceed the domestic ones cannot be rejected, as expected. As the income elasticities are less than unity, food is a necessity, in accordance with Engel's law (although the foreign variety is close to the cut-off value of unity). There is not a great deal of substitution as the price elasticities of

\footnotetext{
${ }^{10}$ For further implications of the estimates in Table 4.4, see Appendix A10.
} 
columns 8 and 9 are reasonably low, reflecting the broad nature of the goods involved. Finally, as shown by column 4, panel A of Table 4.3, completely ignoring the role of prices by setting all price coefficients to zero would be unwise, as expected. All in all, the estimates of Table 4.4 seem not unreasonable.

\section{The Macro Aggregates and Micro Elements}

The linear structure of the model means that consistent aggregates can be obtained by summing over subsets of goods. Taking imports as an example, denote the set of all foreignvariety goods (other than wood, to be treated separately) by $\boldsymbol{V}_{2}$. The budget and marginal shares of imports of all goods are $\bar{W}_{2 t}=\sum_{g \in V_{2}} \bar{w}_{2 t}^{g}, \quad \Theta_{2}=\sum_{g \in V_{2}} \theta_{2}^{g}$, so that $\bar{w}_{2 t}^{g} / \bar{W}_{2 t}$ and $\theta_{2}^{g} / \Theta_{2}$ are the shares of good $g$ within imports, or the conditional shares. The corresponding conditional Divisia volume and Frisch price indexes use these shares as weights:

$$
D Q_{2 t}=\sum_{g \in V_{2}} \frac{\bar{w}_{2 t}^{g}}{\bar{W}_{2 t}} D q_{2 t}^{g}, \quad D P_{2 t}^{\prime}=\sum_{g \in V_{2}} \frac{\theta_{2}^{g}}{\Theta_{2}} D p_{2 t}^{g}
$$

The demand for total imports is given by summing over $g \in \boldsymbol{V}_{2}$ both sides of the preference independent demand equation, Equation (4.1) for $i=2$ and with $\phi \theta_{2}^{g}$ substituted for $v_{i i}^{g}$ :

$$
\sum_{g \in \boldsymbol{V}_{2}} \bar{w}_{2 t}^{g} D q_{2 t}^{g}=\sum_{g \in \boldsymbol{V}_{2}} \theta_{2}^{g} D Q_{t}+\sum_{g \in \boldsymbol{V}_{2}} \phi \theta_{2}^{g}\left(D p_{2 t}^{g}-D P_{t}^{\prime}\right)
$$

which can be expressed as (see Appendix A7 for details)

$$
\bar{W}_{2 t} D Q_{2 t}=\Theta_{2} D Q_{t}+\phi \Theta_{2}\left(D P_{2 t}^{\prime}-D P_{t}^{\prime}\right)
$$

where, for simplicity, the disturbance has been omitted. This is the demand for all imports, or the group demand equation; thus, imports depend on the changes in real income, $D Q_{t}$, and their relative price, $D P_{2 t}^{\prime}-D P_{t}^{\prime}$.

Dividing both sides of Equation (5.1) by $\bar{W}_{2 t}$ shows that $\frac{\Theta_{2}}{\bar{W}_{2 t}}$ and $\phi \frac{\Theta_{2}}{\bar{W}_{2 t}}$ are the income and price elasticities of demand for $\boldsymbol{V}_{2}$. Since $\frac{\Theta_{2}}{\bar{W}_{2 t}}=\sum_{g \in \boldsymbol{V}_{2}} \frac{\bar{w}_{2 t}^{g}}{\bar{W}_{2 t}} \frac{\theta_{2}^{g}}{\bar{w}_{2 t}^{g}}$, the income elasticity of demand for all imports is a weighted average of those of imports of individual goods; and the corresponding price elasticity has a similar weighted-average property. This unification 
between import demand at the macro level and the demands for the individual goods is an attractive feature of the approach. Note also that equation (5.1) is an "uppercase" version of (4.1), a further macro-micro relationship. The final row of panel B of Table 5.1 indicates that, on average, the budget share $\bar{W}_{2 t}=26.27$ percent, which means that imports account for a little over one-quarter of total expenditure. From the last two elements of that row, the income elasticity of imports is 1.77 , so they are a fairly strong luxury, while their price elasticity is $-0.64 .^{11}$

Not only is there a demand equation for imports as a whole, but also demands for each good within imports. As shown in Appendix A7, the conditional demand for imports of group $g$ is

$$
\frac{\bar{w}_{2 t}^{g}}{\bar{W}_{2 t}} D q_{2 t}^{g}=\frac{\theta_{2}^{g}}{\Theta_{2}} D Q_{2 t}+\left(\phi \frac{\Theta_{2}}{\bar{W}_{2 t}}\right) \frac{\theta_{2}^{g}}{\Theta_{2}}\left(D p_{2 t}^{g}-D P_{2 t}^{\prime}\right)
$$

which also has the same general form as Equation (5.1). Rows 1-4 and 6-8 of panel B of Table 5.1 contain the conditional elasticities implied by this equation for each group (other than wood). Thus, for example, from row 1, conditional on total imports remaining unchanged, the income elasticity of food imports is 0.54 and the price elasticity is -0.34 . There is also an aggregate demand equation for domestic goods (represented by the set $\boldsymbol{V}_{1}$ ), as well as corresponding conditional demands, which are contained in panel A of Table 5.1. Panel C refers to wood (set $\boldsymbol{V}_{3}$ ), the group with the cross-price effects. A similar approach yields the total demand for each good (from both sources), as well as the conditional demand for each of the two varieties of the good. For example, there is the demand for all food from both sources,

\footnotetext{
${ }^{11}$ Equation (5.1) is not estimated directly; rather, its parameters are derived from the estimates of those of the underlying micro system (4.2) given in Table 4.4. Note also as wood accounts for only about 3 percent of imports, the income elasticity of total imports closely approximates the -0.64 value of this paragraph.
} 
and two conditional demands - one for domestically produced and the other for imported food. Table 5.2 contains these demands. These are consistent with the individual demand equations, as above.

This approach is useful for three purposes. First, it is a convenient way to focus attention of a variable of macroeconomic importance, total imports. Second, as will be demonstrated in the next section, the approach can be used for counter-factual analysis. A third use is for measuring goodness-of-fit. The left-hand side of the $i^{\text {th }}$ equation of the demand model, in infinitesimal changes, is the quantity change weighted by the budget share, $w_{i} d \log q_{i}$. This share is $w_{i}=\frac{p_{i} q_{i}}{M}$ with $d w_{i}=w_{i} d \log p_{i}+w_{i} d \log q_{i}-w_{i} d \log M$, which shows that the variable on the left of the demand equation is the quantity component of the change in the budget share. With income and prices taken as given, the predicted change in the quantity component can be converted into budget-share projections and Table 5.3 summarised the results. ${ }^{12}$ For comparison, we also use a "naïve” model of no-change extrapolation whereby the predicted share is last year's observed value. Columns 2-7 of this table indicate that, for individual varieties and groups, the demand model outperforms the naïve alternative in most cases (the exceptions are "Chemicals” and “Motor Vehicles and Transport”). For all varieties and groups as a whole, the demand model again outperforms the naïve approach, as shown by columns 8-9.

\section{Why Did Imports Surge?}

Figure 1.1 shows that import penetration in Australia rise noticeably during the last two decades. To shed light on the reasons for this, we use the aggregation approach described in the previous section for counter-factual simulations.

\footnotetext{
${ }^{12}$ For full details, see Appendix A8.
} 
Consider the change in a generic budget share: $d w_{i}=d\left(\frac{p_{i} q_{i}}{M}\right)=w_{i}\left\{d\left(\log \frac{p_{i}}{P}\right)+\right.$ $\left.d\left(\log \frac{q_{i}}{Q}\right)\right\}$, where $d(\log P)=\sum_{i} w_{i} d\left(\log p_{i}\right)$ and $d(\log Q)=\sum_{i} w_{i} d\left(\log q_{i}\right)$ are price and volume indexes satisfying $d(\log P)+d(\log Q)=d(\log M)$. Thus, the change in the share comprises price and volume components. Column 6 of Table 6.1 shows that for 6 of the 8 groups, the relative price of imports falls, which, from above, has a negative direct effect on the share. Such an effect cannot contribute to an explanation of the rise in the import share. The volume component, which is proportional to $d\left(\log \frac{q_{i}}{Q}\right)$, reflects the role of income and price substitution, an indirect effect of prices. For price substitution, the fall in the relative price, coupled with the negative price elasticity, leads to a rise in the share, but for two reasons this effect is only modest. First, the price elasticities are low; for example, the price elasticity of all types of imports (other than wood) is -0.64 (Table 5.1, last element of column 6 of panel B). Second, although the relative prices mostly fall, over the 21-year period, the falls are not particularly large; for example, the relative price of all imports falls by about 8.6 percent (Table 6.1, second-last element of column 6). Coupled with the low elasticity, the indirect price effect is insufficient to offset the direct effect. This leaves income as the dominant driver of the rise in the import shares. On average, income rises by approximately 0.86 percent p. a. (Table 4.1, last element of column 5), so the total increase over the whole period is about 17 percent. This is to be combined with the income elasticities, which, on average, are high; the elasticity of total imports, for example, is 1.77 (Table 5.1, last element of column 5 of panel B). It is this combination that leads to a rise in the import shares. ${ }^{13}$ The role of high income elasticities in driving imports agrees with prior research such as Houthakker and Magee (1969).

\footnotetext{
${ }^{13}$ There is also a residual component of the demand equation and a finite-change approximation error. As shown in Appendix A9, these additional terms are accounted for in the simulations that follow. Accordingly, the differences between simulated and actual values solely reflect the influence of the counter-factual shock.
} 
The change in income in year $t$ is the Divisia volume index $D Q_{t}, t=1996, \cdots, 2017$. Suppose income now changes in all years $t>1996$ by $D Q_{t}+r$. To simulate the change in total imports, we use the corresponding demand equation, equation (5.1), to eliminate the effects of observed income, add the effects of $D Q_{t}+r$, and hold all other factors unchanged. Accumulating these changes then leads to the simple result that in, year $s$, simulated imports (measured by its expenditure share, to be denoted by $\left.\widetilde{W}_{2 s}\right)$ is equal to the observed value $\left(W_{2 s}\right)$ plus the accumulated difference, that is, $\widetilde{W}_{2 s}=W_{2 s}+\sum_{t=1996}^{s}\left(\Theta_{2}-\bar{W}_{2 t}\right) r$. The term $\left(\Theta_{2}-\bar{W}_{2 t}\right)$ is the excess of the marginal share over the budget share of imports. Denoting the mean of this term by $\bar{W}_{2}\left(\eta_{2}-1\right)$, with $\eta_{2}$ the income elasticity, simulated imports can be expressed as

(6.1) $\quad \widetilde{W}_{2 s}=W_{2 s}+\bar{W}_{2}\left(\eta_{2}-1\right)(s-1996) r$.

Thus, the difference in imports on account of the income shock, $\widetilde{W}_{2 s}-W_{2 s}$, is $\bar{W}_{2}\left(\eta_{2}-1\right)(s-1996) r$. This is proportional to the product of (i) the annual shock scaled up by the number of years of the shock, $(s-1996) r$; and (ii) the deviation of the income elasticity from unity, $\left(\eta_{2}-1\right)$. Consequently, a positive shock to income results in higher imports when they are a luxury. ${ }^{14}$

To analyse the effects of income growth on imports in more detail, we consider three related counter-factual simulations:

1. Income shock. We use in Equation (6.1) a shock of $r=-\frac{1}{22} \sum_{t=1996}^{2017} D Q_{t}$, the negative of the mean income growth rate. Thus, income growth is simulated to be positive in years of above-average observed growth, and negative in below-average years, with deviations washing out over the whole period. Panel A1 of Figure 6.1 reveals that this leads to considerably more modest growth in imports share, rather than it increasing by

\footnotetext{
${ }^{14}$ For details of the material in this paragraph, see Appendix A9.
} 
more than 12 percentage points. As the confidence bands do not overlap with actual, the lowering of income leads to significantly lower import penetration, as is demonstrated in panel A2. The plots in panel B of this figure show the effects of the same reduction in income on imports of each good (as percentages of total expenditure on the good). The results are less dramatic, but in each case there is a noticeable decline in the share. The conclusion is clear -- higher income can account for much of the import penetration.

2. Group expenditure shock. The demand for imports of good $g$, conditional on total spending on the good, is $\frac{\bar{w}_{2 t}^{g}}{\bar{W}_{t}^{g}} D q_{2 t}^{g}=\frac{\theta_{2}^{g}}{\Theta^{g}} D Q_{t}^{g}+\left(\phi \frac{\Theta^{g}}{\bar{W}_{t}^{g}}\right) \frac{\theta_{2}^{g}}{\Theta^{g}}\left(D p_{2 t}^{g}-D P_{t}^{g^{\prime}}\right)$, as in Table 5.2. To study the effects of growth in spending on $g$, we use the same general approach as before and now change the Divisia volume index of the group from $D Q_{t}^{g}$ to $D Q_{t}^{g}+$ $r$, where $r=-\frac{1}{22} \sum_{t=1996}^{2017} D Q_{t}^{g}$. Panel C of Figure 6.1 indicates this lowers the import shares by roughly the same amount as previous income shock. The only exception to this rule is for energy and minerals, where the effect is smaller.

3. Total imports shock. Equation (5.2) refers to the demand for imports of good $g$ conditional on total imports, as measured by $D Q_{2 t}$. The effects of a change in total imports on imports of $g$ is simulated by replacing $D Q_{2 t}$ in (5.2) with $D Q_{2 t}+r$, where $r=-\frac{1}{22} \sum_{t=1996}^{2017} D Q_{2 t}$. From panel D of Figure 6.1, this shock has a very substantial effect on each conditional import share, so much so that the shares at the end of the period are lower than at the start.

\section{Concluding Comments}

Globalisation has opened up markets in many countries and led to higher incomes, more choice for consumers, increased competition from foreign-produced goods and greater import penetration. To analyse the key drivers of import penetration, this paper developed a consumer- 
demand framework that emphasises the substitutability between foreign and domestic varieties of goods. The demand for total imports is the consistent aggregation over the demands for foreign varieties of individual goods, so the macro elasticities are explicit weighted averages of their micro counterparts. Our approach extends the previous literature as it is fairly general, not involving restrictive assumptions such as homotheticity; allows for an array of hypothesis tests; and can be implemented with relatively short time-series data, which is important for those countries with limited availability of data. The approach can also be used in counterfactual simulations that isolate the separate determinants of imports.

We used the Australian experience to illustrate the application of the approach. Over the last two decades, imports have risen considerably -- from about 20 percent of total goods expenditure to about 32 percent. There have also been similar substantial rises in import penetration for individual goods. The prices of imports mostly fell, but coupled with low price elasticities, these were insufficient to account for the import surge. Income growth was the primary reason -- the higher incomes were spent on more luxurious goods, which in many cases were imports. This is an unexpected result.

It is appropriate to conclude by acknowledging the limitations of the paper. First, the supply-side of the economy is minimised by treating prices and income as given to consumers. As the prices of foreign varieties are linked to world prices, taking these as given seems not unreasonable. Many of the domestic goods have sizable service components, which tend to be nontraded. Thus, the exogeneity of the prices of these goods could be of more concern. It is also not unreasonable to take real income as given, as this usually evolves only slowly over time in response to long-term demographic/productivity trends. One way to allow for production/pricing technology to play a role and for income to be generated endogenously would be to embed our approach within a CGE model, but such an extension is beyond the scope of the paper. One aspect of our empirical results requires comment. As foreign and 
domestic varieties were matched in our data, the expectation was that they would be at least moderately substitutable. This was not borne out by the results, however. Low substitutability is also reflected in our estimate of the income flexibility (the inverse of the income elasticity of the marginal utility), which is noticeably lower than previous estimates. As this issue remains a puzzle, the estimates should be treated with due care.

\section{$\underline{\text { References }}$}

Armington, P. S. (1969). “A Theory of Demand for Products Distinguished by Place of Production.” IMF Staff Papers 26: 159-78.

Barten, A. P. (1964). "Consumer Demand Functions under Conditions of Almost Additive Preferences.” Econometrica 32: 1-38.

Barten A. P. (1969). "Maximum Likelihood Estimation of a Complete System of Demand Equations.” European Economic Review 1: 7-73.

Berner, R. (1977). “Estimating Consumer Import Demand Equations.” International Finance Discussion Paper No. 105, Board of Governors of the Federal Reserve System, Washington, DC.

Brown, A., and A. Deaton (1972). "Surveys in Applied Economics: Models of Consumer Behaviour.” Economic Journal 82: 1145-236.

Brown, M., and D. M. Heien (1972). “The S-Branch Utility Tree: A Generalization of the Linear Expenditure System.” Econometrica 40: 737-47.

Clements, K. W. (2019). “Four Laws of Consumption.” Economic Record 95: 358-85.

Clements, K. W., and X. Zhao (2009). Economics and Marijuana: Consumption, Pricing and Legalisation. Cambridge: Cambridge University Press.

Costinot, A., and A. Rodríguez-Clare (2014). “Trade Theory with Numbers: Quantifying the Consequences of Globalisation.” In Handbook of International Economics, Vol. 4. Elsevier. Pp. 197-261. 
Deardorff, A. V., and R. M. Stern (1981). “A Disaggregated Model of World Production and Trade: An Estimate of the Impact of the Tokyo Round.” Journal of Policy Modelling 3: $127-52$.

Dixon, P. B., B. R. Parmenter, J. Sutton and D. P. Vincent (1982). ORANI: A Multisectoral Model of the Australian Economy. Amsterdam: North Holland.

Dixon, P. B., and M. T. Rimmer (2002). Dynamic General and Equilibrium Modelling for Forecasting and Policy: A Practical Guide and Documentation of MONASH. Amsterdam: Elsevier.

Feenstra, R. C., P. Luck, M. Obstfeld and K. N. Russ (2018). "In Search of the Armington Elasticity.” Review of Economic Statistics 100: 135-50.

Goldstein, M., and M. Khan (1985). “Income and Price Elasticities in Foreign Trade.” In R. Jones and P. Kenen (eds.), Handbook of International Trade, vol. II. Amsterdam: NorthHolland.

Gorman, W. M. (1959). “Separability Utility and Aggregation.” Econometrica 27: 469-81.

Hertel, T. (1997). Global Trade Analysis: Modelling and Applications. Cambridge and New York: Cambridge University Press.

Hooper, P., K. Johnson and J. Marquez (2000). Trade Elasticities for the G7. Princeton Studies in International Finance, 87.

Houthakker, H. S., and S. P. Magee (1969). “Income and Price Elasticities in World Trade.”

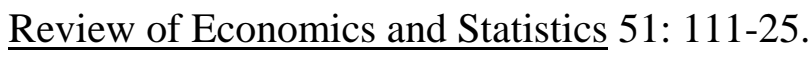

Hummels, D., and K. Y. Lee (2018). “The Income Elasticity of Import Demand: Micro Evidence and an Application.” Journal of International Economics 113: 20-34.

Imbs, J., and I. Méjean (2015). “Elasticity Optimism.” American Economic Journal: Macroeconomics 7: 43-83. 
Kee, H. L., A. Nicita and M. Olarreaga (2008). “Import Demand Elasticities and Trade Distortions.” Review of Economics and Statistics 90: 666-82.

Lloyd, P. J. (1979a). “Intra-Industry Trade, Lowering Trade Barriers and Gains from Trade.” In H. Giersch (ed.), On the Economics of Intra-industry Trade. Tübingen: J. C. B. Mohr. Lloyd, P. J. (1979b). “Tax Distortions and the Rate of Economic Growth: A Numerical General Equilibrium Analysis.” Keio Economic Studies 15: 33-51.

Lloyd, P. J. and X. G. Zhang (2006). “The Armington Model.” Productivity Commission Staff Working Paper, Melbourne, January.

Magee, S. P. (1975). "Prices, Income and Foreign Trade: A Survey of Recent Economic Studies.” In P. B. Kenen (ed.) International Trade and Finance: Frontiers for Research. Cambridge: Cambridge University Press.

Marquez, J. (1990). “Bilateral Trade Elasticities.” Review of Economics and Statistics 72: 7077.

Marquez, J. (1993). “The Autonomy of Elasticities for Trade among Canada, Japan and the United States.” Japan and the World Economy 5: 179-95.

Marquez, J. (1999). “Long-Period Trade Elasticities for Canada, Japan, and the United States.” Review of International Economics 7: 102-16.

Marquez, J. (2002). Estimating Trade Elasticities. Dordrecht: Kluwer.

Miller, M. H., and J. E. Spencer (1977). “The Static Effects of the UK Joining the EEC: A General Equilibrium Approach.” Review of Economic Studies 44: 71- 93.

Sato, K. (1968). “A Two-Level Constant-Elasticity-of-Substitution Production Function.” Review of Economic Studies 34: 201-18.

Selvanathan, S. (1991). “The Reliability of ML Estimators of Systems of Demand Equations: Evidence from OECD Countries.” Review of Economics and Statistics 73: 346-53. 
Shoven, J., and J. Whalley (1984). “Applied General Equilibrium Models of Taxation and International Trade.” Journal of Economic Literature 22: 1007-51.

Stern, R. M., J. Francis and B. Schumacher (1976). Price Elasticities in International Trade: An Annotated Bibliography. London: Macmillan.

Stoeckel, A. B., D. Pearce and G. Banks (1990). Western Trade Blocs: Game Set or Match for Asia-Pacific and the World Economy. Canberra: Centre for International Economics.

Stone, R. (1954). “Linear Expenditure Systems and Demand Analysis: An Application to the Pattern of British Demand.” Economic Journal 64: 511-27.

Theil, H. (1965). “The Information Approach to Demand Analysis.” Econometrica 33: 67-87.

Theil, H. (1975/76). Theory and Measurement of Consumer Demand. Two vols. Amsterdam: Elsevier.

Theil, H. (1987). “The Econometrics of Demand Systems.” Chapter 3 in H. Theil and K. W. Clements, Applied Demand Analysis: Results from System-Wide Approaches. Ballinger: Cambridge, Mass. Pp. 101-62. 
Table 2.1. Notation for Domestic and Foreign Varieties

\begin{tabular}{|c|c|c|c|c|c|c|c|}
\hline \multirow{3}{*}{$\begin{array}{l}\text { Variety } i \\
\text { of goods in } \\
\text { group } g \\
\text { (1) }\end{array}$} & \multicolumn{3}{|c|}{ Variables } & \multicolumn{3}{|c|}{ Coefficients of demand equations } & \multirow{3}{*}{$\begin{array}{c}\text { Disturbance } \\
\text { terms } \\
(8)\end{array}$} \\
\hline & \multirow[b]{2}{*}{$\begin{array}{c}\text { Quantities } \\
\text { (2) }\end{array}$} & \multirow[b]{2}{*}{$\begin{array}{c}\text { Prices } \\
\text { (3) }\end{array}$} & \multirow{2}{*}{$\begin{array}{c}\text { Budget } \\
\text { shares } \\
\text { (4) }\end{array}$} & \multirow{2}{*}{$\begin{array}{c}\text { Marginal } \\
\text { shares } \\
\text { (5) }\end{array}$} & \multicolumn{2}{|c|}{ Price } & \\
\hline & & & & & $\begin{array}{c}\text { Domestic } \\
\text { (6) }\end{array}$ & $\begin{array}{c}\text { Foreign } \\
\text { (7) }\end{array}$ & \\
\hline Domestic, $i=1$ & $D q_{1 t}^{g}$ & $D p_{1 t}^{g}$ & $\bar{w}_{1 t}^{g}$ & $\theta_{1}^{g}$ & $v_{11}^{g}$ & $v_{12}^{g}$ & $\varepsilon_{1 t}^{g}$ \\
\hline Foreign, $i=2$ & $D q_{2 t}^{g}$ & $D p_{2 t}^{g}$ & $\bar{w}_{2 t}^{g}$ & $\theta_{2}^{g}$ & $v_{21}^{g}$ & $v_{22}^{g}$ & $\varepsilon_{2 t}^{g}$ \\
\hline
\end{tabular}

Note: This table summarises the notation used for the two-variety demand model, Equation (2.11).

Table 4.1. Means and Standard Deviations, Australia, 1996-2017

\begin{tabular}{|c|c|c|c|c|}
\hline \multirow[b]{2}{*}{$\begin{array}{l}\text { Commodity group } g \\
\text { (1) }\end{array}$} & \multirow[b]{2}{*}{$\begin{array}{l}\text { Variety } i \\
\text { (2) }\end{array}$} & \multirow[b]{2}{*}{$\begin{array}{c}\text { Budget share } \\
\qquad w_{i}^{g} \\
\text { (3) }\end{array}$} & \multicolumn{2}{|c|}{ "Log-changes in } \\
\hline & & & $\begin{array}{c}\text { Relative price } \\
D p_{i}^{g}-D P \\
\text { (4) }\end{array}$ & $\begin{array}{l}\text { Relative quantity } \\
\qquad D q_{i}^{g}-D Q \\
\text { (5) }\end{array}$ \\
\hline $\begin{array}{l}\text { 1. Food and Agricultural } \\
\text { Commodities }\end{array}$ & $\begin{array}{l}\text { Domestic, } 1 \\
\text { Foreign, } 2\end{array}$ & $\begin{array}{c}20.19(1.23) \\
1.82(0.47)\end{array}$ & $\begin{array}{l}0.75(3.17) \\
0.39(5.97)\end{array}$ & $\begin{array}{c}-0.77(3.88) \\
2.87(4.97)\end{array}$ \\
\hline 2. Energy and Minerals & $\begin{array}{l}1 \\
2\end{array}$ & $\begin{array}{l}22.29(1.16) \\
6.53(1.84)\end{array}$ & $\begin{array}{l}0.36(5.85) \\
0.46(6.66)\end{array}$ & $\begin{array}{l}-0.92(5.50) \\
2.45(5.94)\end{array}$ \\
\hline 3. Chemicals & $\begin{array}{l}1 \\
2\end{array}$ & $\begin{array}{l}5.32(0.28) \\
2.91(0.31)\end{array}$ & $\begin{array}{l}-0.53(2.90) \\
-1.37(4.62)\end{array}$ & $\begin{array}{l}0.04(4.04) \\
3.04(2.96)\end{array}$ \\
\hline $\begin{array}{l}\text { 4. Textile, Leather, Clothing } \\
\text { and Footwear }\end{array}$ & $\begin{array}{l}1 \\
2\end{array}$ & $\begin{array}{l}4.56(0.55) \\
1.92(0.35)\end{array}$ & $\begin{array}{l}-0.12(2.04) \\
-0.09(7.94)\end{array}$ & $\begin{array}{l}-1.38(3.74) \\
2.25(6.42)\end{array}$ \\
\hline 5. Wood and Paper Products & $\begin{array}{l}1 \\
2\end{array}$ & $\begin{array}{l}4.81(1.02) \\
0.76(0.10)\end{array}$ & $\begin{array}{l}0.10(1.66) \\
-0.26(7.51)\end{array}$ & $\begin{array}{l}-2.58(5.48) \\
-1.21(8.06)\end{array}$ \\
\hline 6. Machinery and Equipment & 1 & $\begin{array}{l}7.41(0.32) \\
7.75(0.90)\end{array}$ & $\begin{array}{l}-0.29(1.69) \\
-0.57(6.78)\end{array}$ & $\begin{array}{c}-0.32(3.88) \\
2.66(6.57)\end{array}$ \\
\hline $\begin{array}{l}\text { 7. Motor Vehicles and } \\
\text { Transport }\end{array}$ & 1 & $\begin{array}{l}5.92(1.20) \\
4.45(0.54)\end{array}$ & $\begin{array}{l}-0.74(1.76) \\
-0.83(4.52)\end{array}$ & $\begin{array}{c}-1.96(6.31) \\
2.49(8.13)\end{array}$ \\
\hline $\begin{array}{l}\text { 8. Miscellaneous } \\
\text { Manufactured Goods }\end{array}$ & $\begin{array}{l}1 \\
2\end{array}$ & $\begin{array}{l}2.48(0.31) \\
0.89(0.21)\end{array}$ & $\begin{array}{c}0.10(2.67) \\
-0.60(7.52)\end{array}$ & $\begin{array}{c}-1.45(4.40) \\
4.83(6.72)\end{array}$ \\
\hline & & & $\begin{array}{l}\text { Divisia price } \\
\quad \text { index } \\
D P: 1.43(1.65) \\
\end{array}$ & $\begin{array}{l}\text { Divisia quantity } \\
\text { index } \\
D Q: 0.86(2.47)\end{array}$ \\
\hline
\end{tabular}

Notes:

1. For variety $i(i=1,2)$ in group $g(g=1, \cdots, 8)$, the price $\left(p_{i}^{g}\right)$ is the expenditure-share weighted mean of the prices of corresponding disaggregated items (see Appendix A4 for details); the corresponding quantity $\left(q_{i}^{g}\right)$ is per capita expenditure deflated by the price.

2. Columns 3 - 5: The Divisia price and quantity indexes of the last row are defined as $D P_{t}=$ $\sum_{g=1}^{8} \sum_{i=1}^{2} \bar{w}_{i t}^{g} D p_{i t}^{g}$ and $D Q_{t}=\sum_{g=1}^{8} \sum_{i=1}^{2} \bar{w}_{i t}^{g} D q_{i t}^{g}$, where $\bar{w}_{i t}^{g}$ denotes the average over years $t-1$ and $t$ of the budget share.

3. Standard deviations in parentheses.

4. All entries are multiplied by 100 . 
Table 4.2. Domestic and Foreign Demands under Preference Dependence $\bar{w}_{i t}^{g} D q_{i t}^{g}=\theta_{i}^{g} D Q_{t}+\sum_{j=1}^{2} v_{i j}^{g}\left(D p_{j t}^{g}-D P_{t}^{\prime}\right)+\varepsilon_{i t}^{g}, \quad i, j=1,2 ; g=1, \cdots, 8$

\begin{tabular}{|c|c|c|c|c|c|c|c|c|}
\hline \multirow{3}{*}{$\begin{array}{l}\text { Commodity } \\
\text { group } g\end{array}$} & \multirow[b]{3}{*}{ Variety $i$} & \multirow{3}{*}{$\begin{array}{c}\text { Budget share } \\
\text { (Sample mean } \\
\times 100) \\
w_{i}^{g}\end{array}$} & \multicolumn{3}{|c|}{ Coefficients $(\times 100)$} & \multicolumn{3}{|c|}{ Elasticities } \\
\hline & & & \multirow[b]{2}{*}{$\begin{array}{c}\text { Marginal } \\
\text { share } \\
\theta_{i}^{g}\end{array}$} & \multicolumn{2}{|c|}{ Price coefficients } & \multirow{3}{*}{$\begin{array}{c}\text { Income } \\
\eta_{i}^{g}=\frac{\theta_{i}^{g}}{w_{i}^{g}} \\
(7)\end{array}$} & \multicolumn{2}{|c|}{ Frisch price } \\
\hline & & & & $\begin{array}{c}\text { Domestic } \\
v_{i 1}^{g}\end{array}$ & $\begin{array}{l}\text { Foreign } \\
\qquad v_{i 2}^{g}\end{array}$ & & $\begin{array}{l}\text { Domestic } \\
F_{i 1}^{g}=\frac{v_{i 1}^{g}}{w_{i}^{g}}\end{array}$ & $\begin{array}{c}\text { Foreign } \\
F_{i 2}^{g}=\frac{v_{i 2}^{g}}{w_{i}^{g}}\end{array}$ \\
\hline$(1)$ & $(2)$ & (3) & (4) & (5) & (6) & & (8) & (9) \\
\hline \multirow{2}{*}{ 1. Food and Agricultural Commodities } & Domestic, 1 & 20.19 & $3.47(5.15)$ & $-2.26(2.61)$ & $0.51(0.32)$ & $0.17(0.26)$ & $-\mathbf{0 . 1 1}(0.12)$ & $0.03(0.02)$ \\
\hline & Foreign, 2 & 1.82 & $1.59(0.52)$ & & $-1.31(0.25)$ & $0.87(0.29)$ & $0.28(0.17)$ & $-\mathbf{0 . 7 2}(0.14)$ \\
\hline \multirow{2}{*}{ 2. Energy and Minerals } & 1 & 22.29 & $34.25(6.52)$ & $-14.35(3.74)$ & $-3.00(1.56)$ & $1.54(0.26)$ & $-0.64(0.14)$ & $-0.13(0.06)$ \\
\hline & 2 & 6.53 & $16.18(4.56)$ & & $-5.20(2.27)$ & $2.48(0.70)$ & $-0.46(0.22)$ & $-\mathbf{0 . 8 0}(0.30)$ \\
\hline \multirow{2}{*}{ 3. Chemicals } & 1 & 5.32 & $3.58(1.72)$ & $-1.67(0.90)$ & $-0.15(0.39)$ & $0.67(0.32)$ & $-\mathbf{0 . 3 1}(0.16)$ & $-0.03(0.07)$ \\
\hline & 2 & 2.91 & $3.65(0.68)$ & & $-1.70(0.35)$ & $1.25(0.24)$ & $-0.05(0.13)$ & $-0.59(0.12)$ \\
\hline \multirow{2}{*}{ 4. Textile, Leather, Clothing and Footwear } & 1 & 4.56 & $1.91(1.16)$ & $-1.38(0.69)$ & $0.42(0.26)$ & $0.42(0.25)$ & $-\mathbf{0 . 3 0}(0.14)$ & $0.09(0.06)$ \\
\hline & 2 & 1.92 & $1.17(0.47)$ & & $-1.01(0.19)$ & $0.61(0.26)$ & $0.22(0.14)$ & $-0.53(0.10)$ \\
\hline \multirow{2}{*}{ 5. Wood and Paper Products } & 1 & 4.81 & $0.18(1.60)$ & $-0.65(0.88)$ & $0.55(0.21)$ & $0.04(0.34)$ & $-\mathbf{0 . 1 3}(0.17)$ & $0.12(0.04)$ \\
\hline & 2 & 0.76 & $0.23(0.33)$ & & $-0.67(0.13)$ & $0.31(0.42)$ & $0.73(0.27)$ & $-\mathbf{0 . 8 8}(0.17)$ \\
\hline \multirow{2}{*}{ 6. Machinery and Equipment } & 1 & 7.41 & $7.51(1.82)$ & $-3.61(1.35)$ & $-0.19(0.79)$ & $1.01(0.26)$ & $-\mathbf{0 . 4 9}(0.17)$ & $-0.03(0.11)$ \\
\hline & 2 & 7.75 & $12.71(2.63)$ & & $-6.25(0.98)$ & $1.64(0.32)$ & $-0.02(0.10)$ & $-\mathbf{0 . 8 1}(0.12)$ \\
\hline \multirow{2}{*}{ 7. Motor Vehicles and Transport } & 1 & 5.92 & $4.68(2.58)$ & $-2.28(2.13)$ & $-0.09(1.44)$ & $0.79(0.45)$ & $-0.38(0.35)$ & $-0.02(0.24)$ \\
\hline & 2 & 4.45 & $6.60(2.18)$ & & $-3.25(1.27)$ & $1.48(0.50)$ & $-0.02(0.32)$ & $-0.73(0.28)$ \\
\hline \multirow{2}{*}{ 8. Miscellaneous Manufactured Goods } & 1 & 2.48 & $1.17(0.80)$ & $-0.65(0.48)$ & $0.06(0.19)$ & $0.47(0.34)$ & $-0.26(0.18)$ & $0.02(0.07)$ \\
\hline & 2 & 0.89 & $1.32(0.37)$ & & $-0.73(0.12)$ & $1.48(0.36)$ & $0.07(0.19)$ & $-\mathbf{0 . 8 2}(0.12)$ \\
\hline & & \multicolumn{7}{|c|}{ Income flexibility $\phi=-0.506(0.092)$} \\
\hline
\end{tabular}

Notes:

1. Columns 5-6: As the $2 \times 2$ matrices $\left[v_{i j}^{g}\right], g=1, \cdots, 8$, are symmetric, only the upper triangles are presented.

2. Columns $8-9$ : The Frisch price elasticity $F_{i j}^{g}$ is the elasticity of demand for variety $i$ in group $g$ with respect to the relative price of variety $j$ in the same group $g$ $(i, j=1,2 ; g=1, \cdots, 8)$. The price is the Frisch-deflated relative price, $D p_{j t}^{g}-D P_{t}^{\prime}$, which holds the marginal utility of income constant. The Frisch own-price elasticities, $F_{i i}^{g}$, are emboldened. Examples: $F_{11}^{1}=-\mathbf{0 . 1 1}$ is the Frisch own-price elasticity of the domestic variety of food etc. $(i=1, g=1)$, while $F_{21}^{1}=0.28$ is the elasticity of the foreign variety of the same good $(i=2, g=1)$ with respect to the price of the domestic variety $(j=1)$.

3 . Bootstrap standard errors with 10,000 replications in parentheses. 
Table 4.3. Hypothesis Tests

\begin{tabular}{|c|c|c|c|}
\hline \multicolumn{4}{|c|}{$\begin{array}{c}\text { A. } \underline{\text { F-tests }} \\
{\left[\text { Observed F-stat }\left(95^{\text {th }} \text { and } 99^{\text {th }} \text { percentiles }\right)\right]}\end{array}$} \\
\hline \multirow[b]{2}{*}{$\begin{array}{l}\text { Alternative } \\
\text { (1) }\end{array}$} & \multicolumn{3}{|c|}{$\begin{array}{ll} & \text { Null } \\
\end{array}$} \\
\hline & $\begin{array}{l}\text { PPI } \\
(2)\end{array}$ & $\begin{array}{l}\text { PI } \\
(3)\end{array}$ & $\begin{array}{l}\text { No price effects } \\
\text { NP } \\
\text { (4) }\end{array}$ \\
\hline $\begin{array}{l}\text { 1. Preference Dependence (PD), } \\
v_{12}^{g}=v_{21}^{g} \neq 0 ; g=1, \ldots, 8\end{array}$ & $3.67(3.16,5.08)$ & $3.71(2.79,4.69)$ & $14.10(2.02,2.78)$ \\
\hline $\begin{array}{l}\text { 2. Partial Preference Independence } \\
\text { (PPI), } v_{12}^{g}=v_{21}^{g}=0 ; g= \\
1, \ldots, 8 ; g \neq 5, v_{12}^{5}=v_{21}^{5} \neq 0\end{array}$ & - & $3.79(2.33,4.30)$ & $47.96(4.25,7.26)$ \\
\hline $\begin{array}{l}\text { 3. Preference Independence (PI), } \\
v_{12}^{g}=v_{21}^{g}=0 ; g=1, \ldots, 8\end{array}$ & - & - & 91.37 (7.82, 13.95) \\
\hline \multicolumn{4}{|c|}{ B. $\underline{\text { t-tests }}$} \\
\hline \multicolumn{4}{|c|}{$\begin{array}{c}\text { LD = PI + Domestic income elasticity is } \\
\text { lower: } \theta_{1}^{g} / w_{1}^{g} \leq \theta_{2}^{g} / w_{2}^{g}\end{array}$} \\
\hline \multirow[b]{2}{*}{ Comm. group $g$} & $\mathrm{PD}: v_{12}^{g}=v_{21}^{g} \neq 0$ & \multicolumn{2}{|c|}{$\begin{array}{l}\text { PI + Domestic income elasticity is higher: } \\
\qquad \theta_{1}^{g} / w_{1}^{g}>\theta_{2}^{g} / w_{2}^{g}\end{array}$} \\
\hline & $\begin{array}{l}\text { [Observed t-stat } \\
\left(2.5^{\text {th }} \text { and } 97.5^{\text {th }}\right. \\
\text { percentiles })] \\
\text { (2) }\end{array}$ & \multicolumn{2}{|c|}{ [Observed t-stat ( $95^{\text {th }}$ percentile)] } \\
\hline 1. Food and Agricultural Comm. & $1.17(0.35,3.33)$ & \multicolumn{2}{|c|}{$-1.04(-0.48)$} \\
\hline 2. Energy and Minerals & $-3.63(-8.62,-2.69)$ & \multicolumn{2}{|c|}{$-0.44(1.06)$} \\
\hline 3. Chemicals & $-0.28(-1.55,1.45)$ & \multicolumn{2}{|c|}{$-0.93(-0.44)$} \\
\hline 4. Textile, Leather, Cloth. and Fw. & $1.16(0.73,3.72)$ & \multicolumn{2}{|c|}{$-0.57(0.02)$} \\
\hline 5. Wood and Paper Products & $2.16(0.95,4.36)$ & \multicolumn{2}{|c|}{$-0.79(0.27)$} \\
\hline 6. Machinery and Equipment & $-0.27(-1.12,3.36)$ & \multicolumn{2}{|c|}{$-2.10(-0.75)$} \\
\hline 7. Motor Vehicles and Transport & $-0.09(-2.34,3.60)$ & \multicolumn{2}{|c|}{$-1.72(-0.31)$} \\
\hline 8. Misc. Manufactured Goods & $0.25(-0.36,2.83)$ & \multicolumn{2}{|c|}{$-1.45(-1.08)$} \\
\hline
\end{tabular}

Notes:

1. Panel A:

(i) Interpretation: The null hypothesis is rejected when the observed F-statistic exceeds the critical value. Critical values given in parentheses are the $95^{\text {th }}$ and $99^{\text {th }}$ percentiles of 10,000 bootstrap replications of the corresponding F-statistic.

(ii) Row 1: Relative to PD, at the 1-percent level of significance, we are unable to reject PPI and PI but are able to reject NP. All three null hypotheses are rejected at the 5-percent level.

(iii) Row 2: Relative to PPI, at the 1-percent level we are unable to reject PI, but can reject it at the 5percent level; NP is rejected at the 5- and 1-percent levels.

(iv) Row 3: Relative to PI, we reject NP at the 5- and 1-percent levels.

2. Panel B:

(i) Column 2: The null is rejected when the observed t-statistic is either smaller than the lower critical value or greater than the upper critical value. Critical values given in parentheses are the $2.5^{\text {th }}$ and $97.5^{\text {th }}$ percentiles of 10,000 bootstrap replications of the t-statistic under PI. In all cases we are unable to reject the null.

(ii) Column 3: The null is rejected when the observed t-statistic is greater than the critical value. Critical values given in parentheses are the $95^{\text {th }}$ percentile of 10,000 bootstrap realisations of the t-statistic under LD. These tests use mean budget shares. In all cases we are unable to reject the null.

3. Some commodity names in column 1 are abbreviated.

4. See Appendix A6 for further details of the tests, as well as plots of the distributions of the F-statistics. 
Table 4.4. Domestic and Foreign Demands under Partial Preference Independence $\bar{w}_{i t}^{g} D q_{i t}^{g}=\theta_{i}^{g} D Q_{t}+\phi A_{i t}^{g}(\boldsymbol{\theta})+\delta(g)[2 \gamma(i)-1] v_{12}^{g} \Delta p_{21, t}^{g}+\varepsilon_{i t}^{g} ; i=1,2 ; g=1, \ldots 8$

\begin{tabular}{|c|c|c|c|c|c|c|c|c|}
\hline \multirow{3}{*}{$\begin{array}{l}\text { Commodity } \\
\text { group } g\end{array}$} & \multirow[b]{3}{*}{ Variety $i$} & \multirow{3}{*}{$\begin{array}{c}\text { Budget share } \\
\text { (Sample mean } \\
\times 100) \\
w_{i}^{g} \\
\text { (3) }\end{array}$} & \multicolumn{3}{|c|}{ Coefficients $(\times 100)$} & \multicolumn{3}{|c|}{ Elasticities } \\
\hline & & & \multirow[b]{2}{*}{$\begin{array}{c}\text { Marginal } \\
\text { share } \\
\theta_{i}^{g} \\
(4)\end{array}$} & \multicolumn{2}{|c|}{ Price coefficients } & \multirow[b]{2}{*}{$\begin{array}{c}\text { Income } \\
\eta_{i}^{g}=\frac{\theta_{i}^{g}}{w_{i}^{g}} \\
\text { (7) }\end{array}$} & \multicolumn{2}{|c|}{ Frisch price } \\
\hline & & & & $\begin{array}{c}\text { Domestic } \\
v_{i 1}^{g} \\
(5)\end{array}$ & $\begin{array}{c}\text { Foreign } \\
v_{i 2}^{g} \\
(6)\end{array}$ & & $\begin{array}{c}\text { Domestic } \\
F_{i 1}^{g}=\frac{v_{i 1}^{g}}{w_{i}^{g}} \\
\text { (8) }\end{array}$ & $\begin{array}{c}\text { Foreign } \\
F_{i 2}^{g}=\frac{v_{i 2}^{g}}{w_{i}^{g}} \\
\text { (9) }\end{array}$ \\
\hline 1. Food and Agricultural Commodities & $\begin{array}{l}\text { Domestic, } 1 \\
\text { Foreign, } 2\end{array}$ & $\begin{array}{c}20.19 \\
1.82\end{array}$ & $\begin{array}{l}3.36(5.28) \\
1.73(0.52)\end{array}$ & $-1.21(1.73)$ & $-0.62(0.20)$ & $\begin{array}{l}0.17(0.26) \\
0.95(0.29)\end{array}$ & $-\mathbf{0 . 0 6}(0.09)$ & $-0.34(0.11)$ \\
\hline 2. Energy and Minerals & $\begin{array}{l}1 \\
2 \\
\end{array}$ & $\begin{array}{c}22.29 \\
6.53\end{array}$ & $\begin{array}{l}30.74(5.99) \\
17.23(4.41)\end{array}$ & $-11.05(2.02)$ & $-6.19(1.66)$ & $\begin{array}{l}1.38(0.27) \\
2.64(0.68)\end{array}$ & $-\mathbf{0 . 5 0}(0.09)$ & $-0.95(0.25)$ \\
\hline 3. Chemicals & $\begin{array}{l}1 \\
2\end{array}$ & $\begin{array}{l}5.32 \\
2.91\end{array}$ & $\begin{array}{l}3.51(1.70) \\
3.68(0.61)\end{array}$ & $-1.26(0.59)$ & $-1.32(0.29)$ & $\begin{array}{l}0.66(0.32) \\
1.26(0.21)\end{array}$ & $-0.24(0.11)$ & $-0.45(0.10)$ \\
\hline 4. Textile, Leather, Clothing and Footwear & $\begin{array}{l}1 \\
2\end{array}$ & $\begin{array}{l}4.56 \\
1.92 \\
\end{array}$ & $\begin{array}{l}1.75(1.19) \\
1.43(0.57)\end{array}$ & $-0.63(0.39)$ & $-0.51(0.20)$ & $\begin{array}{l}0.38(0.26) \\
0.75(0.30)\end{array}$ & $-\mathbf{0 . 1 4}(0.09)$ & $-0.27(0.10)$ \\
\hline 5. Wood and Paper Products & $\begin{array}{l}1 \\
2\end{array}$ & $\begin{array}{l}4.81 \\
0.76\end{array}$ & $\begin{array}{l}0.23(1.64) \\
0.24(0.33)\end{array}$ & $-0.67(0.56)$ & $\begin{array}{c}0.58(0.17) \\
-0.67(0.13)\end{array}$ & $\begin{array}{l}0.05(0.34) \\
0.32(0.43)\end{array}$ & $\begin{array}{c}\mathbf{- 0 . 1 4}(0.12) \\
0.77(0.22)\end{array}$ & $\begin{array}{c}0.12(0.03) \\
-\mathbf{0 . 8 8}(0.17)\end{array}$ \\
\hline 6. Machinery and Equipment & $\begin{array}{l}1 \\
2\end{array}$ & $\begin{array}{l}7.41 \\
7.75\end{array}$ & $\begin{array}{c}7.75(1.93) \\
13.72(2.31)\end{array}$ & $-2.78(0.72)$ & $-4.93(0.91)$ & $\begin{array}{l}1.05(0.26) \\
1.77(0.30)\end{array}$ & $-0.38(0.10)$ & $-0.64(0.12)$ \\
\hline 7. Motor Vehicles and Transport & $\begin{array}{l}1 \\
2\end{array}$ & $\begin{array}{l}5.92 \\
4.45\end{array}$ & $\begin{array}{l}4.91(2.67) \\
7.15(2.11)\end{array}$ & $-1.77(0.89)$ & $-2.57(0.74)$ & $\begin{array}{l}0.83(0.45) \\
1.61(0.47)\end{array}$ & $-0.30(0.15)$ & $-0.58(0.17)$ \\
\hline 8. Miscellaneous Manufactured Goods & $\begin{array}{l}1 \\
2\end{array}$ & $\begin{array}{l}2.48 \\
0.89\end{array}$ & $\begin{array}{l}1.07(0.83) \\
1.49(0.26)\end{array}$ & $-0.39(0.28)$ & $-0.54(0.11)$ & $\begin{array}{l}0.43(0.34) \\
1.68(0.30)\end{array}$ & $-0.16(0.11)$ & $-\mathbf{0 . 6 0}(0.12)$ \\
\hline & & & & & me flexibility & $=-0.359(0$ & & \\
\hline
\end{tabular}

Notes:

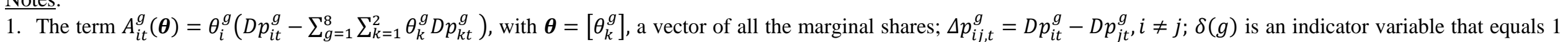
when $g=5$ (for wood) and zero when $g \neq 5$; $\gamma(i)$ is an indicator variable that equals 1 when $i=1$ and zero when $i=2$; and the cross-price coefficients $v_{12}^{g}=v_{21}^{g}$. See notes to Table 4.2 for further details.

2. The Frisch own-price elasticities, $F_{i i}^{g}$, are emboldened.

3. Bootstrap standard errors with 10,000 replications in parentheses. 
Table 5.1. Aggregated and Disaggregated Demands by Variety

\begin{tabular}{|c|c|c|c|c|c|}
\hline $\begin{array}{l}\text { Commodity } \\
\text { group } g \\
\text { /aggregate } \\
\text { (1) } \\
\end{array}$ & $\begin{array}{l}\text { Demand equations } \\
\qquad(2)\end{array}$ & $\begin{array}{c}\text { Budget } \\
\text { share } \\
(3)\end{array}$ & $\begin{array}{l}\text { Marginal } \\
\text { share } \\
(4) \\
\end{array}$ & $\begin{array}{l}\text { Income } \\
\text { elasticity } \\
(5)\end{array}$ & $\begin{array}{l}\text { Own-price } \\
\text { elasticity } \\
\text { (6) }\end{array}$ \\
\hline \multicolumn{6}{|c|}{ A. Variety 1: Domestic } \\
\hline 1. Food & \multirow{8}{*}{$\begin{array}{r}\frac{\bar{w}_{1 t}^{g}}{\bar{W}_{1 t}} D q_{1 t}^{g}=\frac{\theta_{1}^{g}}{\theta_{1}} D Q_{1 t}+\left(\phi \frac{\theta_{1}}{\bar{W}_{1 t}}\right) \frac{\theta_{1}^{g}}{\theta_{1}}\left(D p_{1 t}^{g}-\right. \\
\left.D P_{1 t}^{\prime}\right), g=1, \ldots, 8, g \neq 5\end{array}$} & 29.62 & 6.23 & 0.21 & -0.06 \\
\hline 2. Energy & & 32.70 & 57.89 & 1.77 & -0.49 \\
\hline 3. Chemicals & & 7.80 & 6.66 & 0.85 & -0.24 \\
\hline 4. Textiles & & 6.68 & 3.33 & 0.50 & -0.14 \\
\hline 6. Machinery & & 10.87 & 14.60 & 1.34 & -0.38 \\
\hline 7. Transports & & 8.69 & 9.27 & 1.07 & -0.30 \\
\hline 8. Misc. & & 3.63 & 2.02 & 0.56 & -0.16 \\
\hline Sum & & 100 & 100 & & \\
\hline All groups & $\bar{W}_{1 t} D Q_{1 t}=\Theta_{1} D Q_{t}+\phi \Theta_{1}\left(D P_{1 t}^{\prime}-D P_{t}^{\prime}\right)$ & 68.15 & 53.13 & 0.78 & -0.28 \\
\hline \multicolumn{6}{|c|}{ B. Variety 2: Foreign } \\
\hline 1. Food & \multirow{8}{*}{$\begin{array}{r}\frac{\bar{w}_{2 t}^{g}}{\bar{w}_{2 t}} D q_{2 t}^{g}=\frac{\theta_{2}^{g}}{\theta_{2}} D Q_{2 t}+\left(\phi \frac{\theta_{2}}{\bar{w}_{2 t}}\right) \frac{\theta_{2}^{g}}{\theta_{2}}\left(D p_{2 t}^{g}-\right. \\
\left.D P_{2 t}^{\prime}\right), g=1, \ldots, 8, g \neq 5\end{array}$} & 6.92 & 3.73 & 0.54 & -0.34 \\
\hline 2. Energy & & 24.86 & 37.20 & 1.50 & -0.95 \\
\hline 3. Chemicals & & 11.08 & 7.93 & 0.72 & -0.46 \\
\hline 4. Textiles & & 7.30 & 3.08 & 0.42 & -0.27 \\
\hline 6. Machinery & & 29.51 & 29.44 & 1.00 & -0.63 \\
\hline 7. Transports & & 16.95 & 15.40 & 0.91 & -0.58 \\
\hline 8. Misc. & & 3.38 & 3.22 & 0.95 & -0.61 \\
\hline Sum & & 100 & 100 & & \\
\hline All groups & $\bar{W}_{2 t} D Q_{2 t}=\Theta_{2} D Q_{t}+\phi \Theta_{2}\left(D P_{2 t}^{\prime}-D P_{t}^{\prime}\right)$ & 26.27 & 46.63 & 1.77 & -0.64 \\
\hline \multicolumn{6}{|c|}{ C. Variety 3: Wood } \\
\hline 1. Domestic & \multirow{3}{*}{$\begin{array}{l}\frac{\bar{w}_{1 t}^{5}}{\bar{W}_{3 t}} D q_{1 t}^{5}=\frac{\theta_{1}^{5}}{\theta_{3}} D Q_{3 t}+\sum_{j=1}^{2} v_{1 j}^{5}\left(D p_{j t}^{5}-D P_{3 t}^{\prime}\right) \\
\frac{\bar{w}_{2 t}^{5}}{\bar{w}_{3 t}} D q_{2 t}^{5}=\frac{\theta_{2}^{5}}{\theta_{3}} D Q_{3 t}+\sum_{j=1}^{2} v_{2 j}^{5}\left(D p_{j t}^{5}-D P_{3 t}^{\prime}\right)\end{array}$} & 86.35 & 46.24 & 0.54 & -0.01 \\
\hline 2. Foreign & & 13.65 & 53.76 & 3.94 & -0.05 \\
\hline Sum & & 100 & 100 & & \\
\hline All groups & $\bar{W}_{3 t} D Q_{3 t}=\Theta_{3} D Q_{t}+\phi \Theta_{3}\left(D P_{3 t}^{\prime}-D P_{t}^{\prime}\right)$ & 5.57 & 0.45 & 0.08 & -0.03 \\
\hline \multicolumn{2}{|c|}{ Sum all groups, all three varieties $(A+B+C)$} & 100 & 100 & & \\
\hline
\end{tabular}

\section{Notes:}

1. Notation and indexes: There are 8 groups of goods, denoted by the superscript $g=1, \cdots, 8$, and 2 items in each, domestically and foreign produced, denoted by the subscript $i=1,2$. The budget and marginal shares of item $i$ of group $g$ are $\bar{w}_{i t}^{g}$ and $\theta_{i}^{g}$, respectively. The overall Divisia volume index is $D Q_{t}=\sum_{g=1}^{g} \sum_{i=1}^{2} \bar{w}_{i t}^{g} D q_{i t}^{g}$, where $q_{i t}^{g}$ is the per capita quantity demand of $i$ in $g$ and $D$ is the log-change operator from $t-1$ to $t$. The overall Frisch price index is $D P_{t}^{\prime}=\sum_{g=1}^{8} \sum_{i=1}^{2} \theta_{i}^{g} D p_{i t}^{g}$, where $p_{i t}^{g}$ is the price of $i$ in $g$.

2. Three varieties: The $2 \times 8=16$ "elementary" goods are divided into 3 varieties:

(i) Domestically produced goods other than Wood: These are goods indexed by $i=1, g=1, \cdots, 8, g \neq 5$, denoted by the set $\boldsymbol{V}_{1}$.

(ii) Imported goods other than Wood are those indexed by $i=2, g=1, \cdots, 8, g \neq 5$, denoted by $\boldsymbol{V}_{2}$.

(iii) Wood refers to those goods for which $i=1,2, g=5$, denoted by $\boldsymbol{V}_{3}$.

3. Budget and marginal shares: For variety $k(k=1,2,3)$, these shares are $\bar{W}_{k t}=\sum_{g \in \boldsymbol{V}_{k}} \bar{w}_{k t}^{g}, \quad \Theta_{k}=\sum_{g \in \boldsymbol{V}_{k}} \theta_{k}^{g}$, and the corresponding Divisia volume and Frisch price indexes are $D Q_{k t}=\sum_{g \in V_{k}} \frac{\bar{w}_{k t}^{g}}{\bar{W}_{k t}} D q_{k t}^{g}, D P_{k t}^{\prime}=\sum_{g \in V_{k}} \frac{\theta_{k}^{g}}{\Theta_{k}} D p_{k t}^{g}$.

4. Other coefficients. $\phi$ is the income flexibility, and $v_{i j}^{5}, i, j=1,2$, are the price coefficients for Wood, which satisfy $v_{12}^{5}=v_{21}^{5}$ and $\sum_{j=1}^{2} v_{i j}^{5}=\phi \theta_{i}^{5}, i=1,2$.

5. Column 1: Commodity names abbreviated.

6. Column 2: Disturbance terms are omitted.

7. Columns $3-4$ : All entries are multiplied by 100 . Budget shares are sample averages.

8. Columns 5 and 6: "Income" elasticities are with respect to the high-level aggregate. Own-price elasticities are of the Frisch type (marginal utility of income constant).

9. See Appendix A7 for details of derivations. 
Table 5.2. Aggregated and Disaggregated Demands by Commodity Group

\begin{tabular}{|c|c|c|c|c|c|}
\hline $\begin{array}{l}\text { Commodity } \\
\text { group } g \\
\text { (1) }\end{array}$ & $\begin{array}{l}\text { Demand equations } \\
\text { (3) }\end{array}$ & $\begin{array}{l}\text { Budget } \\
\text { share } \\
\text { (4) }\end{array}$ & $\begin{array}{l}\text { Marginal } \\
\text { share } \\
\text { (5) }\end{array}$ & $\begin{array}{l}\text { Income } \\
\text { elasticity } \\
\text { (6) }\end{array}$ & $\begin{array}{l}\text { Own- } \\
\text { price } \\
\text { elasticity } \\
\quad(7)\end{array}$ \\
\hline \multirow{2}{*}{$\begin{array}{l}\text { 1. Food and } \\
\text { Agricultural } \\
\text { Commodities }\end{array}$} & 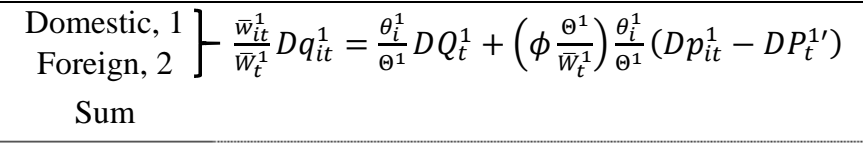 & $\begin{array}{c}91.74 \\
8.26 \\
100\end{array}$ & $\begin{array}{c}65.56 \\
34.44 \\
100\end{array}$ & $\begin{array}{l}0.71 \\
4.17\end{array}$ & $\begin{array}{l}-0.06 \\
-0.34\end{array}$ \\
\hline & $\begin{array}{c}\text { Both } \\
\text { varieties }\end{array} \bar{W}_{t}^{1} D Q_{t}^{1}=\Theta^{1} D Q_{t}+\phi \Theta^{1}\left(D P_{t}^{1 \prime}-D P_{t}^{\prime}\right)$ & 22.00 & 5.05 & 0.23 & -0.08 \\
\hline \multirow{2}{*}{$\begin{array}{l}\text { 2. Energy and } \\
\text { Minerals }\end{array}$} & $\begin{array}{l}1 \\
2 \\
\text { Sum }\end{array} \quad \frac{\bar{w}_{i t}^{2}}{\bar{w}_{t}^{2}} D q_{i t}^{2}=\frac{\theta_{i}^{2}}{\Theta^{2}} D Q_{t}^{2}+\left(\phi \frac{\Theta^{2}}{\bar{w}_{t}^{2}}\right) \frac{\theta_{i}^{2}}{\Theta^{2}}\left(D p_{i t}^{2}-D P_{t}^{2 \prime}\right)$ & $\begin{array}{c}77.33 \\
22.67 \\
100\end{array}$ & $\begin{array}{c}63.94 \\
36.06 \\
100\end{array}$ & $\begin{array}{l}0.83 \\
1.59\end{array}$ & $\begin{array}{l}-0.49 \\
-0.95\end{array}$ \\
\hline & $\bar{W}_{t}^{2} D Q_{t}^{2}=\Theta^{2} D Q_{t}+\phi \Theta^{2}\left(D P_{t}^{2 \prime}-D P_{t}^{\prime}\right)$ & 28.82 & 48.10 & 1.67 & -0.60 \\
\hline \multirow[t]{2}{*}{ 3. Chemicals } & $\frac{\bar{w}_{i t}^{3}}{\bar{w}_{t}^{3}} D q_{i t}^{3}=\frac{\theta_{i}^{3}}{\Theta^{3}} D Q_{t}^{3}+\left(\phi \frac{\Theta^{3}}{\bar{w}_{t}^{3}}\right) \frac{\theta_{i}^{3}}{\Theta^{3}}\left(D p_{i t}^{3}-D P_{t}^{3 \prime}\right)$ & $\begin{array}{c}64.61 \\
35.39 \\
100\end{array}$ & $\begin{array}{c}48.90 \\
51.10 \\
100\end{array}$ & $\begin{array}{l}0.76 \\
1.44\end{array}$ & $\begin{array}{l}-0.24 \\
-0.46\end{array}$ \\
\hline & $\bar{W}_{t}^{3} D Q_{t}^{3}=\Theta^{3} D Q_{t}+\phi \Theta^{3}\left(D P_{t}^{3 \prime}-D P_{t}^{\prime}\right)$ & 8.23 & 7.24 & 0.88 & -0.32 \\
\hline \multirow{2}{*}{$\begin{array}{l}\text { 4. Textile, } \\
\text { Leather, } \\
\text { Clothing and } \\
\text { Footwear }\end{array}$} & $\frac{\bar{w}_{i t}^{4}}{\bar{W}_{t}^{4}} D q_{i t}^{4}=\frac{\theta_{i}^{4}}{\Theta^{4}} D Q_{t}^{4}+\left(\phi \frac{\Theta^{4}}{\bar{W}_{t}^{4}}\right) \frac{\theta_{i}^{4}}{\Theta^{4}}\left(D p_{i t}^{4}-D P_{t}^{4 \prime}\right)$ & $\begin{array}{c}70.38 \\
29.62 \\
100\end{array}$ & $\begin{array}{c}55.16 \\
44.84 \\
100\end{array}$ & $\begin{array}{l}0.78 \\
1.51\end{array}$ & $\begin{array}{l}-0.14 \\
-0.27\end{array}$ \\
\hline & $\bar{W}_{t}^{4} D Q_{t}^{4}=\Theta^{4} D Q_{t}+\phi \Theta^{4}\left(D P_{t}^{4 \prime}-D P_{t}^{\prime}\right)$ & 6.47 & 3.21 & 0.50 & -0.18 \\
\hline \multirow{2}{*}{$\begin{array}{l}\text { 5. Wood and } \\
\text { Paper Products }\end{array}$} & $\frac{\bar{w}_{i t}^{5}}{\bar{w}_{t}^{5}} D q_{i t}^{5}=\frac{\theta_{i}^{5}}{\Theta^{5}} D Q_{t}^{5}+\sum_{j=1}^{2} v_{i j}^{5}\left(D p_{j t}^{5}-D P_{t}^{5 \prime}\right)$ & $\begin{array}{c}86.35 \\
13.65 \\
100\end{array}$ & $\begin{array}{c}46.24 \\
53.76 \\
100\end{array}$ & $\begin{array}{l}0.54 \\
3.94\end{array}$ & $\begin{array}{l}-0.01 \\
-0.05\end{array}$ \\
\hline & $\bar{W}_{t}^{5} D Q_{t}^{5}=\Theta^{5} D Q_{t}+\phi \Theta^{5}\left(D P_{t}^{5 \prime}-D P_{t}^{\prime}\right)$ & 5.57 & 0.45 & 0.08 & -0.03 \\
\hline \multirow{2}{*}{$\begin{array}{l}\text { 6. Machinery and } \\
\text { Equipment }\end{array}$} & $\frac{\bar{w}_{i t}^{6}}{\bar{w}_{t}^{6}} D q_{i t}^{6}=\frac{\theta_{i}^{6}}{\Theta^{6}} D Q_{t}^{6}+\left(\phi \frac{\Theta^{6}}{\bar{w}_{t}^{6}}\right) \frac{\theta_{i}^{6}}{\Theta^{6}}\left(D p_{i t}^{6}-D P_{t}^{6 \prime}\right)$ & $\begin{array}{c}48.86 \\
51.14 \\
100\end{array}$ & $\begin{array}{c}36.10 \\
63.90 \\
100\end{array}$ & $\begin{array}{l}0.74 \\
1.25\end{array}$ & $\begin{array}{l}-0.38 \\
-0.63\end{array}$ \\
\hline & $\bar{W}_{t}^{6} D Q_{t}^{6}=\Theta^{6} D Q_{t}+\phi \Theta^{6}\left(D P_{t}^{6 \prime}-D P_{t}^{\prime}\right)$ & 15.16 & 21.48 & 1.42 & -0.51 \\
\hline \multirow{2}{*}{$\begin{array}{l}\text { 7. Motor } \\
\text { Vehicles and } \\
\text { Transport }\end{array}$} & $\frac{\bar{w}_{i t}^{7}}{\bar{w}_{t}^{7}} D q_{i t}^{7}=\frac{\theta_{i}^{7}}{\Theta^{7}} D Q_{t}^{7}+\left(\phi \frac{\Theta^{7}}{\bar{w}_{t}^{7}}\right) \frac{\theta_{i}^{7}}{\Theta^{7}}\left(D p_{i t}^{7}-D P_{t}^{7 \prime}\right)$ & $\begin{array}{c}57.09 \\
42.91 \\
100\end{array}$ & $\begin{array}{c}40.68 \\
59.32 \\
100\end{array}$ & $\begin{array}{l}0.71 \\
1.38\end{array}$ & $\begin{array}{l}-0.30 \\
-0.58\end{array}$ \\
\hline & $\bar{W}_{t}^{7} D Q_{t}^{7}=\Theta^{7} D Q_{t}+\phi \Theta^{7}\left(D P_{t}^{7 \prime}-D P_{t}^{\prime}\right)$ & 10.38 & 12.10 & 1.17 & -0.42 \\
\hline \multirow{3}{*}{$\begin{array}{l}\text { 8. Miscellaneous } \\
\text { Manufactured } \\
\text { Goods }\end{array}$} & $\frac{\bar{w}_{i t}^{8}}{\bar{W}_{t}^{8}} D q_{i t}^{8}=\frac{\theta_{i}^{8}}{\Theta^{8}} D Q_{t}^{8}+\left(\phi \frac{\Theta^{8}}{\bar{w}_{t}^{8}}\right) \frac{\theta_{i}^{8}}{\Theta^{8}}\left(D p_{i t}^{8}-D P_{t}^{8 \prime}\right)$ & $\begin{array}{c}73.60 \\
26.40 \\
100\end{array}$ & $\begin{array}{c}41.65 \\
58.35 \\
100\end{array}$ & $\begin{array}{l}0.57 \\
2.21\end{array}$ & $\begin{array}{l}-0.16 \\
-0.61\end{array}$ \\
\hline & $\bar{W}_{t}^{8} D Q_{t}^{8}=\Theta^{8} D Q_{t}+\phi \Theta^{8}\left(D P_{t}^{8 \prime}-D P_{t}^{\prime}\right)$ & 3.37 & 2.58 & 0.77 & -0.27 \\
\hline & Sum all groups, both varieties $(1+2+\cdots+8)$ & 100 & 100 & & \\
\hline
\end{tabular}

Notes:

1. Notation and indexes: See Table 5.1.

2. Aggregation: Adding over goods from the two sources, the budget and marginal shares of group $g$ are $\bar{W}_{t}^{g}=\sum_{i=1}^{2} \bar{w}_{i t}^{g}$ and $\Theta^{g}=\sum_{i=1}^{2} \theta_{i}^{g}, g=1, \cdots, 8$. The corresponding Divisia and Frisch indexes are $D Q_{t}^{g}=\sum_{i=1}^{2}\left(\bar{w}_{i t}^{g} / \bar{W}_{t}^{g}\right) D q_{i t}^{g}$ and $D P_{t}^{g^{\prime}}=$ $\sum_{i=1}^{2}\left(\theta_{i}^{g} / \Theta^{g}\right) D p_{i t}^{g}, g=1, \cdots, 8$.

3. Columns 4-5: All entries are multiplied by 100. Budget share are sample averages.

4. Columns 6 and 7: "Income" elasticities are with respect to the high-level aggregate. Own-price elasticities are of the Frisch type (marginal utility of income constant).

5. See Appendix A7 for details of derivations. 
Table 5.3. Budget-Share Predictions

\begin{tabular}{|c|c|c|c|c|c|c|c|c|c|c|}
\hline \multirow[b]{3}{*}{ Aggregate } & \multirow[b]{3}{*}{$\begin{array}{c}\text { Mean } \\
\text { budget } \\
\text { share } \\
\\
\text { (1) }\end{array}$} & \multirow{2}{*}{\multicolumn{3}{|c|}{ Root-mean-squared errors }} & \multicolumn{6}{|c|}{ Information inaccuracies } \\
\hline & & & & & \multicolumn{3}{|c|}{ Individual items } & \multicolumn{3}{|c|}{ All items jointly } \\
\hline & & $\begin{array}{c}\text { Demand } \\
\text { model } \\
(2)\end{array}$ & $\begin{array}{c}\text { Naïve } \\
\text { (3) }\end{array}$ & $\begin{array}{c}\text { Demand } \\
\text { model } \\
\text { better? } \\
(4)\end{array}$ & $\begin{array}{c}\text { Demand } \\
\text { model } \\
\text { (5) }\end{array}$ & $\begin{array}{c}\text { Naïve } \\
(6)\end{array}$ & $\begin{array}{c}\text { Demand } \\
\text { model } \\
\text { better? } \\
(7)\end{array}$ & $\begin{array}{l}\text { Model } \\
\text { (8) }\end{array}$ & $\begin{array}{c}\text { Naïve } \\
\text { (9) }\end{array}$ & $\begin{array}{c}\text { Demand } \\
\text { model } \\
\text { better? } \\
(10)\end{array}$ \\
\hline \multicolumn{11}{|c|}{ A. Varieties } \\
\hline 1. Domestic Goods & 68.17 & 0.837 & 0.936 & Yes & 0.0164 & 0.0206 & Yes & & & \\
\hline 2. Foreign Goods & 26.25 & 0.850 & 1.026 & Yes & 0.0189 & 0.0283 & Yes & 0.0249 & 0.0348 & Yes \\
\hline 3. Wood and Paper Products & 5.58 & 0.240 & 0.273 & Yes & 0.0060 & 0.0076 & Yes & & & \\
\hline \multicolumn{11}{|c|}{ B. Groups } \\
\hline 1. Food and Agricultural Commodities & 22.06 & 0.591 & 0.667 & Yes & 0.0101 & 0.0129 & Yes & & & \\
\hline 2. Energy and Minerals & 28.76 & 1.004 & 1.021 & Yes & 0.0246 & 0.0249 & Yes & & & \\
\hline 3. Chemicals & 8.22 & 0.214 & 0.210 & No & 0.0030 & 0.0029 & No & & & \\
\hline 4. Textile, Leather, Clothing and Footwear & 6.51 & 0.163 & 0.190 & Yes & 0.0022 & 0.0030 & Yes & & & \\
\hline 5. Wood and Paper Products & 5.58 & 0.240 & 0.273 & Yes & 0.0060 & 0.0076 & Yes & 0.0584 & 0.0624 & Yes \\
\hline 6. Machinery and Equipment & 15.13 & 0.402 & 0.469 & Yes & 0.0063 & 0.0085 & Yes & & & \\
\hline 7. Motor Vehicles and Transport & 10.38 & 0.560 & 0.522 & No & 0.0172 & 0.0149 & No & & & \\
\hline 8. Miscellaneous Manufactured Goods & 3.37 & 0.101 & 0.104 & Yes & 0.0016 & 0.0017 & Yes & & & \\
\hline
\end{tabular}

Notes:

1. Columns $5-6$ : These are sample means of $w_{m t} \log \frac{w_{m t}}{\widehat{w}_{m t}}+\left(1-w_{m t}\right) \log \frac{1-w_{m t}}{1-\widehat{w}_{m t}}$, where $\widehat{w}_{m t}$ is either (i) the predicted budget share from the demand model; or (ii) the naïve extrapolation $w_{m, t-1} ; w_{m t}$ is the actual value of the budget share; and $m=1,2,3$ (varieties) or $m=1, \ldots, 8$ (groups).

2. Columns 8-9: These are sample means of $\sum_{m=1}^{n} w_{m t} \log \frac{w_{m t}}{\widehat{w}_{m t}}(n=3,8)$.

3. All entries are multiplied by 100 .

4. See Appendix A8 for details. 
Table 6.1. Two-Decade Changes in Consumption and Prices

\begin{tabular}{|c|c|c|c|c|c|}
\hline \multirow{2}{*}{$\begin{array}{l}\text { Commodity } \\
\text { group } g\end{array}$} & \multirow{2}{*}{ Variety $i$} & \multicolumn{3}{|c|}{ Budget shares } & \multirow{3}{*}{$\begin{array}{c}\text { Log-change in } \\
\text { relative price, } \\
\text { 1997-2017 } \\
\text { (6) }\end{array}$} \\
\hline & & 1996 & 2017 & Change & \\
\hline$(1)$ & $(2)$ & (3) & (4) & (5) & \\
\hline \multirow{3}{*}{ 1. Food and Agricultural Commodities } & Domestic, 1 & 94.08 & 88.33 & -5.75 & 0.66 \\
\hline & Foreign, 2 & 5.92 & 11.67 & 5.75 & -7.19 \\
\hline & Total & 100 & 100 & 0 & 14.80 \\
\hline \multirow{3}{*}{ 2. Energy and Minerals } & 1 & 84.92 & 73.10 & -11.82 & -0.48 \\
\hline & 2 & 15.08 & 26.90 & 11.82 & 1.62 \\
\hline & Total & 100 & 100 & 0 & 7.48 \\
\hline \multirow{3}{*}{ 3. Chemicals } & 1 & 68.98 & 59.01 & -9.97 & 6.50 \\
\hline & 2 & 31.02 & 40.99 & 9.97 & -11.77 \\
\hline & Total & 100 & 100 & 0 & -19.29 \\
\hline \multirow{3}{*}{ 4. Textile, Leather, Clothing and Footwear } & 1 & 76.71 & 59.80 & -16.92 & -0.18 \\
\hline & 2 & 23.29 & 40.20 & 16.92 & 0.43 \\
\hline & Total & 100 & 100 & 0 & -3.48 \\
\hline \multirow{3}{*}{ 5. Wood and Paper Products } & 1 & 86.63 & 83.17 & -3.46 & 1.08 \\
\hline & 2 & 13.37 & 16.83 & 3.46 & -6.82 \\
\hline & Total & 100 & 100 & 0 & 0.09 \\
\hline \multirow{3}{*}{ 6. Machinery and Equipment } & 1 & 57.76 & 43.79 & -13.96 & 3.12 \\
\hline & 2 & 42.24 & 56.21 & 13.96 & -2.94 \\
\hline & Total & 100 & 100 & 0 & -10.61 \\
\hline \multirow{3}{*}{ 7. Motor Vehicles and Transport } & 1 & 67.80 & 43.79 & -24.01 & 0.87 \\
\hline & 2 & 32.20 & 56.21 & 24.01 & -1.13 \\
\hline & Total & 100 & 100 & 0 & -18.22 \\
\hline \multirow{3}{*}{ 8. Miscellaneous Manufactured Goods } & 1 & 84.61 & 62.96 & -21.64 & 4.10 \\
\hline & 2 & 15.39 & 37.04 & 21.64 & -11.14 \\
\hline & Total & 100 & 100 & 0 & -3.03 \\
\hline \multirow{3}{*}{ All groups } & 1 & 79.67 & 67.25 & -12.42 & 3.22 \\
\hline & 2 & 20.33 & 32.75 & 12.42 & -8.55 \\
\hline & Total & 100 & 100 & 0 & 32.56 \\
\hline
\end{tabular}

\section{Notes:}

1. All rows except the last 3 :

(i) Columns $3-4$ : The budget share of variety $i$ of good $g$ is expenditure on this variety as a proportion of total expenditure on $g, \frac{\bar{w}_{i t}^{g}}{\bar{w}_{t}^{g}}(g=1, \ldots, 8 ; i=1,2 ; t=1996,2017)$, where $\bar{W}_{t}^{g}=\bar{w}_{1 t}^{g}+\bar{w}_{2 t}^{g}$ is the budget share of $g$.

(ii) Column 6: The relative price change over the 22-year period is $\sum_{t=1996}^{2017}\left(D p_{i t}^{g}-D P_{t}^{g}\right)$, where $D P_{t}^{g}=$ $\sum_{i=1}^{2}\left(\frac{\bar{w}_{i}^{g}}{\bar{W}^{g}}\right) D p_{i t}^{g}$ is the Divisia price index of group $g$, with $\bar{w}_{i}^{g}=\frac{1}{22} \sum_{t=1996}^{2017} \bar{w}_{i t}^{g}$ and $\bar{W}^{g}=\frac{1}{22} \sum_{t=1996}^{2017} \bar{W}_{t}^{g}$. The "total" rows give $\sum_{t=1996}^{2017}\left(D P_{t}^{g}-D P_{t}\right)$, where $D P_{t}=\sum_{g=1}^{8} \sum_{i=1}^{2} \bar{w}_{i}^{g} D p_{i t}^{g}$ is the Divisia price index of all varieties/goods.

\section{Last 3 rows:}

(i) Columns $3-4$ : The combined budget share of all 8 goods of variety $i$ is $\bar{W}_{i t}=\sum_{g=1}^{8} \bar{w}_{i t}^{g}$. The "total" row contains $\sum_{i=1}^{2} \bar{W}_{i t}$.

(ii) Column 6: The relative price change over the 22-year period is $\sum_{t=1996}^{2017}\left(D P_{i t}-D P_{t}\right)$, where $D P_{i t}=$ $\sum_{g=1}^{8}\left(\frac{\bar{w}_{i}^{g}}{\bar{w}_{i}}\right) D p_{i t}^{g}$ is the Divisia price index of variety $i$ with $\bar{W}_{i}=\frac{1}{22} \sum_{t=1996}^{2017} \bar{W}_{i t}$. The "total" row reports $\sum_{t=1996}^{2017} D P_{t}$.

3. Column 5: The difference between columns 4 and 3.

4. All entries are multiplied by 100 . 
Figure 1.1. Import Shares, Australia (\%)

A. Food and Agricultural Products

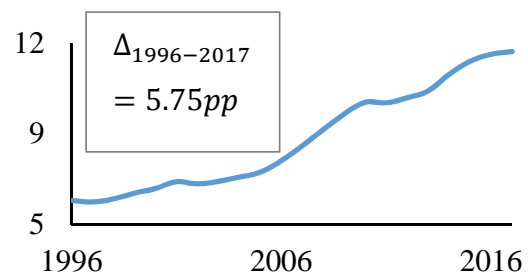

C. Chemicals

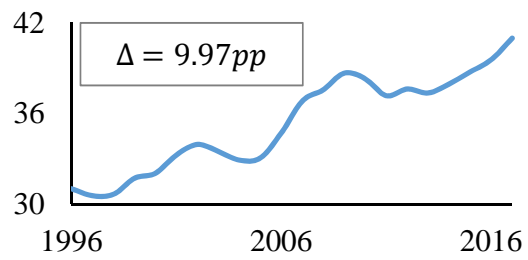

E. Wood and Paper Products

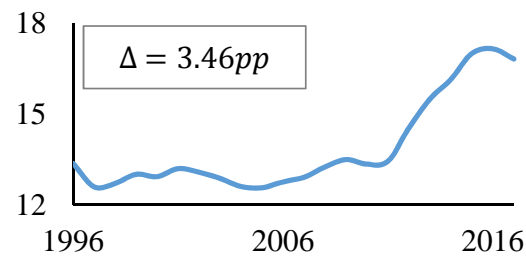

G. Motor Vehicles and Transport

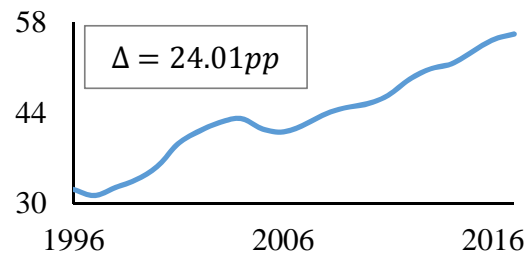

B. Energy and Minerals

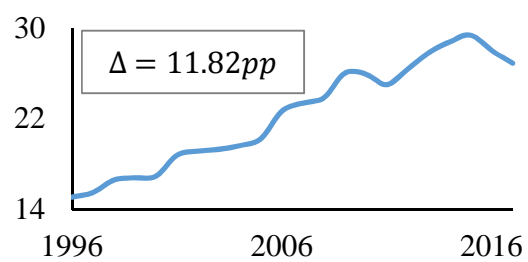

D. Textile, Leather, Clothing and Footwear

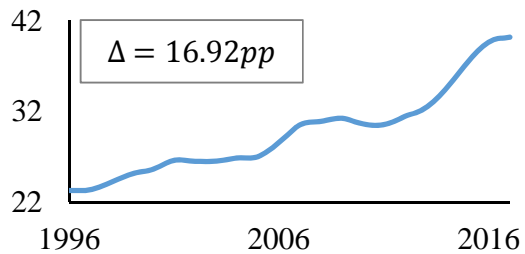

F. Machinery and Equipment

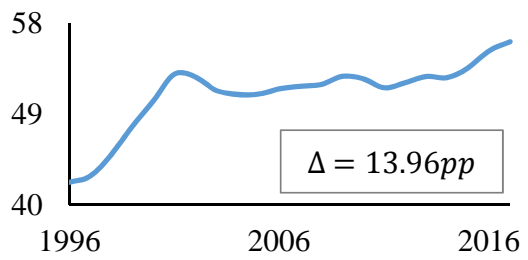

H. Miscellaneous Manufactured Goods

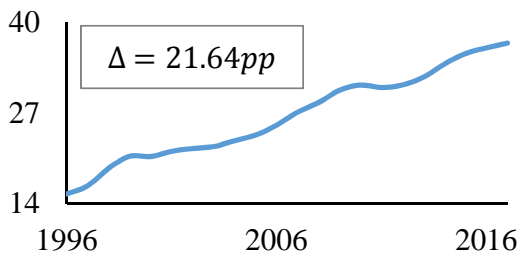

I. All Groups

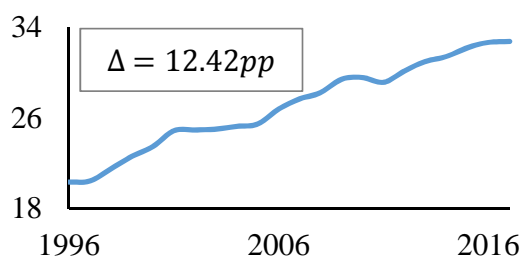

Notes:

1. Panels $A-H$ : These panels refer to the shares of imports in sales, defined as $\frac{\bar{w}_{2 t}^{g}}{\bar{w}_{t}^{g}}(g=1, \ldots, 8 ; t=1996, \ldots, 2017)$, where $\bar{w}_{2 t}^{g}$ denotes imports of group $g$ in year $t$ as a proportion of total expenditure and $\bar{W}_{t}^{g}=\bar{w}_{1 t}^{g}+\bar{w}_{2 t}^{g}$ is expenditure on the domestic and imported varieties of $g$ as a proportion of total expenditure.

2. Panel I: This panel refers to $\bar{W}_{2 t}=\sum_{g=1}^{8} \bar{w}_{2 t}^{g}$, the share of imports of all goods in total expenditure.

3. The box in each panel gives the change in the share over the period 1996 - 2017, in percentage points $(p p)$. 
Figure 4.1. Price-Quantity Scatters

\section{Domestic}

$(n=22)$
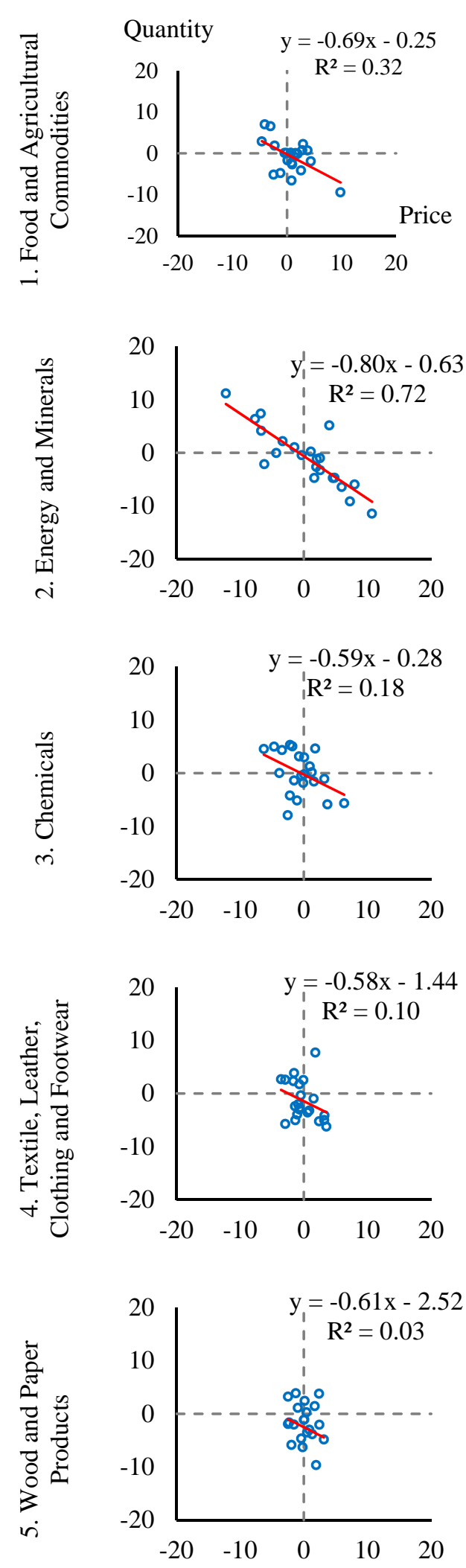

\section{Foreign}

$(n=22)$
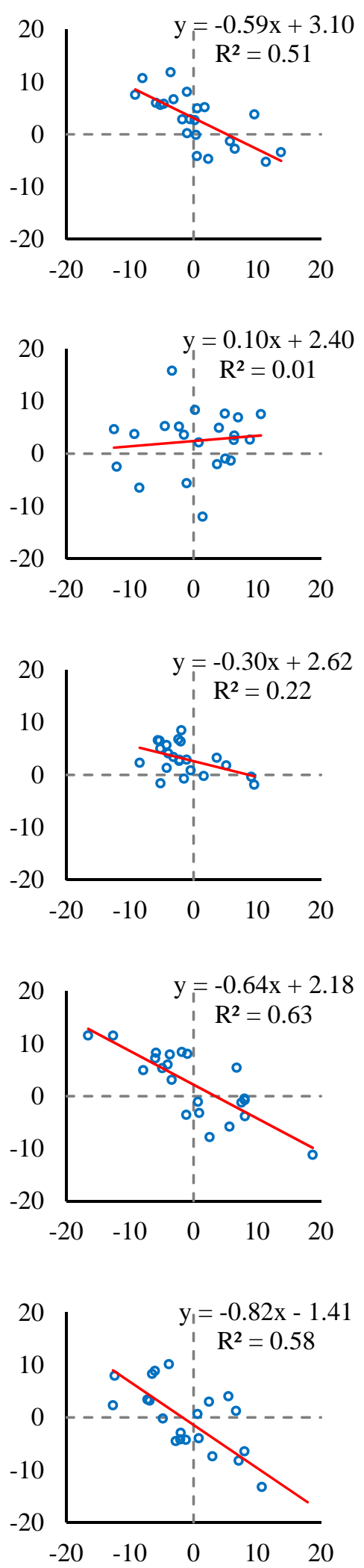

Both Varieties

$(n=44)$
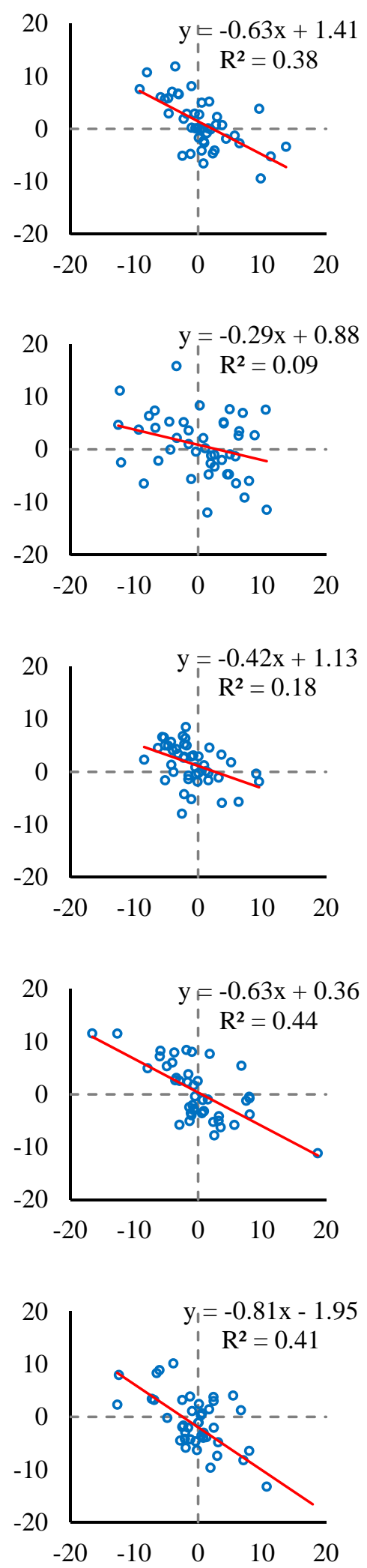

(continued on next page) 
Figure 4.1. (continued)

\section{Domestic}

$(n=22)$
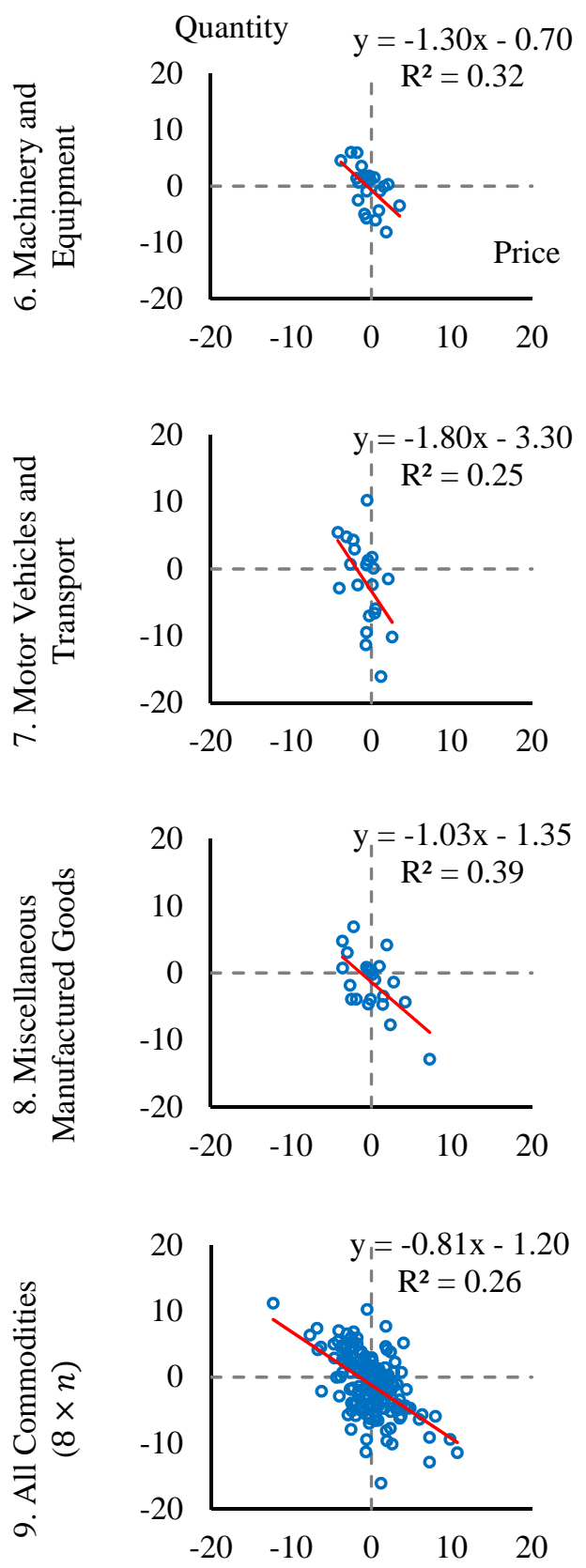

\section{Foreign}

$(n=22)$
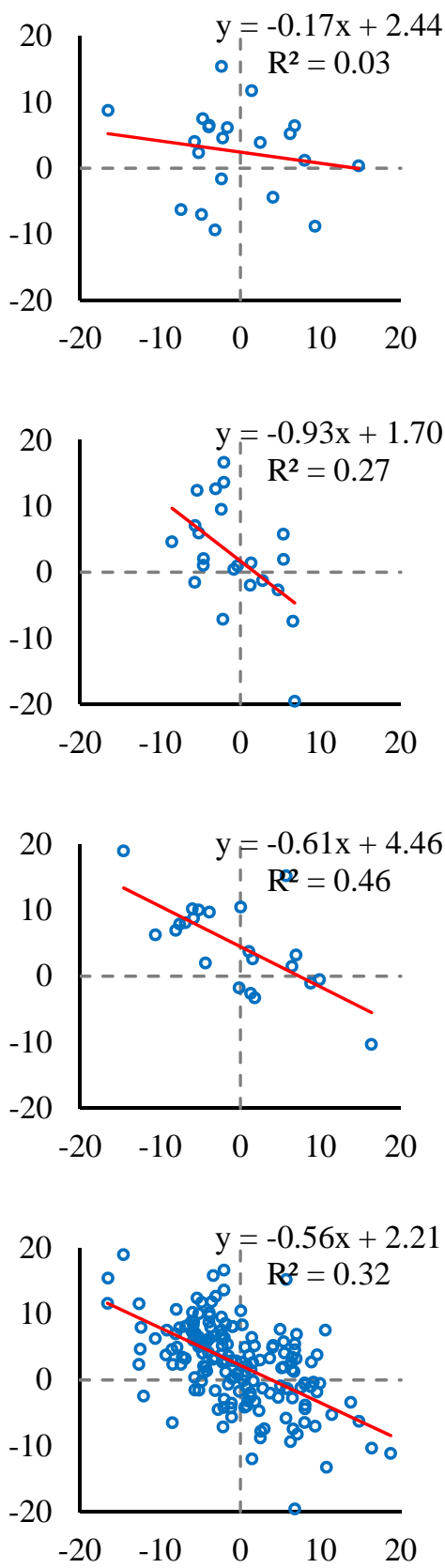

Both Varieties

$(n=44)$
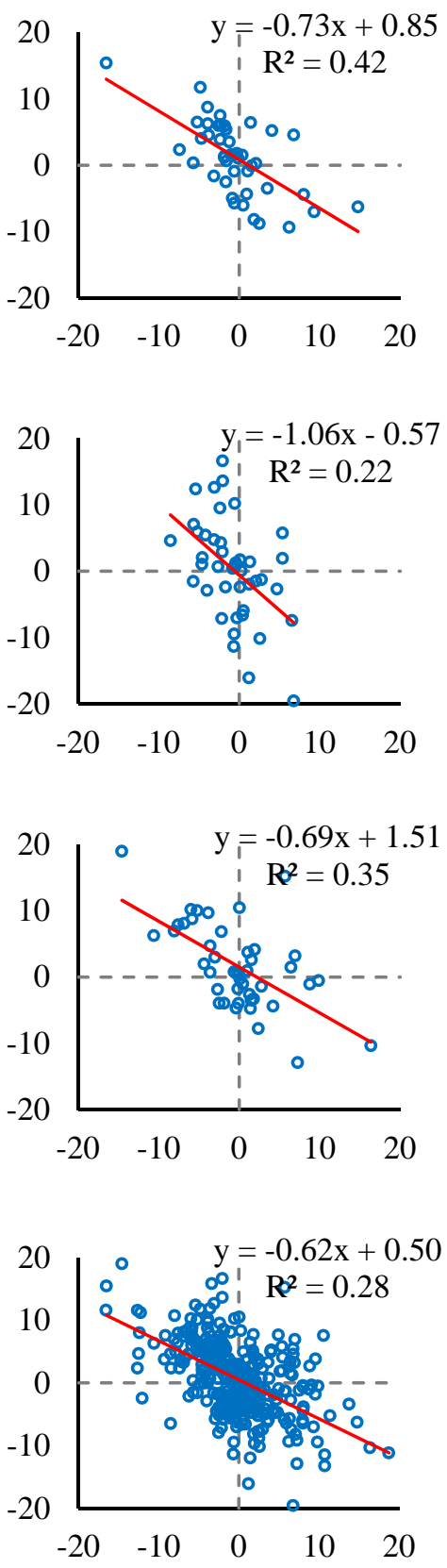

Notes:

1. Horizontal axis: The log-change in year $t$ of the relative price of variety $i$ of $\operatorname{good} g(i=1,2 ; g=1, \ldots, 8), D p_{i t}^{g}-$ $D P_{t}, t=1, \cdots, 22$, where $D P_{t}=\sum_{g=1}^{8} \sum_{i=1}^{2} \bar{w}_{i t}^{g} D p_{i t}^{g}$ is the Divisia price index.

2. Vertical axis: The corresponding log-change in the relative quantity, $D q_{i t}^{g}-D Q_{t}$, where $D Q_{t}=$ $\sum_{g=1}^{8} \sum_{i=1}^{2} \bar{w}_{i t}^{g} D q_{i t}^{g}$ is the Divisia quantity index.

3. All values are multiplied by 100 . 
Figure 6.1. Import Penetration Simulations (\%)
A1. Levels
A. Total Imports, Income Shock

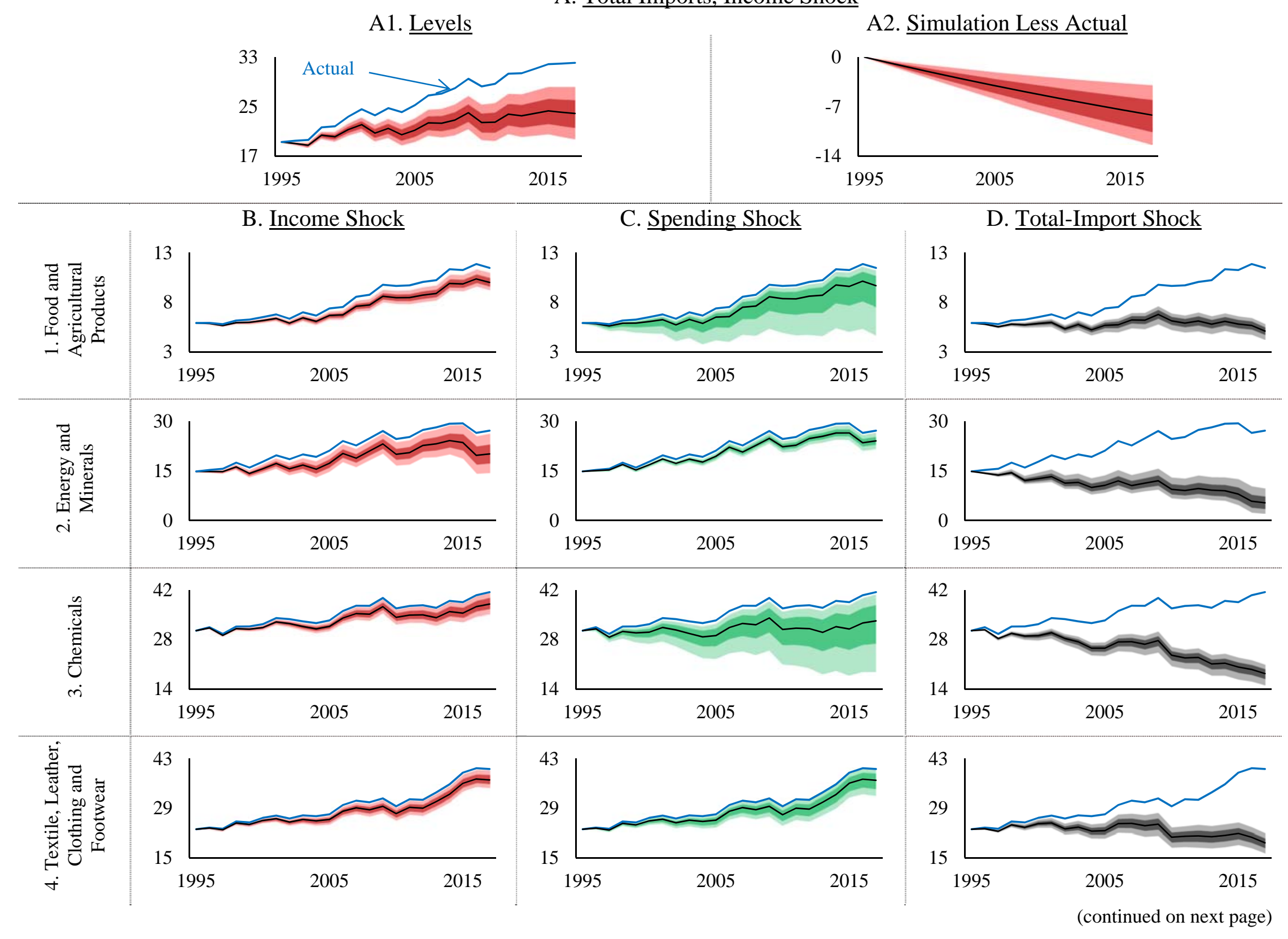


Figure 6.1. (continued)

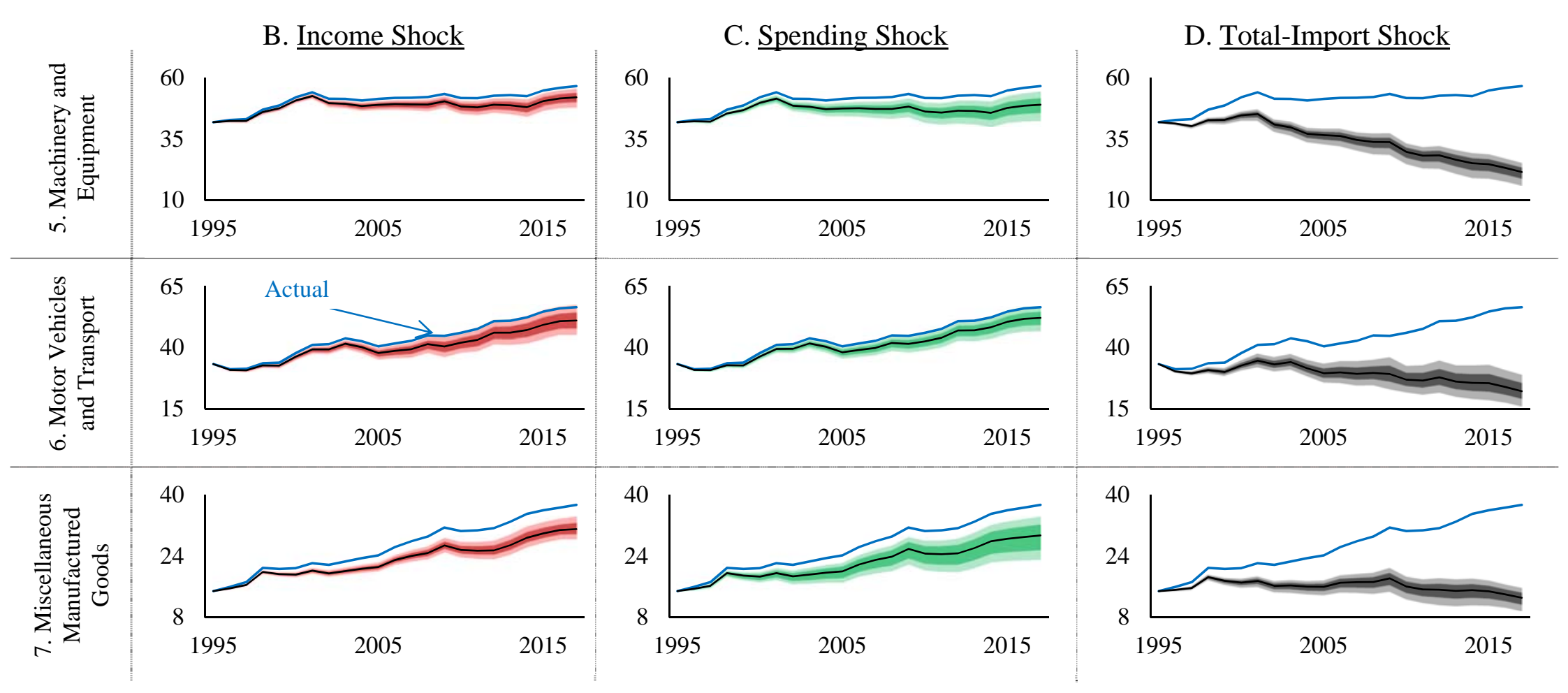

Notes:

1. The first row:

(i) Each plot refers to the expenditure share of all imports (other than wood), defined as $\mathrm{W}_{2 \mathrm{t}}=\sum_{\mathrm{g}=1, \mathrm{~g} \neq 5}^{\mathrm{g}} \mathrm{w}_{2 \mathrm{t}}^{\mathrm{g}}$.

(ii) The shock is a fall in the growth in real income, with shock equal to the sample average of the growth in real income.

2. The last 7 rows:

(i) Each plots refers to the share of the imported component in total sales of a good, defined as $w_{2 t}^{g} / W_{t}^{g}(g=1, \ldots, 8 ; g \neq 5 ; t=1995, \ldots, 2017)$, where $w_{2 t}^{g}$ denotes expenditure on imports of good $g$ in year $t$ as a proportion of total expenditure, and $W_{t}^{g}=w_{1 t}^{g}+w_{2 t}^{g}$ is the share of expenditure on the domestic and imported varieties of the good.

(ii) There are three types of shocks (represented by panels B - D): A fall in the growth of (a) real income, (b) spending on $g$ and (c) total import spending. The shocks are equal to the negative of the sample averages of the shocked variables.

3. Shares are percentages. The only exception is in panel A2, which refers to percentage-point changes in the share.

4. The dark (light) shaded areas indicate the $68 \%$ (95\%) confidence intervals, constructed from 10,000 bootstrap replications. The solid black line in the middle of the bands represents the median. The blue solid line represents actual data. 


\section{SUPPLEMENTARY MATERIALS}

\section{A-1}

\section{APPENDICES}

\section{A1. The Stacked Format}

Table A1.1 presents the matrix forms of four specifications of the demand model used in our study. These form was used in Section 3 and is the basis of the hypothesis tests of Table 4.3, as well as subsequent analyses in Sections $4-6$.

\section{A2. More on the Covariance Matrix}

The $2 G \times 2 G$ disturbance covariance matrix of model (3.2) is $\left[\sigma_{k l}\right]$. This matrix will be structured under the following conditions:

1. Negative covariances. The Divisia volume index $D Q_{t}$ on the right-hand side of (3.2) is the sum of the left-hand side variables, that is, $D Q_{t}=\sum_{k=1}^{2 G} \bar{w}_{k t} D q_{k t}$, which implies $\sum_{k=1}^{2 G} \varepsilon_{k t}=0$ and $\sum_{l=1}^{2 G} \sigma_{k l}=0$. As $\sigma_{k k}>0$, it follows that the average covariance, $(2 G-1)^{-1} \sum_{l=1, l \neq k}^{2 G} \sigma_{k l}=-(2 G-1)^{-1} \sigma_{k k}$, is negative. We shall make the stronger assumption that each covariance is negative.

2. Decomposable covariances. In order to preserve the budget constraint, a shock to one demand equation has to be offset by shocks to the others, as represented by the requirement that $\sum_{k=1}^{2 G} \varepsilon_{k t}=0$. Imagine a shock $\lambda_{k}^{2}$ to the demand for good $k$. How might this impact the other demands? A simple provisional answer might be that the shock has a proportional effect on all others so the covariance is of the form $-\sigma^{2} \lambda_{k}^{2}$, where $\sigma>0$ is a proportionality factor. If the same is true for a good-l shock, $\lambda_{l}^{2}$, its impact on the others would be $-\sigma^{2} \lambda_{l}^{2}$. But symmetry of the covariances requires the two effects coincide, so we must revise the answer. A natural comprise is the geometric mean of $\sigma^{2} \lambda_{k}^{2}$ and $\sigma^{2} \lambda_{l}^{2}$, which is $\sigma^{2} \lambda_{k} \lambda_{l}$. The covariances then become $\sigma_{k l}=-\sigma^{2} \lambda_{k} \lambda_{l}, k \neq l$. This specification preserves the symmetry and negativity of the covariances, but as it involves products of two factors, one for each item, it rules out specific interactions between individual pairs, which can be restrictive in certain cases. When the items are fairly broad aggregates, however, most pairwise relations are probably of a more general nature. In such a case, the dominant relationship between goods reflects the condition that at the margin, spending on each good has the same utility value with all goods having a more-or-less equal claim on the consumer's income. Thus, for broad aggregates, the above covariance specification is 


\section{SUPPLEMENTARY MATERIALS}

A-2

probably reasonable and the one that we shall use for all pairs of commodity groups $k, l=$ $1, \cdots, 2 G, k \neq l$.

3. Importance of goods. The left-hand side of (3.2) involves the budget share of good $k, \bar{w}_{k t}$, which reflects the relative size of the good as measured by its expenditure. As a good that absorbs a larger part of the budget will tend to be more variable, it is likely its covariances also reflect size. We thus assume that the factor for good $k, \lambda_{k}$, coincides with its mean budget share, $w_{k}=\frac{1}{T} \sum_{t=1}^{T} w_{k t}$, so that

(A2.1) $\sigma_{k l}=-\sigma^{2} w_{k} w_{l}, k \neq l$.

4. Variances. As $\sum_{l=1}^{2 G} \sigma_{k l}=0$, Equation (A2.1) implies $\sigma_{k k}=\sigma^{2} \sum_{l=1, l \neq k}^{2 G} w_{k} w_{l}$, or, as $\sum_{l=1}^{2 G} w_{l}=1$,

(A2.2) $\sigma_{k k}=\sigma^{2} w_{k}\left(1-w_{k}\right)$.

Equations (A2.2) and (A2.3) are the variances and covariances associated with the multinomial distribution with probabilities $w_{1}, \cdots, w_{2 G}$. To interpret this, think of a random selection of commodities: We draw (with replacement) from an urn balls colour-coded that reflect the identity of commodities. When each dollar of total expenditure has the same chance of selection, the number of balls of the same colour is proportional to expenditure on the good, and the probability of selecting good $k$ is its budget share $w_{k}$ (Theil, 1967, p. 136).

The above two equations imply that the negative of the correlation coefficient between $k$ and $l$ is $\left\{\left(\frac{w_{k}}{1-w_{k}}\right)\left(\frac{w_{l}}{1-w_{l}}\right)\right\}^{1 / 2}$, the geometric mean of the odds of drawing the two items. Denoting by $\boldsymbol{w}=\left[w_{i}\right]$ the vector of the $2 G$ budget shares and $\boldsymbol{W}=\operatorname{diag}[\boldsymbol{w}]$, Equations (A2.2) and (A2.3) for $k, l=1, \cdots, 2 G$ mean the covariance matrix $\left[\sigma_{k l}\right]$ takes the form $\sigma^{2}\left(\boldsymbol{W}-\boldsymbol{w} \boldsymbol{w}^{\prime}\right)$, which is denoted by $\boldsymbol{\Sigma}$ in the text. Note that Step 2 above used the geometric mean of the two shocks. What if the arithmetic mean were used instead? The result is qualitatively similar, as expected, but not so convenient: Equations (A2.1) and (A2.2) would then become, respectively, $\sigma_{k l}=$ $-\frac{\sigma^{2}}{2}\left(w_{k}+w_{l}\right)$ and $\sigma_{k k}=\sigma^{2}(G-1) w_{k}+\frac{\sigma^{2}}{2}$.

Many demand systems can be written in the form $y_{i t}=\boldsymbol{\beta}_{i}^{\prime} \boldsymbol{x}_{t}+\varepsilon_{i t}, i=1, \cdots, n, E\left(\boldsymbol{\varepsilon}_{t} \boldsymbol{\varepsilon}_{t}^{\prime}\right)=$ $\boldsymbol{\Sigma}$. The usual approach is to treat this as a multivariate regression and estimate by SURE or ML, which involves the inverse of the covariance matrix $\boldsymbol{\Sigma}^{-1}$. The matrix $\boldsymbol{\Sigma}$ is symmetric positive semidefinite, but otherwise unrestricted and according to the usual approach, is estimated by mean squares and cross-products of the residuals. But as shown by Chen (1995), Laitinen (1978), 


\section{SUPPLEMENTARY MATERIALS}

\section{A-3}

Meisner (1979), Selvanathan (1991) and Theil (1987), such an approach can lead to a serious understatement of the standard errors when the sample size $(T)$ is small relative to the number of goods (n). Laitinen (1978) established that $\boldsymbol{\Sigma}$ is nonsingular only when $T>2 n$. The multinomial approach deals with this issue by setting $\boldsymbol{\Sigma}=\sigma^{2}\left(\boldsymbol{W}-\boldsymbol{w} \boldsymbol{w}^{\prime}\right)$, leading to the estimation of a single equation, as discussed in the text.

The covariance matrix of the reduced system and its inverse [Equation (3.3) of the text] are:

$$
\widetilde{\boldsymbol{\Sigma}}=\sigma^{2}\left(\widetilde{\boldsymbol{W}}-\widetilde{\boldsymbol{W}} \widetilde{\boldsymbol{w}}^{\prime}\right), \widetilde{\boldsymbol{\Sigma}}^{-1}=\frac{1}{\sigma^{2}}\left(\widetilde{\boldsymbol{W}}^{-1}+\frac{1}{w_{2 G}} \boldsymbol{\iota}^{\prime}\right) .
$$

Recognising that $\widetilde{\boldsymbol{W}} \boldsymbol{\iota}=\widetilde{\boldsymbol{w}}$ and $\widetilde{\boldsymbol{w}}^{\prime} \widetilde{\boldsymbol{W}}^{-\mathbf{1}}=\boldsymbol{\iota}^{\prime}$, it is straightforward to verify this inverse:

$$
\begin{aligned}
\widetilde{\boldsymbol{\Sigma}} \widetilde{\boldsymbol{\Sigma}}^{-1} & =\left(\widetilde{\boldsymbol{W}}-\widetilde{\boldsymbol{w}} \widetilde{\boldsymbol{w}}^{\prime}\right)\left(\widetilde{\boldsymbol{W}}-\mathbf{1}+\frac{1}{w_{2 G}} \boldsymbol{\iota}^{\prime}\right) \\
& =\widetilde{\boldsymbol{W}} \widetilde{\boldsymbol{W}}^{-1}+\frac{1}{w_{2 G}} \widetilde{\boldsymbol{W}} \boldsymbol{\iota}^{\prime}-\widetilde{\boldsymbol{w}} \widetilde{\boldsymbol{w}}^{\prime} \widetilde{\boldsymbol{W}}^{-1}-\frac{1}{w_{2 G}} \widetilde{\boldsymbol{w}} \widetilde{\boldsymbol{w}}^{\prime} \boldsymbol{\iota}^{\prime} \\
& =\boldsymbol{I}+\frac{1}{w_{2 G}} \widetilde{\boldsymbol{w}} \boldsymbol{\iota}^{\prime}-\widetilde{\boldsymbol{w}} \boldsymbol{\iota}^{\prime}-\frac{1}{w_{2 G}} \widetilde{\boldsymbol{w}}\left(1-w_{2 G}\right) \boldsymbol{\iota}^{\prime} \quad\left[\text { as } \widetilde{\boldsymbol{w}}^{\prime} \boldsymbol{\iota}=\left(1-w_{2 G}\right)\right] \\
& =\boldsymbol{I}+\widetilde{\boldsymbol{w}} \boldsymbol{\iota}^{\prime}\left\{\frac{1}{w_{2 G}}-1-\frac{1}{w_{2 G}}\left(1-w_{2 G}\right)\right\}=\boldsymbol{I} \boldsymbol{\square}
\end{aligned}
$$

\section{A3. More on Estimation}

This appendix describes the estimation procedures used to derive the results presented in Section 4 of the text.

\section{An Iterative Procedure}

Model (3.1) of the text is nonlinear in the parameters due to the term $A_{i t}^{g}(\boldsymbol{\theta})$, but this was ignored above by treating the vector of marginal shares, $\boldsymbol{\theta}$, as known. We deal with the nonlinearity with the following iterative procedure:

Step 1: Obtain initial estimates of the marginal shares $\boldsymbol{\theta}=\left\{\theta_{1}^{1}, \theta_{2}^{1}, \ldots, \theta_{1}^{8}, \theta_{2}^{8}\right\}$ by regressing $\bar{w}_{i t}^{g} D q_{i t}^{g}$ on $D Q_{t}$. Denote these by $\widehat{\boldsymbol{\theta}}_{0}=\left\{\hat{\theta}_{1(0)}^{1}, \hat{\theta}_{2(0)}^{1}, \ldots, \hat{\theta}_{1(0)}^{G}, \hat{\theta}_{2(0)}^{G}\right\}$. The initial Frisch price index is then $D P_{t(0)}^{\prime}=\sum_{g=1}^{G} \sum_{i=1}^{2} \hat{\theta}_{i(0)}^{g} D p_{i t}^{g}$ and $A_{i t}^{g}\left(\widehat{\boldsymbol{\theta}}_{0}\right)=\hat{\theta}_{i(0)}^{g}\left(D p_{i t}^{g}-D P_{t(0)}^{\prime}\right)$.

Step 2: Use $A_{i t}^{g}\left(\widehat{\boldsymbol{\theta}}_{0}\right)$ to construct the matrix $\boldsymbol{X}_{t}^{*}$ (see Appendix A1 for details). Then compute the first-round estimate of the coefficient vector $\boldsymbol{\beta}$ and $A_{i t}^{g}\left(\widehat{\boldsymbol{\theta}}_{1}\right)$.

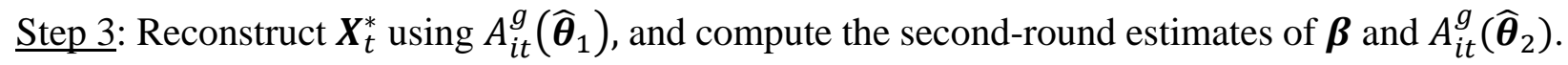
Repeat this step until convergence is reached. 


\section{SUPPLEMENTARY MATERIALS}

\section{A-4}

Step 4: Use the converged estimates and constraints (2.12) and (2.13) of the text to obtain estimates of the eliminated parameters.

\section{Bootstrap Standard Errors}

To avoid relying on asymptotics, we use the following bootstrap procedure:

Step 1: Using the converged estimates, extract the $2 G \times 1$ vectors of residuals $\boldsymbol{e}_{t}^{*}=\boldsymbol{y}_{t}^{*}-$ $\boldsymbol{X}_{t}^{*} \widehat{\boldsymbol{\beta}}(t=1, \ldots, T)$, the elements of which are the weighted commodity-specific residuals, $\hat{\varepsilon}_{i t}^{g *}(i=1,2 ; g=1, \ldots, G)$.

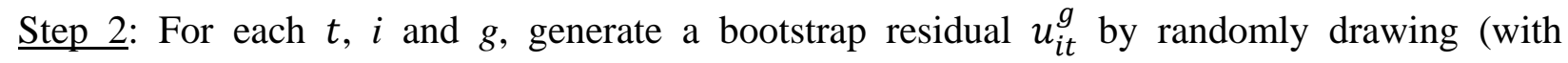
replacement) from the corresponding commodity-specific residuals. ${ }^{15}$

Step 3: Construct a bootstrap sample as $\boldsymbol{y}_{t}^{* \#}=\boldsymbol{X}_{t}^{*} \widehat{\boldsymbol{\beta}}+\boldsymbol{u}_{t}$, where $\boldsymbol{u}_{t}=\left\{u_{i t}^{g}\right\}$.

Step 4: Repeat steps $2-3$ until we have $T$ vectors of $\boldsymbol{y}_{t}^{* \#}$.

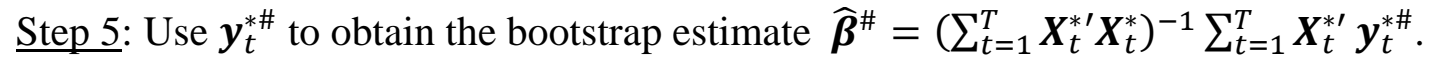

Step 6: Repeat 10,000 times steps $2-5$. The standard deviations of the 10,000 estimates are the bootstrap standard errors. The standard errors of the elasticities are computed similarly, with means of the budget shares.

\section{A4. The Data}

We collected data for various manufacturing sectors in Australia. Our data inputs were obtained from supply-use tables (SUT), international trade statistics and national accounts, all of which are provided by the Australian Bureau of Statistics. Table A4.1 presents detailed descriptions of the data and their sources. Note that in this paper, we exclude service sectors to ensure availability of measurable import data. Additionally, non-merchandise goods are mostly complimentary rather than substitutable with imported services.

As these datasets have different aggregation structure and correspond to different time frequencies, we apply a number of transformations to construct a unified database with consistent timeframe and commodity classification. Figure A4.1 provides the data construction schematics.

Specifically, the following adjustments were applied:

1. Commodity aggregation. The values of the 60 goods classified in the Standardised International Trade Classification (SITC) and 57 goods in the SUT were aggregated into 20 broad commodity groups, using the structures presented in Tables A4.2 and A4.3.

\footnotetext{
${ }^{15}$ In order to preserve the cross-commodity correlation structure, we draw vectors of residuals.
} 


\section{SUPPLEMENTARY MATERIALS}

\section{A-5}

2. Time aggregation. The price indices are quarterly, while the value data are published on an annual basis. We converted the quarterly prices into annual data using value-shareweighted average prices.

3. Domestic sales. The domestic sales value of a given product is derived by the difference between domestic production and export sales.

4. Scale deflation. The values were deflated by population converting them into a per capita basis.

5. Quantities. The quantities of domestic and imported varieties were derived by deflating nominal values by the corresponding prices.

Using Table A4.4, the 20 commodities are further classified into $G=8$ broad groups which form the basis of the analyses presented in this paper. The steps involved in the process to compress SITC and SUT disaggregated into 8 groups are detailed in Figure A4.1. Expenditures of these groups are computed by aggregating the expenditures of underlying commodities. Group prices are expenditure-weighted price indices. Each of the groups now contains two categories: Domestic and foreign varieties. The data span over $T=23$ years from 1995 to 2017. One observation is lost when we construct the moving average budget shares and the logarithmic changes in prices and quantities.

Based on the group data, we present the Divisia price and quantity indices, their variances and their correlation in Table A4.5. Figure A4.2 is a scatterplot of quantity standard deviations against price standard deviations, which reveals that for the majority of observations, quantities are more dispersed than prices. From column 6 of Table A4.5, it can be seen that the crosscommodity price-quantity correlations are negative. These results agree with prior studies as summarised by Clements (2019).

\section{A5. The Slutsky Coefficients}

Equations (2.5) and (2.8) of the text represent, respectively, the relative and absolute price versions of the Rotterdam model. These are linked by the relation between the Slutsky coefficients, the coefficients of the undeflated price changes $\left(\pi_{i j}\right)$, and the coefficients attached to the Frischdeflated relative prices $\left(v_{i j}\right)$ :

$$
\pi_{i j}=v_{i j}-\phi \theta_{i} \theta_{j} ; i, j=1, \cdots, n .
$$

A similar relationship holds for the domestic-foreign model (2.11). For group $g$ and variety $i$, the substitution term of that model is 


\section{SUPPLEMENTARY MATERIALS}

A-6

$$
\sum_{j=1}^{2} v_{i j}^{g}\left(D p_{j t}^{g}-D P_{t}^{\prime}\right)=\sum_{j=1}^{2} v_{i j}^{g}\left\{D p_{j t}^{g}-\left(\sum_{j=1}^{2} v_{i j}^{g}\right) \sum_{h=1}^{G} \sum_{j=1}^{2} \theta_{j}^{h} D p_{j t}^{h}\right\} .
$$

As $\sum_{j=1}^{2} v_{i j}^{g}=\phi \theta_{i}^{g}$, which is constraint (2.13), the above becomes

$$
\sum_{h=1}^{G} \sum_{j=1}^{2}\left\{v_{i j}^{g} \delta_{g h}-\phi \theta_{i}^{g} \theta_{j}^{h}\right\} D p_{j t}^{h}=\sum_{h=1}^{G} \sum_{j=1}^{2} \pi_{i j}^{g h} D p_{j t}^{h},
$$

where $\delta_{g h}$ denotes the Kronecker delta and

$$
\pi_{i j}^{g h}=v_{i j}^{g} \delta_{g h}-\phi \theta_{i}^{g} \theta_{j}^{h}, i, j=1,2 ; g, h=1, \cdots, G
$$

are the Slutsky coefficients, which have the same form as those in (A5.1). At the end of Section 2, it was stated that the Slutsky price elasticities implied by model (2.11) are $S_{i j}^{g h}=F_{i j}^{g h}-\phi \eta_{i}^{g} \theta_{j}^{h}$, which are the coefficients in (A5.2) divided by the budget share, with $F_{i j}^{g h}=\frac{v_{i j}^{g}}{\bar{w}_{i t}^{g}} \delta_{g h}$ the Frisch price elasticity.

\section{A6. Hypothesis Tests}

In this appendix, we present the details of the bootstrap tests discussed in Section 4. The null hypothesis of the joint significance of the price coefficients are tested using F-statistics (panel A of Table 4.3 contains the results), while the null of lower domestic income elasticities (LD) is tested using a one-tail t-statistic (panel B of Table 4.3). Additionally, the null of preference independence (PI) is tested using both an F-test (panel A) and t-tests (panel B).

We denote the general form of an unrestricted model by $\boldsymbol{y}_{t}^{*}=\boldsymbol{X}_{t}^{*} \boldsymbol{\beta}+\boldsymbol{\varepsilon}_{t}^{*}$ and its restricted counterpart as $\boldsymbol{y}_{t}^{*}=\boldsymbol{X}_{t}^{* R} \boldsymbol{\beta}^{R}+\boldsymbol{\varepsilon}_{t}^{R}$. After weighting, the pooled OLS estimators of these models take the forms: $\widehat{\boldsymbol{\beta}}=\left(\sum_{t=1}^{T} \boldsymbol{X}_{t}^{* \prime} \boldsymbol{X}_{t}^{*}\right)^{-1} \sum_{t=1}^{T} \boldsymbol{X}_{t}^{* \prime} \boldsymbol{y}_{t}^{*} ; \widehat{\boldsymbol{\beta}}^{R}=\left(\sum_{t=1}^{T} \boldsymbol{X}_{t}^{* R^{\prime}} \boldsymbol{X}_{t}^{* R}\right)^{-1} \sum_{t=1}^{T} \boldsymbol{X}_{t}^{* R^{\prime}} \boldsymbol{y}_{t}^{*}$. The bootstrap tests are as follows:

Step 1: Use the procedures described in Appendix A3 to obtain bootstrap estimates and standard errors of the unrestricted model. Denote these by $\widehat{\boldsymbol{\beta}}^{\#}$ and $S E\left(\widehat{\boldsymbol{\beta}}^{\#}\right)$.

$\underline{\text { Step 2: }}$ Use the elements of $\widehat{\boldsymbol{\beta}}^{\#}$ and $S E\left(\widehat{\boldsymbol{\beta}}^{\#}\right)$ to form $t_{P I}^{g \#}=\frac{\widehat{v}_{i j}^{g \#}}{S E\left(\widehat{v}_{i j}^{g \#}\right)}$ and $t_{L D}^{g \#}=$ $\frac{\frac{\widehat{\theta}_{1}^{g \#}}{w_{1}^{g}}-\frac{\widehat{\theta}_{2}^{g \#}}{w_{2}^{g}}}{\sqrt{\left[\frac{S E\left(\widehat{\theta}_{1}^{g \#}\right)}{w_{1}^{g}}\right]^{2}+\left[\frac{S E\left(\widehat{\theta}_{2}^{g \#}\right)}{w_{2}^{g}}\right]^{2}}}$, where $\hat{\theta}_{1}^{g \#}$ and $\hat{\theta}_{2}^{g \#}$ denote the bootstrap estimates of the domestic and foreign marginal shares and $S E\left(\hat{\theta}_{1}^{g \#}\right)$ and $S E\left(\hat{\theta}_{2}^{g \#}\right)$ are their standard errors; and $w_{1}^{g}$ and $w_{2}^{g}$ are the mean budget shares. 


\section{SUPPLEMENTARY MATERIALS}

A-7

Step 3: Generate 10,000 bootstrap t-statistics by repeating steps $1-2$. We reject the PI null $H_{0}: v_{i j}^{g}=0(i \neq j ; g=1, \cdots, 8)$ at the $5 \%$ significance level if the observed test statistic, $t_{P I}=\frac{\widehat{v}_{i j}^{g *}}{S E\left(\widehat{v}_{i j}^{g *}\right)}$, is either smaller than the $2.5^{\text {th }}$ percentile or larger than the $97.5^{\text {th }}$ percentile of $t_{P I}^{g \#}$. We reject the LD null $H_{0}: \theta_{1}^{g} / w_{1}^{g} \leq \theta_{2}^{g} / w_{2}^{g}(g=1, \ldots, 8)$ if the observed test statistic, $t_{L D}=\frac{\frac{\widehat{\theta}_{1}^{g *}}{w_{1}^{g}}-\frac{\widehat{\theta}_{2}^{g *}}{w_{2}^{g}}}{\sqrt{\left[\frac{S E\left(\widehat{\theta}_{1}^{g *}\right)}{w_{1}^{g}}\right]^{2}+\left[\frac{S E\left(\widehat{\theta}_{2}^{g *}\right)}{w_{2}^{g}}\right]^{2}}}$, is larger than the $95^{\text {th }}$ percentile of $t_{L D}^{g \#}$.

Step 4: To test the joint hypotheses, we first compute the observed and bootstrap estimates of the restricted model, i.e., $\widehat{\boldsymbol{\beta}}^{R}$ and $\widehat{\boldsymbol{\beta}}^{R \#}$. Then, the bootstrap F-statistic is:

$$
F^{\#}=\frac{R S S_{R}^{\#}-R S S_{U}^{\#}}{R S S_{U}^{\#}} \cdot \frac{d f_{d e m}}{d f_{\text {num }}},
$$

where $\quad R S S_{R}^{\#}=\sum_{t=1}^{T}\left(\boldsymbol{y}_{t}^{* R \#}-\boldsymbol{X}_{t}^{* R} \widehat{\boldsymbol{\beta}}^{R \#}\right)^{\prime}\left(\boldsymbol{y}_{t}^{* R \#}-\boldsymbol{X}_{t}^{R *} \widehat{\boldsymbol{\beta}}^{R \#}\right) \quad$ and $\quad R S S_{U}^{\#}=\sum_{t=1}^{T}\left(\boldsymbol{y}_{t}^{* R \#}-\right.$ $\left.\boldsymbol{X}_{t}^{*} \widehat{\boldsymbol{\beta}}^{\#}\right)^{\prime}\left(\boldsymbol{y}_{t}^{* R \#}-\boldsymbol{X}_{t}^{*} \widehat{\boldsymbol{\beta}}^{\#}\right)$ are the bootstrap residual sums of squared errors of the restricted and unrestricted models, respectively; $\boldsymbol{y}_{t}^{* R \#}$ denotes the bootstrap value generated under the null; and $d f_{\text {dem }}$ and $d f_{\text {num }}$ denote the degrees of freedom (see Table A6.1). The observed test statistic is:

$$
F=\frac{R S S_{R}-R S S_{U}}{R S S_{U}} \cdot \frac{d f_{d e m}}{d f_{\text {num }}}
$$

where $R S S_{R}=\sum_{t=1}^{T}\left(\boldsymbol{y}_{t}^{*}-\boldsymbol{X}_{t}^{* R} \widehat{\boldsymbol{\beta}}^{R}\right)^{\prime}\left(\boldsymbol{y}_{t}^{*}-\boldsymbol{X}_{t}^{* R} \widehat{\boldsymbol{\beta}}^{R}\right)$ and $R S S_{U}=\sum_{t=1}^{T}\left(\boldsymbol{y}_{t}^{*}-\boldsymbol{X}_{t}^{*} \widehat{\boldsymbol{\beta}}\right)^{\prime}\left(\boldsymbol{y}_{t}^{*}-\right.$ $\left.\boldsymbol{X}_{t}^{*} \widehat{\boldsymbol{\beta}}\right)$.

Step 5: Generate 10,000 bootstrap values of $F^{\#}$ by repeating step 4 . The null hypothesis is rejected at the $5 \%$ significance level if $F$ is larger than the $95^{\text {th }}$ percentile of $F^{\#}$.

The plots of the distributions of the bootstrap F-statistics (indicated by the solid black curves) are presented in Figure A6.1. As can be seen, in many cases these curves closely track the asymptotic F-statistic distributions.

\section{A7. Derivations for the Macro Aggregates and Micro Elements}

There are 2 items in each group of goods (domestically and foreign produced) and there are 8 groups. Thus, there are 16 “elementary” goods. For the 7 groups other than the $5^{\text {th }}$, the demand models are of a preference independence form, viz.,

$$
\bar{w}_{i t}^{g} D q_{i t}^{g}=\theta_{i}^{g} D Q_{t}+\phi \theta_{i}^{g}\left(D p_{i t}^{g}-D P_{t}^{\prime}\right)+\varepsilon_{i t}^{g}, \quad i=1,2 ; g=1, \cdots, 8 ; g \neq 5 \text {. }
$$




\section{SUPPLEMENTARY MATERIALS}

A-8

For the $5^{\text {th }}$ group “Wood and Paper Products" (which for simplicity, is referred to as "Wood”), we have

$$
\bar{w}_{i t}^{5} D q_{i t}^{5}=\theta_{i}^{5} D Q_{t}+\sum_{j=1}^{2} v_{i j}^{5}\left(D p_{j t}^{5}-D P_{t}^{\prime}\right)+\varepsilon_{i t}^{5}, \quad i=1,2,
$$

with $\quad v_{12}^{5}=v_{21}^{5}, \sum_{j=1}^{2} v_{i j}^{5}=\phi \theta_{i}^{5}, i=1,2$. Here, $\quad D Q_{t}=\sum_{g=1}^{G} \sum_{i=1}^{2} \bar{w}_{i t}^{g} D q_{i t}^{g} \quad$ and $D P_{t}^{\prime}=$ $\sum_{g=1}^{G} \sum_{i=1}^{2} \theta_{i}^{g} D p_{i t}^{g}$. Together, Equations (A7.1) and (A7.2) constitute the "partial preference independence” (PPI) model.

We divide the 16 elementary goods into 3 varieties:

1. Domestically produced goods other than Wood: Goods in this variety are indexed by $i=$ $1, g=1, \cdots, 8, g \neq 5$. Denote these by the set $\boldsymbol{V}_{1}$.

2. Imported goods other than Wood are those indexed by $i=2, g=1, \cdots, 8, g \neq 5$. Denote by $\boldsymbol{V}_{2}$.

3. Wood are those for which $i=1,2, g=5$. Denote by $\boldsymbol{V}_{3}$.

Equation (A7.1) contains on the right-hand side only the own (relative) price, while (A7.2) has both the own price and the cross prices within the Wood group. In the PPI setting, there are no price effects of goods from other groups, so that $v_{i j}^{g h}=0, i, j=1,2, g \neq h$. This implies the three varieties are separable in the utility function and so there exists well-defined aggregates and subaggregates of goods, as shown below.

Aggregating by Variety

This subsection shows how we can aggregate the demands equations for members of a given variety. Each of the three varieties is considered separately.

Domestic Goods $\left(\boldsymbol{V}_{1}\right)$ : To aggregate variety-1 goods, we set the subscript $i=1$ and add variables over groups, that is, over the superscript $g=1, \cdots, 8, g \neq 5$. Thus, the budget and marginal shares of variety 1 are

$$
\bar{W}_{1 t}=\sum_{g \in V_{1}} \bar{w}_{1 t}^{g}, \quad \Theta_{1}=\sum_{g \in V_{1}} \theta_{1}^{g},
$$

and the corresponding Divisia volume index and Frisch price index are

$$
D Q_{1 t}=\sum_{g \in V_{1}} \frac{\bar{w}_{1 t}^{g}}{\bar{W}_{1 t}} D q_{1 t}^{g}, \quad D P_{1 t}^{\prime}=\sum_{g \in V_{1}} \frac{\theta_{1}^{g}}{\Theta_{1}} D p_{1 t}^{g} .
$$

The volume index is a weighted average of the changes in the quantities demanded of variety-1 goods, with weights equal to $\bar{w}_{1 t}^{g} / \bar{W}_{1 t}$, the expenditure shares of goods within the variety. These 


\section{SUPPLEMENTARY MATERIALS}

A-9

weights are all positive and have a unit sum. The above price index has a similar interpretation, but now the weights are the within-variety marginal shares $\theta_{1}^{g} / \Theta_{1}$.

Next, aggregate both sides of system (A7.1) for $i=1$ over $g \in \boldsymbol{V}_{1}$ :

$$
\sum_{g \in V_{1}} \bar{w}_{1 t}^{g} D q_{1 t}^{g}=\sum_{g \in V_{1}} \theta_{1}^{g} D Q_{t}+\sum_{g \in V_{1}} \phi \theta_{1}^{g}\left(D p_{1 t}^{g}-D P_{t}^{\prime}\right)+\sum_{g \in V_{1}} \varepsilon_{1 t}^{g} \text {. }
$$

Then, using definition (A7.3) and $\Theta_{1}=\sum_{g \in V_{1}} \theta_{i}^{g}$, the term on the left-hand side and the first term on the right of the above become

$$
\sum_{g \in V_{1}} \bar{w}_{1 t}^{g} D q_{1 t}^{g}=\bar{W}_{1 t} D Q_{1 t}, \sum_{g \in V_{1}} \theta_{1}^{g} D Q_{t}=\Theta_{1} D Q_{t} .
$$

The substitution term is

$$
\sum_{g \in V_{1}} \phi \theta_{1}^{g}\left(D p_{1 t}^{g}-D P_{t}^{\prime}\right)=\phi \Theta_{1} \sum_{g \in V_{1}} \frac{\theta_{1}^{g}}{\Theta_{1}}\left(D p_{1 t}^{g}-D P_{t}^{\prime}\right)=\phi \Theta_{1}\left(D P_{1 t}^{\prime}-D P_{t}^{\prime}\right) .
$$

Consequently, the demand for $\boldsymbol{V}_{1}$ as a group is

$$
\bar{W}_{1 t} D Q_{1 t}=\Theta_{1} D Q_{t}+\phi \Theta_{1}\left(D P_{1 t}^{\prime}-D P_{t}^{\prime}\right)+E_{1 t}
$$

where $E_{1 t}=\sum_{g \in V_{1}} \varepsilon_{1 t}^{g}$. This is an "uppercase" version of (A7.1), demonstrating that $\boldsymbol{V}_{1}$ is a preference independent group.

Dividing both sides of Equation (A7.4) by $\bar{W}_{1 t}$, it can be seen that $\frac{\Theta_{1}}{\bar{W}_{1 t}}$ is the income elasticity of demand for $\boldsymbol{V}_{1}$. This can be expressed as

$$
\frac{\Theta_{1}}{\bar{W}_{1 t}}=\frac{\sum_{g \in V_{1}} \theta_{i}^{g}}{\bar{W}_{1 t}}=\sum_{g \in V_{1}} \frac{\bar{w}_{1 t}^{g}}{\bar{W}_{1 t}} \frac{\theta_{i}^{g}}{\bar{w}_{1 t}^{g}}
$$

which shows that the group income elasticity is a weighted average of those of the members of the group, the weights being the within-group budget shares $\frac{\bar{w}_{1 t}^{g}}{\bar{W}_{1 t}}$. As $\phi \frac{\Theta_{1}}{\bar{W}_{1 t}}$ is the own-price elasticity of $\boldsymbol{V}_{1}$, this also is a share-weighted average of the corresponding elasticities of the members, that is, $\phi \frac{\Theta_{1}}{\bar{W}_{1 t}}=\sum_{g \in V_{1}} \frac{\bar{w}_{1 t}^{g}}{\bar{W}_{1 t}}\left(\phi \frac{\theta_{i}^{g}}{\bar{w}_{1 t}^{g}}\right)$.

Given the allocation of income to variety $\boldsymbol{V}_{1}$, as measured by $D Q_{1 t}$, this is then distributed to the goods within the variety. To derive the form of the implied demand equations, note that as Equations (A7.1) and (A7.4) both involve $D Q_{t}$, this variable can be eliminated by combining the two equations. Thus, from (A7.4), $D Q_{t}=\frac{\bar{W}_{1 t}}{\Theta_{1}} D Q_{1 t}-\phi\left(D P_{1 t}^{\prime}-D P_{t}^{\prime}\right)-\frac{E_{1 t}}{\Theta_{1}}$; substituting the right-hand side of this equation for $D Q_{t}$ in (A7.1) gives

$$
\begin{aligned}
\bar{w}_{1 t}^{g} D q_{1 t}^{g} & =\theta_{1}^{g}\left\{\frac{\bar{W}_{1 t}}{\Theta_{1}} D Q_{1 t}-\phi\left(D P_{1 t}^{\prime}-D P_{t}^{\prime}\right)-\frac{E_{1 t}}{\Theta_{1}}\right\}+\phi \theta_{1}^{g}\left(D p_{1 t}^{g}-D P_{t}^{\prime}\right)+\varepsilon_{1 t}^{g} \\
& =\frac{\theta_{1}^{g}}{\Theta_{1}} \bar{W}_{1 t} D Q_{1 t}+\phi \theta_{1}^{g}\left(D p_{1 t}^{g}-D P_{1 t}^{\prime}\right)+\varepsilon_{1 t}^{g}-\frac{\theta_{1}^{g}}{\Theta_{1}} E_{1 t} .
\end{aligned}
$$




\section{SUPPLEMENTARY MATERIALS}

A-10

Dividing through by $\bar{W}_{1 t}$, we obtain

$$
\frac{\bar{w}_{1 t}^{g}}{\bar{W}_{1 t}} D q_{1 t}^{g}=\frac{\theta_{1}^{g}}{\Theta_{1}} D Q_{1 t}+\left(\phi \frac{\Theta_{1}}{\bar{W}_{1 t}}\right) \frac{\theta_{1}^{g}}{\Theta_{1}}\left(D p_{1 t}^{g}-D P_{1 t}^{\prime}\right)+\mu_{1 t}^{g}, g=1, \cdots, 8, g \neq 5 .
$$

This equation has on the right-hand side variables that pertain to variety $\boldsymbol{V}_{1}$ only: $D Q_{1 t}$ and the relative price $D p_{1 t}^{g}-D P_{1 t}^{\prime}$, where the price deflator is the Frisch index for that variety, $D P_{1 t}^{\prime}$. The disturbance term is $\mu_{1 t}^{g}=\frac{1}{\bar{W}_{1 t}}\left(\varepsilon_{1 t}^{g}-\frac{\theta_{1}^{g}}{\Theta_{1}} E_{1 t}\right)$, which is proportional to the difference between the original disturbance of (A7.1), $\varepsilon_{1 t}^{g}$, and a fraction $\theta_{1}^{g} / \Theta_{1}$ of the group disturbance $E_{1 t}$. System (A7.5) contains demand equations for domestic good $g, g=1, \cdots, 8, g \neq 5$, given the demand for those goods as a group. Equation (A7.5) can be called “conditional” demands; and they also have the same form as equations (A7.1) and (A7.4).

Foreign Goods $\left(\boldsymbol{V}_{2}\right)$ : The concepts for variety $\boldsymbol{V}_{2}$ parallel Equations (A7.3), (A7.4) and (A7.5) and simply involve changing the first subscript from 1 to 2 :

$$
D Q_{2 t}=\sum_{g \in V_{2}} \frac{\bar{w}_{2 t}^{g}}{\bar{W}_{2 t}} D q_{2 t}^{g}, \quad D P_{2 t}^{\prime}=\sum_{g \in V_{2}} \frac{\theta_{2}^{g}}{\Theta_{2}} D p_{2 t}^{g} \text {, with } \bar{W}_{2 t}=\sum_{g \in \boldsymbol{V}_{2}} \bar{w}_{2 t}^{g}, \Theta_{2}=
$$

$\sum_{g \in V_{2}} \theta_{2}^{g}$

$$
\bar{W}_{2 t} D Q_{2 t}=\Theta_{2} D Q_{t}+\phi \Theta_{2}\left(D P_{2 t}^{\prime}-D P_{t}^{\prime}\right)+E_{2 t} \text {, with } E_{2 t}=\sum_{g \in V_{2}} \varepsilon_{2 t}^{g} \text {, }
$$$$
\frac{\bar{w}_{2 t}^{g}}{\bar{W}_{2 t}} D q_{2 t}^{g}=\frac{\theta_{2}^{g}}{\Theta_{2}} D Q_{2 t}+\left(\phi \frac{\Theta_{2}}{\bar{W}_{2 t}}\right) \frac{\theta_{2}^{g}}{\Theta_{2}}\left(D p_{2 t}^{g}-D P_{2 t}^{\prime}\right)+\mu_{2 t}^{g}, g=1, \cdots, 8, g \neq 5 \text {, }
$$

where $\mu_{2 t}^{g}=\frac{1}{\bar{W}_{2 t}}\left(\varepsilon_{2 t}^{g}-\frac{\theta_{2}^{g}}{\Theta_{2}} E_{2 t}\right)$.

Wood $\left(\boldsymbol{V}_{3}\right)$ : The equation system (A7.2) gives the demands for products in group 5, Wood, which constitute $\boldsymbol{V}_{3}$. There are two elements in $\boldsymbol{V}_{3}$, wood from domestic and foreign sources. The distinguishing feature of system (A7.2) is that $v_{i j}^{5} \neq 0, i \neq j$, so it is not of the preference independent form, unlike (A7.1). But we can still aggregate over the domestic and foreign demands $(i=1,2)$ to give

$$
\begin{aligned}
& D Q_{3 t}=\sum_{i=1}^{2} \frac{\bar{w}_{i t}^{5}}{\bar{W}_{3 t}} D q_{i t}^{5}, \quad D P_{3 t}^{\prime}=\sum_{i=1}^{2} \frac{\theta_{i}^{5}}{\Theta_{3}} D p_{i t}^{5}, \text { with } \bar{W}_{3 t}=\sum_{i=1}^{2} \bar{w}_{i t}^{5}, \Theta_{3}=\sum_{i=1}^{2} \theta_{i}^{5}, \\
& \bar{W}_{3 t} D Q_{3 t}=\Theta_{3} D Q_{t}+\phi \Theta_{3}\left(D P_{3 t}^{\prime}-D P_{t}^{\prime}\right)+E_{3 t}, \text { with } E_{3 t}=\sum_{i=1}^{2} \varepsilon_{i t}^{5}, \\
& \frac{\bar{w}_{i t}^{5}}{\bar{W}_{3 t}} D q_{i t}^{5}=\frac{\theta_{i}^{5}}{\Theta_{3}} D Q_{3 t}+\sum_{j=1}^{2} v_{i j}^{5}\left(D p_{j t}^{5}-D P_{3 t}^{\prime}\right)+\mu_{i t}^{5}, i=1,2,
\end{aligned}
$$

where $\mu_{i t}^{5}=\frac{1}{\bar{W}_{3 t}}\left(\varepsilon_{i t}^{5}-\frac{\theta_{i}^{5}}{\Theta_{3}} E_{3 t}\right)$.

Equation (A7.10) can be verified as follows. We have from Equation (A7.2):

$$
\sum_{i=1}^{2} \bar{w}_{i t}^{5} D q_{i t}^{5}=\sum_{i=1}^{2} \theta_{i}^{5} D Q_{t}+\sum_{i=1}^{2} \sum_{j=1}^{2} v_{i j}^{5}\left(D p_{j t}^{5}-D P_{t}^{\prime}\right)+\sum_{i=1}^{2} \varepsilon_{i t}^{5} .
$$




\section{SUPPLEMENTARY MATERIALS}

A-11

It follows from (A7.9) that the term on the left of the above is $\bar{W}_{3 t} D Q_{3 t}$ and the first one on the right is $\Theta_{3} D Q_{t}$. The substitution term is $\sum_{i=1}^{2} \sum_{j=1}^{2} v_{i j}^{5}\left(D p_{j t}^{5}-D P_{t}^{\prime}\right)$, which by symmetry is equal to $\sum_{i=1}^{2} \sum_{j=1}^{2} v_{j i}^{5}\left(D p_{j t}^{5}-D P_{t}^{\prime}\right)$. The constraint below Equation (A7.2), $\sum_{j=1}^{2} v_{i j}^{5}=\phi \theta_{i}^{5}$, is equivalent to $\sum_{i=1}^{2} v_{j i}^{5}=\phi \theta_{j}^{5}$, so that

$$
\sum_{i=1}^{2} \sum_{j=1}^{2} v_{j i}^{5}\left(D p_{j t}^{5}-D P_{t}^{\prime}\right)=\phi \sum_{j=1}^{2} \theta_{j}^{5}\left(D p_{j t}^{5}-D P_{t}^{\prime}\right)=\phi \Theta_{3}\left(D P_{3 t}^{\prime}-D P_{t}^{\prime}\right) .
$$

This is the substitution term of equation (A7.10).

To derive (A7.11), we proceed as before and rearrange (A7.10) as $D Q_{t}=\frac{\bar{W}_{3 t} D Q_{3 t}}{\Theta_{3}}-$ $\phi\left(D P_{3 t}^{\prime}-D P_{t}^{\prime}\right)-\frac{E_{3 t}}{\Theta_{3}}$ and then substitute into (A7.2) to give

$$
\bar{w}_{i t}^{5} D q_{i t}^{5}=\theta_{i}^{5}\left\{\frac{\bar{W}_{3 t} D Q_{3 t}}{\Theta_{3}}-\phi\left(D P_{3 t}^{\prime}-D P_{t}^{\prime}\right)-\frac{E_{3 t}}{\Theta_{3}}\right\}+\sum_{j=1}^{2} v_{i j}^{5}\left(D p_{j t}^{5}-D P_{t}^{\prime}\right)+\varepsilon_{i t}^{5} .
$$

Using $\sum_{j=1}^{2} v_{i j}^{5}=\phi \theta_{i}^{5}$, the substitution term of the above becomes

$$
\begin{aligned}
& -\phi \theta_{i}^{5}\left(D P_{3 t}^{\prime}-D P_{t}^{\prime}\right)+\sum_{j=1}^{2} v_{i j}^{5}\left(D p_{j t}^{5}-D P_{t}^{\prime}\right) \\
& =-\phi \theta_{i}^{5}\left(D P_{3 t}^{\prime}-D P_{t}^{\prime}\right)+\sum_{j=1}^{2} v_{i j}^{5} D p_{j t}^{5}-\phi \theta_{i}^{5} D P_{t}^{\prime}=\sum_{j=1}^{2} v_{i j}^{5}\left(D p_{j t}^{5}-D P_{3 t}^{\prime}\right) .
\end{aligned}
$$

Equation (A7.11) then follows directly.

\section{Aggregating by Group}

As each good involves domestically and foreign varieties, we can also aggregate over the two varieties to derive the total demand for each. That is, now we add over the $i$ subscript rather than the $g$ superscript. This leads to the budget and marginal shares for $g$

$$
\bar{W}_{t}^{g}=\sum_{i=1}^{2} \bar{w}_{i t}^{g}, \Theta^{g}=\sum_{i=1}^{2} \theta_{i}^{g},
$$

the group disturbance term

$$
E_{t}^{g}=\sum_{i=1}^{2} \varepsilon_{i t}^{g}
$$

the indices

$$
D Q_{t}^{g}=\sum_{i=1}^{2} \frac{\bar{w}_{i t}^{g}}{\bar{W}_{t}^{g}} D q_{i t}^{g}, \quad D P_{t}^{g^{\prime}}=\sum_{i=1}^{2} \frac{\theta_{i}^{g}}{\Theta^{g}} D p_{i t}^{g},
$$

and the group demand equations

$$
\bar{W}_{t}^{g} D Q_{t}^{g}=\Theta^{g} D Q_{t}+\phi \Theta^{g}\left(D P_{t}^{g^{\prime}}-D P_{t}^{\prime}\right)+E_{t}^{g}, g=1, \cdots, 8
$$

Equation (A7.12) applies to all 8 groups, including group 5, which is

$$
\bar{W}_{t}^{5} D Q_{t}^{5}=\Theta^{5} D Q_{t}+\phi \Theta^{5}\left(D P_{t}^{5^{\prime}}-D P_{t}^{\prime}\right)+E_{t}^{5}
$$

Since this group is the only one exhibiting preference dependence among its varieties, it was singled out before and placed in its own variety, $\boldsymbol{V}_{3}$. But as the group as a whole is preference 


\section{SUPPLEMENTARY MATERIALS}

A-12

independent, just like the others, its group demand (A7.13) is of the same form as that of the others. Moreover, as the marginal share of (A7.13), $\Theta^{5}$, coincides with that of $\boldsymbol{V}_{3}$ from Equation (A7.9), $\Theta_{3}$, it follows that the corresponding Frisch price indexes of (A7.13) are the same as those of (A7.9), that is, $D P_{t}^{5^{\prime}}=D P_{3 t}^{\prime}$. Similarly for the disturbances: $E_{t}^{5}=E_{3 t}$. Accordingly, Equation (A7.13) coincides with (A7.10), the group demand for $\boldsymbol{V}_{3}$. This is as it should be as the two approaches to lead to the same aggregated demand for this group.

To derive the demands within groups, we combine Equations (A7.1) and (A7.12) to eliminate $D Q_{t}$, as before. Re-arrangements then yield the conditional demands for groups other than the $5^{\text {th: }}$

$$
\frac{\bar{w}_{i t}^{g}}{\bar{w}_{t}^{g}} D q_{i t}^{g}=\frac{\theta_{i}^{g}}{\Theta^{g}} D Q_{t}^{g}+\left(\phi \frac{\Theta^{g}}{\bar{w}_{t}^{g}}\right) \frac{\theta_{i}^{g}}{{ }^{g}}\left(D p_{i t}^{g}-D P_{t}^{g^{\prime}}\right)+\xi_{i t}^{g}, i=1,2, g=1, \cdots, 8, g \neq 5 .
$$

where $\xi_{i t}^{g}=\frac{1}{\bar{W}_{t}^{g}}\left(\varepsilon_{i t}^{g}-\frac{\theta_{i}^{g}}{\Theta^{g}} E_{t}^{g}\right)$. For the $5^{\text {th }}$ group, the conditional demands are:

$$
\frac{\bar{w}_{i t}^{5}}{\bar{w}_{t}^{5}} D q_{i t}^{5}=\frac{\theta_{i}^{5}}{\Theta^{5}} D Q_{t}^{5}+\sum_{j=1}^{2} v_{i j}^{5}\left(D p_{j t}^{5}-D P_{t}^{5^{\prime}}\right)+\xi_{i t}^{5}, i=1,2,
$$

where $\xi_{i t}^{5}=\frac{1}{\bar{W}_{t}^{5}}\left(\varepsilon_{i t}^{5}-\frac{\theta_{i}^{5}}{\Theta^{5}} E_{t}^{5}\right)$. For reasons similar to those discussed above, after making the appropriate notational equivalences, Equation (A7.15) coincides with (A7.11).

\section{Summary}

A summary of the results is given in Table A7.1. The aggregated values of budget shares, marginal shares and elasticities from the two approaches are presented in Tables 4.5 and 4.6.

\section{A8. The Budget-Share Predictions}

In this appendix, we derive the budget-share predictions implied by our demand models, starting with the analytical foundations from Theil (1975/76, Chap. 5). Consider a function $f(\boldsymbol{x})$ depending on a vector of arguments $\boldsymbol{x}$ with continuous derivatives up to the third order. Taylor's theorem means that the difference $f(\boldsymbol{x}+\boldsymbol{h})-f(\boldsymbol{h})$ can be expressed as

$$
f(\boldsymbol{x}+\boldsymbol{h})-f(\boldsymbol{h})=\frac{1}{2} \boldsymbol{h}^{\prime}\left(\mathbf{f}_{\mathbf{x}}+\mathbf{f}_{\mathbf{x}+\mathbf{h}}\right)+O_{3},
$$

where $\mathbf{f}_{\mathbf{x}}$ and $\mathbf{f}_{\mathbf{x}+\mathbf{h}}$ denote the gradients of $f($.$) at \boldsymbol{x}$ and $\boldsymbol{x}+\boldsymbol{h}$, and $O_{3}$ is a remainder term of the third degree. Thus, $\frac{1}{2} \boldsymbol{h}^{\prime}\left(\mathbf{f}_{\mathbf{x}}+\mathbf{f}_{\mathbf{x}+\mathbf{h}}\right)$ is a second-order approximation to the difference, but only requires information on the two slope vectors.

Since $w_{i}=\frac{p_{i} q_{i}}{M}$, its infinitesimal change is 


\section{SUPPLEMENTARY MATERIALS}

A-13

(A8.2)

$$
d w_{i}=d\left(\frac{p_{i} q_{i}}{M}\right)=w_{i} d\left(\log p_{i}\right)+w_{i} d\left(\log q_{i}\right)-w_{i} d(\log M)
$$

The derivatives of $w_{i}$ with respect to these logarithmic arguments are

$$
\frac{\partial w_{i}}{\partial \log p_{i}}=w_{i}, \frac{\partial w_{i}}{\partial \log q_{i}}=w_{i}, \frac{\partial w_{i}}{\partial \log M}=-w_{i} .
$$

Hence, the gradient of $w_{i}$ is $\left[\begin{array}{lll}w_{i, t-1} & w_{i, t-1}-w_{i, t-1}\end{array}\right]^{\prime}$ in year $t-1$ and $\left[\begin{array}{lll}w_{i t} & w_{i t}-w_{i t}\end{array}\right]^{\prime}$ in year $t$. The average of the two gradients is

$$
\left[\bar{w}_{i t} \bar{w}_{i t}-\bar{w}_{i t}\right]^{\prime}=\frac{1}{2}\left(\mathbf{f}_{\mathbf{x}}+\mathbf{f}_{\mathbf{x}+\mathbf{h}}\right)
$$

where $\quad \bar{w}_{i t}=1 / 2\left(w_{i t}+w_{i, t-1}\right)$,

$$
\boldsymbol{x}=\left[\log p_{i t} \log q_{i t} \log M_{t}\right]^{\prime}
$$

$\left[\log p_{i, t-1} \log q_{i, t-1} \log M_{t-1}\right]^{\prime}$.

Next, define the vector of log-changes as

$$
\boldsymbol{h}=\left[\begin{array}{lll}
D p_{i t} & D q_{i t} & D M_{t}
\end{array}\right]^{\prime}
$$

Substituting (A8.3) and (A8.4) into (A8.1) gives

$$
\Delta w_{i t}=\bar{w}_{i t} D p_{i t}+\bar{w}_{i t} D q_{i t}-\bar{w}_{i t} D M_{t}+O_{3} .
$$

Equation (A8.5) is the finite-change extension of (A8.2). Again, the first three terms on the right of (A8.5) are a second-order approximation to the change in the budget share. Since $\sum_{i=1}^{n} \bar{w}_{i t}=1$, summing both sides of (A8.5) over $i=1, \ldots, n$ gives $0=\sum_{i=1}^{n} \bar{w}_{i t} D p_{i t}+\sum_{i=1}^{n} \bar{w}_{i t} D q_{i t}-D M_{t}+$ $O_{3}$, or $\sum_{i=1}^{n} \bar{w}_{i t} D q_{i t}=D M_{t}-\sum_{i=1}^{n} \bar{w}_{i t} D p_{i t}+O_{3}$, so that

$$
\text { (A8.6) } D Q_{t}=D M_{t}-\sum_{i=1}^{n} \bar{w}_{i t} D p_{i t}+O_{3} \text {. }
$$

Combining (A8.5) and (A8.6) gives

$$
\text { (A8.7) } w_{i t}-w_{i, t-1}=\bar{w}_{i t} D q_{i t}-\bar{w}_{i t} D Q_{t}+\bar{w}_{i t}\left(D p_{i t}-D P_{t}\right)+O_{3}
$$

where $D P_{t}=\sum_{i=1}^{n} w_{i t} D p_{i t}$ denotes the Divisia price index. Equation (A8.7) describes the change in the $i^{\text {th }}$ budget share as the sum of 3 components and a third-order remainder term. The predicted value from the models we use is $\bar{w}_{i t} D q_{i t}-\hat{\varepsilon}_{i t}$, where $\hat{\varepsilon}_{i t}=\bar{w}_{i t} D q_{i t}-\hat{\theta}_{i} D Q_{t}-\sum_{j=1}^{n} \hat{v}_{i j}\left(D p_{j t}-\right.$ $D P_{t}^{\prime}$ ) denotes the $t^{t h}$ residual of the $i^{t h}$ equation. Replacing $\bar{w}_{i t} D q_{i t}$ in (A8.7) with $\bar{w}_{i t} D q_{i t}-\hat{\varepsilon}_{i t}$, the difference between the predicted share $\left(\widehat{w}_{i t}\right)$ and $w_{i, t-1}$ is

$$
\widehat{w}_{i t}-w_{i, t-1}=\left(\bar{w}_{i t} D q_{i t}-\hat{\varepsilon}_{i t}\right)-\bar{w}_{i t} D Q_{t}+\bar{w}_{i t}\left(D p_{i t}-D P_{t}\right)+O_{3}
$$

Finally, subtracting (A8.7) from (A8.8) gives $\widehat{w}_{i t}=w_{i t}-\hat{\varepsilon}_{i t}$ for the prediction of $w_{i t}$.

As a comparison benchmark, we use a naïve no-change extrapolation: $\widehat{w}_{i t}=w_{i, t-1}$. These predictions can be interpreted as coming from a demand equation of the form $\bar{w}_{i t} D q_{i t}=\bar{w}_{i t} D Q_{t}-$ $\bar{w}_{i t}\left(D p_{i t}-D P_{t}\right)$, where the remainder term $O_{3}$ is ignored. This model is of the preference- 


\section{SUPPLEMENTARY MATERIALS}

A-14

independence type with unitary income elasticities $\left(\theta_{i}=\bar{w}_{i t} \forall i\right)$ and income flexibility $(\phi=-1)$. A measure of the accuracy of the $n$ budget share predictions is the information inaccuracy

$$
\sum_{i=1}^{n} w_{i t} \log \frac{w_{i t}}{\widehat{w}_{i t}}
$$

This measure increases when the absolute discrepancies $\left|\widehat{w}_{i t}-w_{i t}\right|$ increase, and vanishes only when the predictions are perfect, that is, $\widehat{w}_{i t}=w_{i t}, i=1, \cdots, n$. Rather than dealing with all $n$ shares jointly, the quality of the prediction of one good can be analysed using a similar measure. This involves comparing with actual the prediction of the $i^{t h}$ share, $\widehat{w}_{i t}$, and that of the combined share of all others, $1-\widehat{w}_{i t}$. That is

$$
w_{i t} \log \frac{w_{i t}}{\widehat{w}_{i t}}+\left(1-w_{i t}\right) \log \frac{1-w_{i t}}{1-\widehat{w}_{i t}} .
$$

The above approach can be applied to the aggregated demand models that refer to (i) the 3 varieties (imports, domestic products and "Wood") and (ii) the 8 groups. To do this, define the residuals as:

$$
\begin{aligned}
& \widehat{E}_{k t}=\bar{W}_{k t} D Q_{i t}-\widehat{\Theta}_{k} D Q_{t}-\widehat{\phi} \widehat{\Theta}_{k}\left(D P_{k t}^{\prime}-D P_{t}^{\prime}\right), k=1,2,3 ; t=1996, \ldots, 2017, \\
& \hat{E}_{t}^{g}=\bar{W}_{t}^{g} D Q_{t}^{g}-\widehat{\Theta}^{g} D Q_{t}-\widehat{\phi} \widehat{\Theta}^{g}\left(D P_{t}^{g^{\prime}}-D P_{t}^{\prime}\right), g=1, \ldots, 8,
\end{aligned}
$$

and the predicted budget shares as $\widehat{W}_{k t}=W_{k t}-\widehat{E}_{k t}$ and $\widehat{W}_{t}^{g}=W_{t}^{g}-\widehat{E}_{t}^{g}$, where $W_{k t}=$ $\sum_{g \in V_{k}} w_{k t}^{g}$ and $W_{t}^{g}=\sum_{i=1}^{2} w_{i t}^{g} \cdot{ }^{16}$ For the wood group (indexed by $k=3$ and $g=5$ ), there is the predicted share using the first approach, viz., $\widehat{W}_{3 t}$, as well as the prediction from the second approach, $\widehat{W}_{t}^{5}$. By construction, the two predictions coincide, i.e., $\widehat{W}_{3 t}=\widehat{W}_{t}^{5}$. The corresponding naïve extrapolations are $W_{k, t-1}$ and $W_{t-1}^{g}$. Figure A8.1 plots the actual and predicted budget shares for domestic- and foreign-sources good and for each commodity group. In most cases, the model seems to perform satisfactorily.

Section 6 considered quality of predictions for the whole period. However, when each year is considered separately, as in Table A8.1, the picture is somewhat different with the demand model outperforming the naïve model in 11/22 years when predicting the variety shares, and in 12/22 years when predicting the group shares. This contrasts possibly reflects the considerable year-on-year noise in the data, much of which is eliminated when averaging over the whole period. The substantial serial dependence from one year to the next of the shares is a further reason for the seemingly reasonable performance of the no-change predictions.

\footnotetext{
${ }^{16}$ Equivalently, $\widehat{E}_{k t}$ and $\widehat{E}_{t}^{g}$ are the corresponding sums of the residuals of the item-specific equations.
} 


\section{SUPPLEMENTARY MATERIALS}

A-15

\section{A9. The Counter-Factual Simulations}

In the following discussion, we describe the procedure used to simulate import budgetshares as a result of exogenous shocks to each of the three sources: (i) Real income (as measured by the overall Divisia quantity index $\left.D Q_{t}\right)$; (ii) individual demands for each group $g\left(D Q_{t}^{g}\right)$; and (iii) total import demand $\left(D Q_{2 t}\right)$. Since the "Wood and Paper Products" group constitutes its own variety, we confine the analyses to non-Wood commodities only. As the share of wood in total imports, $w_{2 t}^{5} /\left(\sum_{g=1}^{8} w_{2 t}^{g}\right)$, is the lowest among the 8 groups (at about 3 percent on average), the results can be interpreted as closely approximating total imports.

We shall use the superscript $p(p=1,2,3)$ to indicate the above three scenarios. Denote

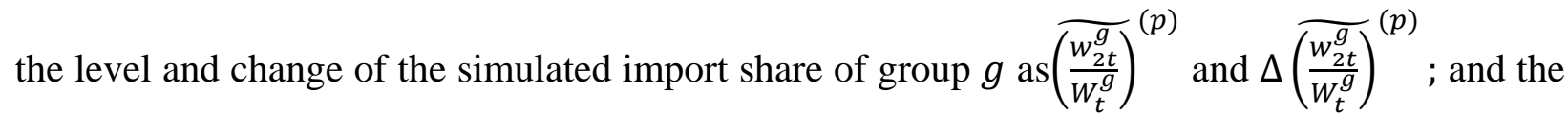
level and change of the corresponding total import share as $\widetilde{W}_{2 t}^{(p)}$ and $\Delta \widetilde{W}_{2 t}^{(p)}$. To isolate the influence of the shock, all variables other than the shocked one retain their actual values. The shock is a changed rate of growth, so that the log-change in a variable $X$ is time-invariant: $\widetilde{D X}_{t}=$ $D X_{t}+r_{t}$ where $r_{t}=r \forall t$. That is, the growth in the shocked variable changes from $D X_{t}$ to $D X_{t}+$ $r$, so the change in the rate of growth is approximately $100 \times r$ percent per annum in each year.

Next, recall from Appendix A7 that:

- The unconditional demand for variety $i(i=1,2$ denoting the domestic and foreign sources) of commodity group $g(g=1, \cdots, 8 ; g \neq 5)$ is

(A9.1) $\bar{w}_{i t}^{g} D q_{i t}^{g}=\theta_{i}^{g} D Q_{t}+\sum_{j \in \boldsymbol{S}_{g}} v_{i j}^{g}\left(D p_{j t}^{g}-D P_{t}^{\prime}\right)+\varepsilon_{i t}^{g}$.

- The demand for the combination of both varieties of group $g$ is

(A9.2) $\quad \bar{W}_{t}^{g} D Q_{t}^{g}=\Theta^{g} D Q_{t}+\phi \Theta^{g}\left(D P_{t}^{g \prime}-D P_{t}^{\prime}\right)+E_{i t}^{g}$.

- The demand for total imports is

(A9.3) $\quad \bar{W}_{2 t} D Q_{2 t}=\Theta_{2} D Q_{t}+\phi \Theta_{2}\left(D P_{2 t}^{\prime}-D P_{t}^{\prime}\right)+E_{2 t}$.

- The imports share of group $g$ is

$$
\frac{\bar{w}_{2 t}^{g}}{\bar{W}_{t}^{g}} D q_{2 t}^{g}=\frac{\theta_{2}^{g}}{\Theta^{g}} D Q_{t}^{g}+\left(\phi \frac{\Theta^{g}}{\bar{W}_{t}^{g}}\right) \frac{\theta_{2}^{g}}{\Theta^{g}}\left(D p_{2 t}^{g}-D P_{t}^{g \prime}\right)+\xi_{i t}^{g} .
$$

- The conditional demand for group $g$ within imports is

$$
\frac{\bar{w}_{2 t}^{g}}{\bar{W}_{2 t}} D q_{2 t}^{g}=\frac{\theta_{2}^{g}}{\Theta_{2}} D Q_{2 t}+\left(\phi \frac{\Theta_{2}}{\bar{W}_{2 t}}\right) \frac{\theta_{2}^{g}}{\Theta_{2}}\left(D p_{2 t}^{g}-D P_{2 t}^{\prime}\right)+\mu_{2 t}^{g} \text {. }
$$




\section{SUPPLEMENTARY MATERIALS}

A-16

\section{Scenario 1: A Change in Real Income}

From Equations (A8.7) and (A9.1), the change in imports of group $g$ is $\Delta w_{2 t}^{g}=w_{2 t}^{g}-w_{2, t-1}^{g}=\left(\theta_{2}^{g}-\bar{w}_{2 t}^{g}\right) D Q_{t}+\bar{w}_{2 t}^{g}\left(D p_{2 t}^{g}-D P_{t}\right)+\sum_{j \in \boldsymbol{S}_{g}} v_{2 j}^{g}\left(D p_{j t}^{g}-D P_{t}^{\prime}\right)+\varepsilon_{2 t}^{g}+O_{3}$, where $O_{3}$ is a third-order remainder term. Simulating $\widetilde{D Q}_{t}=D Q_{t}+r$, and setting all other terms at the observed values, gives a change in the share of

$$
\begin{aligned}
\Delta \widetilde{w}_{2 t}^{g}= & \widetilde{w}_{2 t}^{g}-\widetilde{w}_{2, t-1}^{g} \\
= & \left(\theta_{2}^{g}-\bar{w}_{2 t}^{g}\right) \widetilde{D Q}_{t}+\bar{w}_{2 t}^{g}\left(D p_{2 t}^{g}-D P_{t}\right)+\sum_{j \in S_{g}} v_{2 j}^{g}\left(D p_{j t}^{g}-D P_{t}^{\prime}\right)+\varepsilon_{2 t}^{g}+O_{3} \\
= & \left(\theta_{2}^{g}-\bar{w}_{2 t}^{g}\right) r+\left(\theta_{2}^{g}-\bar{w}_{2 t}^{g}\right) D Q_{t}+\bar{w}_{2 t}^{g}\left(D p_{2 t}^{g}-D P_{t}\right)+\sum_{j \in S_{g}} v_{2 j}^{g}\left(D p_{j t}^{g}-D P_{t}^{\prime}\right)+ \\
& \varepsilon_{2 t}^{g}+O_{3} \\
= & \Delta w_{2 t}^{g}+\left(\theta_{2}^{g}-\bar{w}_{2 t}^{g}\right) r .
\end{aligned}
$$

Then, taking the initial value to be $w_{2,1995}^{g}$, the simulated level at time $s$ ( $s=$ $1996, \ldots, 2017)$ is the sum of $w_{2,1995}^{g}$ and all simulated changes after 1995:

$$
\begin{aligned}
\widetilde{w}_{2 s}^{g} & =w_{2,1995}^{g}+\sum_{t=1996}^{s} \Delta \widetilde{w}_{2 t}^{g} \\
& =w_{2,1995}^{g}+\sum_{t=1996}^{s}\left[\Delta w_{2 t}^{g}+\left(\theta_{2}^{g}-\bar{w}_{2 t}^{g}\right) r\right] \\
& =\left(w_{2,1995}^{g}+\sum_{t=1996}^{s} \Delta w_{2 t}^{g}\right)+\sum_{t=1996}^{s}\left(\theta_{2}^{g}-\bar{w}_{2 t}^{g}\right) r \\
& =w_{2 s}^{g}+(s-1) r\left[\frac{1}{s-1} \sum_{t=1996}^{s}\left(\theta_{2}^{g}-\bar{w}_{2 t}^{g}\right)\right] .
\end{aligned}
$$

Here, $w_{2 s}^{g}$ is the observed share at $s$ and $\frac{1}{s-1} \sum_{t=2}^{s}\left(\theta_{2}^{g}-\bar{w}_{2 t}^{g}\right)$ is the mean of the excess of the marginal share over the budget share, or the mean of $\bar{w}_{2 t}^{g}\left(\eta_{2}^{g}-1\right)$, where $\eta_{2}^{g}$ denotes the income elasticity. By construction, the effects of the shocks accumulate over time and is captured in the second term of (A9.7). To illustrate, suppose $s-1=20$ years, the shock to income growth is $r=0.02$, or about 2 percent, and the income elasticity is $\eta_{2}^{g}=1.5$. It follows that $\widetilde{w}_{2 s}^{g}=w_{2 s}^{g}+$ $20 \times 0.02 \times \bar{w}_{2 s}^{g}(1.5-1) \approx w_{2 s}^{g}(1+0.4 \times 0.5)=1.2 w_{2 s}^{g}$. Thus, in this example, the simulated share after 2-percent additional income growth (in each of 20 years) about 20 percent above the observed value, a difference ten times as large as the annual income shock.

Similar to (A9.6), the simulated change in the budget share of $g$ is

$$
\Delta \widetilde{W}_{t}^{g}=\Delta W_{2 t}^{g}+\left(\Theta^{g}-\bar{W}_{t}^{g}\right) r,
$$

and, similar to (A9.7), the simulated level is

$$
\widetilde{W}_{s}^{g}=W_{s}^{g}+\sum_{t=1996}^{s}\left(\Theta^{g}-\bar{W}_{t}^{g}\right) r .
$$

Next, by combining (A9.7) and (A9.8) the simulated level of the conditional import share is 


\section{SUPPLEMENTARY MATERIALS}

A-17

(A9.9)

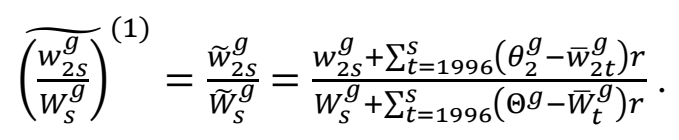

Equation (A9.9) refers to the simulated level of the share of imports in total spending on $g$ following the assumed income change, where the superscript 1 indicates the first simulation.

From (A9.3), the simulated change in spending on all imports (as a proportion of total spending on all goods) is

$$
\Delta \widetilde{W}_{2 t}^{(1)}=\Delta W_{2 t}+\left(\Theta_{2}-\bar{W}_{2 t}\right) r
$$

which implies a level of

$$
\widetilde{W}_{2 s}^{(1)}=W_{2 s}+\sum_{t=1996}^{s}\left(\Theta_{2}-\bar{W}_{2 t}\right) r .
$$

Scenario 2: A Shock to Spending on Group g

Following the same approach as above, given a change on real expenditure on group $g$, $\widetilde{D Q}{ }_{t}^{g}=D Q_{t}^{g}+r(g=1, \ldots, 8 ; g \neq 5)$, the change in conditional share of $g$ is

$$
\begin{aligned}
& \Delta \widetilde{\left(\frac{w_{2 t}^{g}}{w_{t}^{g}}\right)}(2)=\widetilde{\left(\frac{w_{2 t}^{g}}{w_{t}^{g}}\right)}-\left(\widetilde{\frac{w_{2, t-1}^{g}}{w_{t-1}^{g}}}\right) \\
& =\left(\frac{\theta_{2}^{g}}{\Theta^{g}}-\frac{\bar{w}_{2 t}^{g}}{\bar{w}_{t}^{g}}\right)\left(D Q_{t}^{g}+r\right)+\left(\phi \frac{\Theta^{g}}{\bar{w}_{t}^{g}}\right) \frac{\theta_{2}^{g}}{\Theta^{g}}\left(D p_{2 t}^{g}-D P_{t}^{g^{\prime}}\right)+\frac{\varepsilon_{2 t}^{g}}{\bar{w}_{t}^{g}} \\
& =\Delta \frac{w_{2 t}^{g}}{w_{t}^{g}}+\left(\frac{\theta_{2}^{g}}{\Theta^{g}}-\frac{\bar{w}_{2 t}^{g}}{\bar{w}_{t}^{g}}\right) r,
\end{aligned}
$$

and the corresponding level is

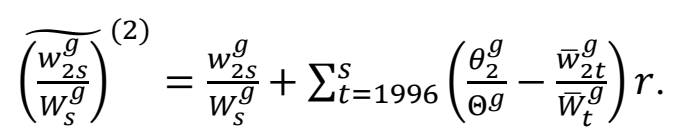

\section{Scenario 3: A Change in Total Imports}

Consider a rise in imports equal to $\widetilde{D Q}_{2 t}=D Q_{2 t}+r$. This might be the subsequent response to a capital-account surplus caused by a surge in the demand for Australian assets by foreigners. Whatever the cause, the simulated change in the total import share is

$$
\begin{aligned}
\Delta \widetilde{W}_{2 t}^{(3)} & =\widetilde{W}_{2 t}^{(3)}-\widetilde{W}_{2, t-1}^{(3)} \\
& =\bar{W}_{2 t}\left(D Q_{2 t}+r\right)+\bar{W}_{2 t}\left(D P_{2 t}-D P_{t}\right)-\bar{W}_{2 t} D Q_{t}+O_{3} \\
& =\Delta W_{2 t}+r,
\end{aligned}
$$

while the level is

$$
\begin{aligned}
\widetilde{W}_{2 s}^{(3)} & =W_{2,1995}+\sum_{t=1996}^{S} \Delta \widetilde{W}_{2 t}^{(3)}=W_{2,1995}+\sum_{t=1996}^{s}\left(\Delta W_{2 t}+r \bar{W}_{2 t}\right) \\
& =\left(W_{2,1995}+\sum_{t=1996}^{s} \Delta W_{2 t}\right)+\sum_{t=1996}^{S} r \bar{W}_{2 t}
\end{aligned}
$$




\section{SUPPLEMENTARY MATERIALS}

A-18

$$
=W_{2 s}+\sum_{t=1996}^{s} r \bar{W}_{2 t} .
$$

From equation (A9.5) the simulated share of $g$ in imports is

$$
\widetilde{\left(\frac{w_{2 s}^{g}}{W_{2 s}}\right)^{(3)}}=\frac{w_{2 s}^{g}}{W_{2 s}}+\sum_{t=1996}^{s}\left(\frac{\theta_{2}^{g}}{\Theta_{2}}-\frac{\bar{w}_{2 t}^{g}}{\bar{W}_{2 t}}\right) r .
$$

Combining (A9.13) and (A9.14) gives the share of imports in total spending on $g$ :

$$
{\widetilde{\left(\frac{w_{2 s}^{g}}{W_{s}^{g}}\right)}}^{(3)}={\widetilde{\left(\frac{w_{2 s}^{g}}{W_{2 s}}\right)}}^{(3)} \widetilde{W}_{2 s}^{(3)}\left(W_{s}^{g}\right)^{-1}
$$

where $W_{s}^{g}$ is the observed share of group $g$ in total expenditure.

\section{Summary}

A summary of the results of this appendix is given in Table A9.1.

\section{A10. Additional Results}

\section{Including Intercepts}

To allow for autonomous consumption trends, we add intercepts, $\alpha_{i}^{g}$, to model (2.11) to give

$$
\text { (A10.1) } \quad \bar{w}_{i t}^{g} D q_{i t}^{g}=\alpha_{i}^{g}+\theta_{i}^{g} D Q_{t}+\sum_{j=1}^{2} v_{i j}^{g}\left(D p_{j t}^{g}-D P_{t}^{\prime}\right)+\varepsilon_{i t}^{g}, i=1,2 ; g=1, \cdots, G \text {. }
$$

These intercepts satisfy $\sum_{g=1}^{G} \sum_{i=1}^{2} \alpha_{i}^{g}=0$. If income and prices are unchanged, then $\bar{w}_{i t}^{g} D q_{i t}^{g}=$ $\alpha_{i}^{g}$, or $D q_{i t}^{g}=\frac{\alpha_{i}^{g}}{\bar{w}_{i t}^{g}}$, so it can be seen that $\frac{\alpha_{i}^{g}}{\bar{w}_{i t}^{g}}$ is interpreted as the residual exponential trend rate of growth in consumption of the good. The estimates of model (A10.1) in Table A10.1 reveal many of the intercepts are insignificant, while the majority of other estimates do not differ greatly from those presented in Table 4.2.

\section{The Preference-Independence Estimates}

Table A10.2 presents the estimates of the preference independence model. As can be seen from column 2, the marginal share of domestic wood is negative, something that violates preference independence.

\section{More Price Elasticities}

Tables A10.3 and A10.4 present the own-price elasticities implied by the preference independence and partial preference independence models. The Frisch elasticities presented in columns 8 and 9 of Table 4.4 of the main text are reproduced in column 3 of Table A10.4. 
A-19

\section{Appendix References}

Chen, D. (1995). "Undersized Samples and Demand Analysis.” Chapter 5 in E. A. Selvanathan and K. W. Clements (eds) Recent Developments in Applied Demand Analysis: Alcohol, Advertising and Global Consumption. Springer-Verlag: Berlin/Heidelberg. Pp. 191-220.

Clements, K. W. (2019). “Four Laws of Consumption.” Economic Record 95: 358-85.

Laitinen, K. (1978). “Why Is Demand Homogeneity So Often Rejected?” Economics Letters 1: 187-91.

Meisner, J. F. (1979). “The Sad Fate of the Asymptotic Slutsky Symmetry Test for Large Systems.” Economics Letters 2: 231-33.

Theil, H. (1975/76). Theory and Measurement of Consumer Demand. Two vols. Elsevier: Amsterdam.

Theil, H. (1967). Economics and Information Theory. New York: Elsevier/North-Holland and Amsterdam: North-Holland.

Theil, H. (1987). “The Econometrics of Demand Systems.” Chapter 3 in H. Theil and K. W. Clements, Applied Demand Analysis: Results from System-Wide Approaches. Ballinger: Cambridge, Mass.: Pp. 101-62.

Selvanathan, S. (1991). "The Reliability of ML Estimators of Systems of Demand Equations: Evidence from OECD Countries.” Review of Economics and Statistics 73: 346-53. 
A-21

Table A4.1. Data Description and Sources

\begin{tabular}{|c|c|c|c|c|c|}
\hline $\begin{array}{c}\text { Variable } \\
\text { (1) }\end{array}$ & $\begin{array}{l}\text { Unit } \\
\text { (2) }\end{array}$ & $\begin{array}{c}\text { Frequency } \\
\text { (3) }\end{array}$ & $\begin{array}{c}\text { Sample period } \\
\text { (4) }\end{array}$ & $\begin{array}{l}\text { Description } \\
\text { (5) }\end{array}$ & $\begin{array}{c}\text { Source } \\
(6)\end{array}$ \\
\hline \multicolumn{6}{|c|}{ A. Trade Values } \\
\hline $\begin{array}{l}\text { 1. Merchandise } \\
\text { imports } \\
\text { 2. Merchandise } \\
\text { exports }\end{array}$ & \multirow{3}{*}{ \$A mil. } & Monthly & $\begin{array}{c}01 / 1988- \\
04 / 2019\end{array}$ & $\begin{array}{l}\text { Standard International } \\
\text { Trade Classification } \\
\text { (SITC): } \\
\text { - } 60 \text { merchandise } \\
\text { commodities (2-digit) } \\
\text { - } 10 \text { broad commodities } \\
\text { (1-digit) }\end{array}$ & $\begin{array}{l}\text { ABS-5368. Available at } \\
\text { https://www.abs.gov.au/ } \\
\text { AUSSTATS/abs@.nsf/D } \\
\text { etailsPage/5368.0Apr\%2 } \\
\text { 02019?OpenDocument }\end{array}$ \\
\hline 3. Imports & & & & \multirow[b]{2}{*}{$\begin{array}{l}\text { IO classification: } \\
\text { - } 57 \text { merchandise } \\
\text { commodities (2-digit) }\end{array}$} & \\
\hline $\begin{array}{l}\text { 4. Exports } \\
\text { 5. Domestic } \\
\text { production }\end{array}$ & & Yearly & $1995-2017$ & & $\begin{array}{l}\text { ABS.Stat: Supply-Use } \\
\text { Tables. Available at } \\
\text { http://stat.data.abs.gov.au } \\
\text { index.aspx }\end{array}$ \\
\hline \multicolumn{6}{|c|}{ B. Prices } \\
\hline 6. Import price & \multirow[t]{2}{*}{ Index } & \multirow[t]{2}{*}{ Quarterly } & $\begin{array}{c}\text { 09/1981 - } \\
03 / 2019\end{array}$ & \multirow{2}{*}{$\begin{array}{l}\text { IO classification: } \\
\text { - } 57 \text { merchandise } \\
\text { commodities (2-digit) }\end{array}$} & $\begin{array}{l}\text { ABS-6457. Available at } \\
\text { https://www.abs.gov.au/ } \\
\text { AUSSTATS/abs@.nsf/D } \\
\text { etailsPage/6457.0Mar\%2 } \\
\underline{\text { 02019?OpenDocument }}\end{array}$ \\
\hline $\begin{array}{l}\text { 8. Domestic } \\
\text { price }\end{array}$ & & & $\begin{array}{c}03 / 1990- \\
06 / 2017\end{array}$ & & $\begin{array}{l}\text { ABS.Stat: Supply-Use } \\
\text { Tables. Available at } \\
\text { http://stat.data.abs.gov.au } \\
\text { index.aspx }\end{array}$ \\
\hline
\end{tabular}


Table A4.2. Mappings from 60 SITC Goods to 20 Commodities

\begin{tabular}{|c|c|}
\hline $\begin{array}{l}60 \text { goods } \\
(1)\end{array}$ & $\begin{array}{c}20 \text { commodities } \\
(2)\end{array}$ \\
\hline 1. Meat and meat preparations ; & Meat Products \\
\hline 2. Dairy products and birds’ eggs ; & Dairy Products and Egg \\
\hline 3. Fish (excl. marine mammals) crustaceans, molluscs and aquatic invertebrates, and preparations & Fish Products \\
\hline 4. Cereals and cereal preparations ; & Other Food Products \\
\hline 5. Vegetables and fruit; & Other Food Products \\
\hline 6. Sugars, sugar preparations and honey ; & Other Food Products \\
\hline 7. Coffee, tea, cocoa, spices, and manufactures thereof ; & Other Food Products \\
\hline 8. Feeding stuff for animals (excl. unmilled cereals) ; & Other Food Products \\
\hline 9. Miscellaneous edible products and preparations ; & Other Food Products \\
\hline 10. Beverages; & Beverage and Tobacco \\
\hline 11. Tobacco and tobacco manufactures ; & Beverage and Tobacco \\
\hline 12. Hides, skins and furskins, raw ; & Other Manufactures \\
\hline 13. Oil-seeds and oleaginous fruits ; & Other Manufactures \\
\hline 14. Crude rubber (incl. synthetic and reclaimed); & Other Manufactures \\
\hline 15. Cork and wood ; & Wood and Products \\
\hline 16. Pulp and waste paper ; & Paper Products \\
\hline 17. Textile fibres (excl. wool tops and other combed wool) and their wastes & Textile and Leather \\
\hline 18. Crude fertilizers (excl. those of Division 56) and crude minerals & Other Manufactures \\
\hline 19. Metalliferous ores and metal scrap ; & Other Manufactures \\
\hline 20. Crude animal and vegetable materials, nes ; & Other Manufactures \\
\hline 21. Coal, coke and briquettes ; & Coal, Petroleum and Gas \\
\hline 22. Petroleum, petroleum products and related materials ; & Coal, Petroleum and Gas \\
\hline 23. Gas, natural and manufactured ; & Coal, Petroleum and Gas \\
\hline 24. Animal oils and fats ; & Other Manufactures \\
\hline 25. Fixed vegetable fats and oils, crude, refined or fractionated ; & Other Manufactures \\
\hline 26. Animal or vegetable fats and oils, processed; waxes of animal or vegetable origin etc.; & Other Manufactures \\
\hline 27. Organic chemicals ; & Basic Chemicals \\
\hline 28. Inorganic chemicals ; & Basic Chemicals \\
\hline 29. Dyeing, tanning and colouring materials ; & Basic Chemicals \\
\hline 30. Medicinal and pharmaceutical products ; & Pharmaceutical Products \\
\hline 31. Essential oils and resinoids and perfume materials; etc. & Basic Chemicals \\
\hline 32. Fertilisers (excl. those of group 272) ; & Basic Chemicals \\
\hline 33. Plastics in primary forms ; & Basic Chemicals \\
\hline 34. Plastics in non-primary forms ; & Basic Chemicals \\
\hline 35. Chemical materials and products, nes ; & Basic Chemicals \\
\hline 36. Leather, leather manufactures, nes, and dressed furskins ; & Textile and Leather \\
\hline 37. Rubber manufactures, nes ; & Textile and Leather \\
\hline 38. Cork and wood manufactures (excl. furniture) ; & Wood and Products \\
\hline 39. Paper, paperboard and articles of paper pulp, of paper or of paperboard ; & Paper Products \\
\hline 40. Textile yarn, fabrics, made-up articles nes, and related products ; & Other Manufactures \\
\hline 41. Non-metallic mineral manufactures, nes ; & Non Metals \\
\hline 42. Iron and steel ; & Iron Steel \\
\hline 43. Non-ferrous metals ; & Non Ferrous Metals \\
\hline 44. Power generating machinery and equipment ; & Machinery Equipment \\
\hline 45. Machinery specialized for particular industries ; & Machinery Equipment \\
\hline 46. Metalworking machinery ; & Machinery Equipment \\
\hline 47. General industrial machinery and equipment, nes, and machine parts, nes ; & Machinery Equipment \\
\hline 48. Office machines and automatic data processing machines ; & Machinery Equipment \\
\hline 49. Telecommunications and sound recording and reproducing apparatus and equipment & Machinery Equipment \\
\hline 50. Electrical machinery, apparatus and appliances, nes, and electrical parts thereof; & Machinery Equipment \\
\hline 51. Road vehicles (incl. air-cushion vehicles) ; & Motor Vehicles and Parts \\
\hline 52. Transport equipment (excl. road vehicles); & Transport Equipment \\
\hline 53. Prefabricated buildings and sanitary, plumbing, heating and lighting fixtures and fittings, nes ; & Other Manufactures \\
\hline 54. Furniture and parts thereof; bedding, mattresses, mattress supports etc.; & Furniture \\
\hline 55. Travel goods, handbags and similar containers ; & Other Manufactures \\
\hline 56. Articles of apparel and clothing accessories ; & Clothing and Footwear \\
\hline 57. Footwear; & Clothing and Footwear \\
\hline 58. Professional, scientific and controlling instruments and apparatus, nes ; & Other Manufactures \\
\hline 59. Photographic apparatus, equipment and supplies and optical goods, nes; watches and clocks ; & Other Manufactures \\
\hline 60. Miscellaneous manufactured articles, nes ; & Other Manufactures \\
\hline
\end{tabular}

Note: Source of column 1 is the Standard International Trade Classification System of the United Nations. 
A-23

Table A4.3. Mappings from 57 SUT Goods to 20 Commodities

\begin{tabular}{|c|c|}
\hline $\begin{array}{l}57 \text { goods } \\
(1)\end{array}$ & $\begin{array}{c}20 \text { commodities } \\
(2)\end{array}$ \\
\hline 1. Aquaculture & Fish Products \\
\hline 2. Coal mining & Coal, Petroleum and Gas \\
\hline 3. Oil and gas extraction & Coal, Petroleum and Gas \\
\hline 4. Iron Ore Mining & Coal, Petroleum and Gas \\
\hline 5. Non Ferrous Metal Ore Mining & Coal, Petroleum and Gas \\
\hline 6. Non Metallic Mineral Mining & Coal, Petroleum and Gas \\
\hline 7. Meat and Meat product Manufacturing & Meat Products \\
\hline 8. Processed Seafood Manufacturing & Fish Products \\
\hline 9. Dairy Product Manufacturing & Dairy Products and Egg \\
\hline 10. Fruit and Vegetable Product Manufacturing & Other Food Products \\
\hline 11. Oils and Fats Manufacturing & Other Food Products \\
\hline 12. Grain Mill and Cereal Product Manufacturing & Other Food Products \\
\hline 13. Bakery Product Manufacturing & Other Food Products \\
\hline 14. Sugar and Confectionery Manufacturing & Other Food Products \\
\hline 15. Other Food Product Manufacturing & Other Food Products \\
\hline 16. Soft Drinks, Cordials and Syrup Manufacturing & Beverage and Tobacco \\
\hline 17. Beer Manufacturing & Beverage and Tobacco \\
\hline 18. Wine, Spirits and Tobacco & Beverage and Tobacco \\
\hline 19. Textile Manufacturing & Textile and Leather \\
\hline 20. Tanned Leather, Dressed Fur and Leather Product Manufacturing & Textile and Leather \\
\hline 21. Textile Product Manufacturing & Textile and Leather \\
\hline 22. Knitted Product Manufacturing & Clothing and Footwear \\
\hline 23. Clothing Manufacturing & Clothing and Footwear \\
\hline 24. Footwear Manufacturing & Clothing and Footwear \\
\hline 25. Sawmill Product Manufacturing & Wood and Products \\
\hline 26. Other Wood Product Manufacturing & Wood and Products \\
\hline 27. Pulp, Paper and Paperboard Manufacturing & Paper Products \\
\hline 28. Paper Stationery and Other Converted Paper Product Manufacturing & Paper Products \\
\hline 29. Printing (including the reproduction of recorded media) & Paper Products \\
\hline 30. Petroleum and Coal Product Manufacturing & Coal, Petroleum and Gas \\
\hline 31. Human Pharmaceutical and Medicinal Product Manufacturing & Pharmaceutical Products \\
\hline 32. Veterinary Pharmaceutical and Medicinal Product Manufacturing & Pharmaceutical Products \\
\hline 33. Basic Chemical Manufacturing & Basic Chemicals \\
\hline 34. Cleaning Compounds and Toiletry Preparation Manufacturing & Basic Chemicals \\
\hline 35. Polymer Product Manufacturing & Non Metals \\
\hline 36. Natural Rubber Product Manufacturing & Non Metals \\
\hline 37. Glass and Glass Product Manufacturing & Non Metals \\
\hline 38. Ceramic Product Manufacturing & Non Metals \\
\hline 39. Cement, Lime and Ready-Mixed Concrete Manufacturing & Non Metals \\
\hline 40. Plaster and Concrete Product Manufacturing & Non Metals \\
\hline 41. Other Non-Metallic Mineral Product Manufacturing & Non Metals \\
\hline 42. Iron and Steel Manufacturing & Iron Steel \\
\hline 43. Basic Non-Ferrous Metal Manufacturing & Non Ferrous Metals \\
\hline 44. Forged Iron and Steel Product Manufacturing & Iron Steel \\
\hline 45. Structural Metal Product Manufacturing & Non Ferrous Metals \\
\hline 46. Metal Containers and Other Sheet Metal Product manufacturing & Non Ferrous Metals \\
\hline 47. Other Fabricated Metal Product manufacturing & Non Ferrous Metals \\
\hline 48. Motor Vehicles and Parts; Other Transport Equipment manufacturing & Motor Vehicles and Parts \\
\hline 49. Ships and Boat Manufacturing & Transport Equipment \\
\hline 50. Railway Rolling Stock Manufacturing & Transport Equipment \\
\hline 51. Aircraft Manufacturing & Transport Equipment \\
\hline 52. Professional, Scientific, Computer and Electronic Equipment Manufacturing & Machinery Equipment \\
\hline 53. Electrical Equipment Manufacturing & Machinery Equipment \\
\hline 54. Domestic Appliance Manufacturing & Machinery Equipment \\
\hline 55. Specialised and other Machinery and Equipment Manufacturing & Machinery Equipment \\
\hline 56. Furniture Manufacturing & Furniture \\
\hline 57. Other Manufactured Products & Other Manufactures \\
\hline
\end{tabular}

Note: Source of column 1 is the Supply-Use Tables provided by Australian Bureau of Statistics. 
A-24

Table A4.4. Mappings from 20 Commodities into 8 Groups

\begin{tabular}{|c|c|c|c|c|c|}
\hline \multirow{2}{*}{$\begin{array}{l}\text { Groups } \\
\text { (1) }\end{array}$} & \multicolumn{5}{|c|}{20 Commodities } \\
\hline & (2) & (3) & (4) & (5) & (6) \\
\hline $\begin{array}{l}\text { 1. Food and Agricultural } \\
\text { Commodities }\end{array}$ & $\begin{array}{l}\text { Dairy Products } \\
\text { and Egg }\end{array}$ & Fish Products & $\begin{array}{l}\text { Beverage } \\
\text { and Tobacco }\end{array}$ & $\begin{array}{l}\text { Meat } \\
\text { Products }\end{array}$ & $\begin{array}{l}\text { Other Food } \\
\text { Products }\end{array}$ \\
\hline 2. Energy and Minerals & $\begin{array}{l}\text { Coal, Petroleum } \\
\text { and Gas }\end{array}$ & Iron Steel & $\begin{array}{l}\text { Non-Ferrous } \\
\text { Metals }\end{array}$ & Non Metals & \\
\hline 3. Chemicals & Basic Chemicals & $\begin{array}{l}\text { Pharmaceutical } \\
\text { Products }\end{array}$ & & & \\
\hline $\begin{array}{l}\text { 4. Textile, Leather, } \\
\text { Clothing and Footwear }\end{array}$ & $\begin{array}{l}\text { Textile and } \\
\text { Leather }\end{array}$ & $\begin{array}{l}\text { Clothing and } \\
\text { Footwear }\end{array}$ & & & \\
\hline $\begin{array}{l}\text { 5. Wood and Paper } \\
\text { Products }\end{array}$ & Wood Products & Paper Products & & & \\
\hline $\begin{array}{l}\text { 6. Machinery and } \\
\text { Equipment }\end{array}$ & $\begin{array}{l}\text { Machinery } \\
\text { Equipment }\end{array}$ & & & & \\
\hline $\begin{array}{l}\text { 7. Motor Vehicles and } \\
\text { Transport }\end{array}$ & $\begin{array}{l}\text { Motor Vehicles } \\
\text { and Parts }\end{array}$ & $\begin{array}{l}\text { Transport } \\
\text { Equipment }\end{array}$ & & & \\
\hline $\begin{array}{l}\text { 8. Miscellaneous } \\
\text { Manufactured Goods }\end{array}$ & $\begin{array}{l}\text { Other } \\
\text { Manufactures }\end{array}$ & Furniture & & & \\
\hline
\end{tabular}

Note: Columns $2-6$ are from Tables A4.2 and A4.3. 
A-25

Table 4.5. Divisia Price and Quantity Indices, Variances and Correlations

\begin{tabular}{|c|c|c|c|c|c|}
\hline \multirow[b]{2}{*}{ Year } & \multicolumn{2}{|c|}{ Index $\left(\times 10^{2}\right)$} & \multicolumn{2}{|c|}{ Variance $\left(\times 10^{4}\right)$} & \multirow[b]{2}{*}{$\begin{array}{c}\text { Correlation } \\
\rho_{t} \\
(6)\end{array}$} \\
\hline & $\begin{array}{c}\text { Price } \\
D P_{t} \\
(2)\end{array}$ & $\begin{array}{c}\text { Quantity } \\
D Q_{t} \\
\text { (3) }\end{array}$ & $\begin{array}{l}\text { Price } \\
V_{t}^{p} \\
(4)\end{array}$ & $\begin{array}{l}\text { Quantity } \\
\qquad V_{t}^{q} \\
\text { (5) }\end{array}$ & \\
\hline 1996 & -0.04 & 1.90 & 4.90 & 11.80 & -0.60 \\
\hline 1997 & -1.46 & 2.90 & 5.30 & 8.80 & -0.60 \\
\hline 1998 & 1.07 & 3.10 & 13.80 & 8.50 & 0.41 \\
\hline 1999 & 4.55 & 0.70 & 10.40 & 22.10 & -0.72 \\
\hline 2000 & 2.70 & 1.50 & 10.00 & 46.80 & -0.73 \\
\hline 2001 & 2.58 & 0.80 & 54.70 & 57.00 & -0.73 \\
\hline 2002 & 1.45 & 2.00 & 5.10 & 23.50 & -0.79 \\
\hline 2003 & -1.08 & 4.30 & 4.80 & 24.00 & -0.39 \\
\hline 2004 & 0.95 & 1.10 & 65.80 & 56.50 & -0.94 \\
\hline 2005 & 3.52 & 4.20 & 23.90 & 33.30 & -0.41 \\
\hline 2006 & 4.40 & 0.20 & 13.80 & 19.30 & 0.08 \\
\hline 2007 & 3.09 & 2.40 & 10.40 & 27.20 & -0.04 \\
\hline 2008 & 1.67 & 4.50 & 42.40 & 57.50 & -0.77 \\
\hline 2009 & 1.51 & -1.40 & 54.00 & 43.60 & -0.62 \\
\hline 2010 & -0.66 & -3.20 & 35.80 & 46.10 & -0.48 \\
\hline 2011 & 1.26 & 1.30 & 8.50 & 12.30 & -0.49 \\
\hline 2012 & 0.16 & 2.50 & 9.10 & 34.60 & -0.33 \\
\hline 2013 & 1.69 & -5.00 & 6.00 & 16.80 & -0.39 \\
\hline 2014 & 1.95 & -1.50 & 24.60 & 20.20 & -0.68 \\
\hline 2015 & -0.24 & -2.00 & 32.40 & 14.40 & -0.09 \\
\hline 2016 & 2.30 & -0.90 & 19.50 & 12.90 & -0.15 \\
\hline 2017 & 0.17 & -0.40 & 13.90 & 28.20 & -0.94 \\
\hline Mean & 1.43 & 0.86 & 21.32 & 28.43 & -0.47 \\
\hline Median & 1.48 & 1.20 & 13.80 & 23.75 & -0.54 \\
\hline SD & 1.65 & 2.47 & 18.39 & 16.21 & 0.34 \\
\hline
\end{tabular}

Notes:

1. Columns 2 - 3: The price and quantity indices are $D P_{t}=$ $\sum_{g=1}^{8} \sum_{i=1}^{2} \bar{w}_{i t}^{g} D p_{i t}^{g} ; D Q_{t}=\sum_{g=1}^{8} \sum_{i=1}^{2} \bar{w}_{i t}^{g} D q_{i t}^{g}$.

2. Columns $4-5$ : The price and quantity variances are $V_{t}^{p}=$ $\sum_{g=1}^{8} \sum_{i=1}^{2} \bar{w}_{i t}^{g}\left(D p_{i t}^{g}-D P_{t}\right)^{2}$ and $V_{t}^{q}=\sum_{g=1}^{8} \sum_{i=1}^{2} \bar{w}_{i t}^{g}\left(D q_{i t}^{g}-D Q_{t}\right)^{2}$.

3. Column 6: The price-quantity correlation is $\rho_{t}=V_{t}^{p q}\left(V_{t}^{p} V_{t}^{q}\right)^{-1 / 2}$, where $V_{t}^{p q}=\sum_{g=1}^{8} \sum_{i=1}^{2} \bar{w}_{i t}^{g}\left(D p_{i t}^{g}-D P_{t}\right)\left(D q_{i t}^{g}-D Q_{t}\right)$ is the price-quantity covariance. 
A-26

Table A6.1. Functional Form and Degrees of Freedom

[Numerator d.f. (Denominator d.f.)]

\begin{tabular}{|c|c|c|c|c|}
\hline \multirow[b]{3}{*}{$\begin{array}{l}\text { Unrestricted/alternative model } \\
\text { (1) }\end{array}$} & \multirow[b]{3}{*}{$\begin{array}{l}\text { Number of } \\
\text { unconstrained } \\
\text { parameters } \\
\text { (2) }\end{array}$} & \multicolumn{3}{|c|}{ "Restricted/null model } \\
\hline & & \multicolumn{2}{|l|}{$\begin{array}{l}\text { Least } \leftarrow \\
\text { restrictive }\end{array}$} & \multirow[t]{2}{*}{$\begin{array}{r}\rightarrow \text { Most } \\
\text { restrictive }\end{array}$} \\
\hline & & $\begin{array}{l}\text { PPI } \\
(3)\end{array}$ & $\begin{array}{l}\text { PI } \\
(4)\end{array}$ & \\
\hline $\begin{array}{l}\text { 1. Preference Dependence (PD) } \\
\bar{w}_{i t}^{g} D q_{i t}^{g}=\theta_{i}^{g} D Q_{t}+\sum_{j=1}^{2} v_{i j}^{g}\left(D p_{j t}^{g}-D P_{t}^{\prime}\right)+\varepsilon_{i t}^{g}\end{array}$ & $\begin{array}{c}\theta_{i}^{g}: 15 \\
v_{12:}^{g}: 8 ; \phi: 1 \\
\text { Total }=24\end{array}$ & 7 (328) & 8 (328) & 9 (328) \\
\hline $\begin{array}{l}\text { 2. Partial Preference Independence (PPI) } \\
\bar{w}_{i t}^{g} D q_{i t}^{g}=\theta_{i}^{g} D Q_{t}+\phi A_{i t}^{g}(\boldsymbol{\theta})+v_{12}^{5}[2 \gamma(i= \\
1)-1] \Delta p_{21, t}^{5}+\varepsilon_{i t}^{g}\end{array}$ & $\begin{array}{c}\theta_{i}^{g}: 15 \\
v_{12:}^{5}: 1 ; \phi: 1 \\
\text { Total }=17\end{array}$ & - & $1(335)$ & $2(335)$ \\
\hline $\begin{array}{l}\text { 3. Preference Independence (PI) } \\
\bar{w}_{i t}^{g} D q_{i t}^{g}=\theta_{i}^{g} D Q_{t}+v_{i i}^{g}\left(D p_{i t}^{g}-D P_{t}^{\prime}\right)+\varepsilon_{i t}^{g}\end{array}$ & $\begin{array}{l}\theta_{i}^{g}: 15 ; \phi: 1 \\
\text { Total }=16\end{array}$ & - & - & $1(336)$ \\
\hline $\begin{array}{l}\text { 4. No price effects (NP) } \\
\bar{w}_{i t}^{g} D q_{i t}^{g}=\theta_{i}^{g} D Q_{t}+\varepsilon_{i t}^{g}\end{array}$ & $\begin{array}{c}\theta_{i}^{g}: 15 \\
\text { Total }=15\end{array}$ & - & - & - \\
\hline
\end{tabular}

Notes: The numerator degrees of freedom are emboldened and equal to the difference in the number of unconstrained parameters in unrestricted/alternative and restricted/null models. The denominator degrees of freedom equal the difference between the number of observations $(22 \times 16=352)$ and number of independent variables in the unrestricted model. 


\section{SUPPLEMENTARY MATERIALS}

\section{A-27}

Table A7.1. Aggregating and Disaggregating Demands

\begin{tabular}{|c|c|c|c|c|c|c|c|}
\hline $\begin{array}{l}\text { Aggregated group } \\
\text { (1) }\end{array}$ & $\begin{array}{l}\text { Demand model } \\
\text { (2) }\end{array}$ & $\begin{array}{l}\text { Budget } \\
\text { share } \\
\text { (3) }\end{array}$ & $\begin{array}{l}\text { Marginal } \\
\text { share } \\
(4)\end{array}$ & $\begin{array}{c}\text { Divisia quantity } \\
\text { index } \\
\text { (5) }\end{array}$ & $\begin{array}{c}\text { Frisch price } \\
\text { index } \\
(6)\end{array}$ & $\begin{array}{l}\text { Income } \\
\text { elasticity } \\
(7)\end{array}$ & $\begin{array}{l}\text { Own-price } \\
\text { elasticity } \\
\text { (8) }\end{array}$ \\
\hline \multicolumn{8}{|c|}{ A. 16 Elementary Goods } \\
\hline $\begin{array}{l}\text { 1. Individual goods, } i= \\
1,2, g=1, \cdots, 8, g \neq 5\end{array}$ & $\bar{w}_{i t}^{g} D q_{i t}^{g}=\theta_{i}^{g} D Q_{t}+\phi \theta_{i}^{g}\left(D p_{i t}^{g}-D P_{t}^{\prime}\right)+\varepsilon_{i t}^{g}$ & $\bar{w}_{i}^{g}$ & $\theta_{i}^{g}$ & \multirow{2}{*}{$\begin{array}{c}D Q_{t}= \\
\sum_{g=1}^{8} \sum_{i=1}^{2} \bar{w}_{i t}^{g} D q_{i t}^{g}\end{array}$} & \multirow{2}{*}{$\begin{array}{c}D P_{t}^{\prime}= \\
\sum_{g=1}^{8} \sum_{i=1}^{2} \theta_{i}^{g} D p_{i t}^{g}\end{array}$} & $\frac{\theta_{i}^{g}}{\bar{w}_{i}^{g}}$ & $\phi \frac{\theta_{i}^{g}}{\bar{w}_{i}^{g}}$ \\
\hline 2. Wood, $g=5, i=1,2$ & $\bar{w}_{i t}^{5} D q_{i t}^{5}=\theta_{i}^{5} D Q_{t}+\sum_{j=1}^{2} v_{i j}^{5}\left(D p_{j t}^{5}-D P_{t}^{\prime}\right)+\varepsilon_{i t}^{5}$ & $\bar{w}_{i}^{5}$ & $\theta_{i}^{5}$ & & & $\frac{\theta_{i}^{5}}{\bar{w}_{i}^{5}}$ & $\frac{v_{i i}^{5}}{\bar{w}_{i}^{5}}$ \\
\hline \multicolumn{8}{|c|}{ B. 3 Varieties of Goods } \\
\hline 3. $\boldsymbol{V}_{1}$ : Domestic goods & $\bar{W}_{1 t} D Q_{1 t}=\Theta_{1} D Q_{t}+\phi \Theta_{1}\left(D P_{1 t}^{\prime}-D P_{t}^{\prime}\right)+E_{1 t}$ & $\begin{array}{c}\bar{W}_{1}= \\
\sum_{g \in V_{1}} \bar{w}_{1}^{g}\end{array}$ & $\begin{array}{c}\Theta_{1}= \\
\sum_{g \in V_{1}} \theta_{1}^{g}\end{array}$ & $\begin{array}{c}D Q_{1 t}= \\
\sum_{g \in V_{1}} \frac{\bar{w}_{1 t}^{g}}{\bar{W}_{1 t}} D q_{1 t}^{g}\end{array}$ & $\begin{array}{c}D P_{1 t}^{\prime}= \\
\sum_{g \in V_{1}} \frac{\theta_{1}^{g}}{\Theta_{1}} D p_{1 t}^{g}\end{array}$ & $\frac{\Theta_{1}}{\bar{w}_{1}}$ & $\phi \frac{\Theta_{1}}{\bar{W}_{1}}$ \\
\hline 4. $\boldsymbol{V}_{2}$ : Foreign goods & $\bar{W}_{2 t} D Q_{2 t}=\Theta_{2} D Q_{t}+\phi \Theta_{2}\left(D P_{2 t}^{\prime}-D P_{t}^{\prime}\right)+E_{2 t}$ & $\begin{array}{c}\bar{W}_{2}= \\
\sum_{g \in V_{2}} \bar{w}_{2}^{g}\end{array}$ & $\begin{array}{c}\Theta_{2}= \\
\sum_{g \in V_{2}} \theta_{2}^{g}\end{array}$ & $\begin{array}{c}D Q_{2 t}= \\
\sum_{g \in V_{2}} \frac{\bar{w}_{2 t}^{g}}{\bar{w}_{2 t}} D q_{2 t}^{g}\end{array}$ & $\begin{array}{c}D P_{2 t}^{\prime}= \\
\sum_{g \in V_{2}} \frac{\theta_{2}^{g}}{\Theta_{2}} D p_{2 t}^{g}\end{array}$ & $\frac{\Theta_{2}}{\bar{W}_{2}}$ & $\phi \frac{\Theta_{2}}{\bar{W}_{2}}$ \\
\hline 5. $V_{3}:$ Wood & $\bar{W}_{3 t} D Q_{3 t}=\Theta_{3} D Q_{t}+\phi \Theta_{3}\left(D P_{3 t}^{\prime}-D P_{t}^{\prime}\right)+E_{3 t}$ & $\begin{array}{c}\bar{W}_{3}= \\
\sum_{i=1}^{2} \bar{W}_{i}^{5}\end{array}$ & $\begin{array}{c}\Theta_{3}= \\
\sum_{i=1}^{2} \theta_{i}^{5}\end{array}$ & $\begin{array}{c}D Q_{3 t}= \\
\sum_{i=1}^{2} \frac{\bar{w}_{i t}^{5}}{\bar{w}_{3 t}} D q_{i t}^{5}\end{array}$ & $\begin{array}{c}D P_{3 t}^{\prime}= \\
\sum_{i=1}^{2} \frac{\theta_{i}^{5}}{\Theta_{3}} D p_{i t}^{5}\end{array}$ & $\frac{\Theta_{3}}{\bar{W}_{3}}$ & $\phi \frac{\Theta_{3}}{\bar{W}_{3}}$ \\
\hline \multicolumn{8}{|c|}{ C. Within 3 Varieties } \\
\hline $\begin{array}{l}\text { 6. } V_{1} \text { : Domestic goods, } \\
g=1, \cdots, 8, g \neq 5\end{array}$ & $\frac{\bar{w}_{1 t}^{g}}{\bar{W}_{1 t}} D q_{1 t}^{g}=\frac{\theta_{1}^{g}}{\Theta_{1}} D Q_{1 t}+\left(\phi \frac{\Theta_{1}}{\bar{W}_{1 t}}\right) \frac{\theta_{1}^{g}}{\Theta_{1}}\left(D p_{1 t}^{g}-D P_{1 t}^{\prime}\right)+\mu_{1 t}^{g}$ & $\frac{\bar{w}_{1}^{g}}{\bar{W}_{1}}$ & $\frac{\theta_{1}^{g}}{\theta_{1}}$ & \multicolumn{2}{|c|}{ As in row 3} & $\frac{\theta_{1}^{g} / \theta_{1}}{\bar{w}_{1}^{g} / \bar{W}_{1}}$ & $\phi \frac{\theta_{1}^{g}}{\bar{w}_{1}^{g}}$ \\
\hline $\begin{array}{l}\text { 7. } V_{2}: \text { Foreign goods, } g= \\
1, \cdots, 8, g \neq 5\end{array}$ & $\frac{\bar{w}_{2 t}^{g}}{\bar{W}_{2 t}} D q_{2 t}^{g}=\frac{\theta_{2}^{g}}{\theta_{2}} D Q_{2 t}+\left(\phi \frac{\Theta_{2}}{\bar{W}_{2 t}}\right) \frac{\theta_{2}^{g}}{\theta_{2}}\left(D p_{2 t}^{g}-D P_{2 t}^{\prime}\right)+\mu_{2 t}^{g}$ & $\frac{\bar{w}_{2}^{g}}{\bar{w}_{2}}$ & $\frac{\theta_{2}^{g}}{\theta_{2}}$ & \multicolumn{2}{|c|}{ As in row 4} & $\frac{\theta_{2}^{g} / \theta_{2}}{\bar{w}_{2}^{g} / \bar{w}_{2}}$ & $\phi \frac{\theta_{2}^{g}}{\bar{w}_{2}^{g}}$ \\
\hline $\begin{array}{l}\text { 8. } \boldsymbol{V}_{3}: \text { Wood, } g=5, i= \\
\quad 1,2\end{array}$ & $\frac{\bar{w}_{i t}^{5}}{\bar{W}_{3 t}} D q_{i t}^{5}=\frac{\theta_{i}^{5}}{\theta_{3}} D Q_{3 t}+\sum_{j=1}^{2} v_{i j}^{5}\left(D p_{j t}^{5}-D P_{3 t}^{\prime}\right)+\mu_{i t}^{5}$ & $\frac{\bar{w}_{i}^{5}}{\bar{W}_{3}}$ & $\frac{\theta_{1}^{5}}{\Theta_{3}}$ & \multicolumn{2}{|c|}{ As in row 5} & $\frac{\theta_{i}^{5} / \Theta_{3}}{\bar{w}_{i}^{5} / \bar{W}_{3}}$ & $\frac{v_{i i}^{5}}{\bar{w}_{i}^{5} / \bar{w}_{3}}$ \\
\hline \multicolumn{8}{|c|}{ D. 8 Groups of Goods } \\
\hline $\begin{array}{l}\text { 9. Individual goods, } g= \\
1, \cdots, 8, g \neq 5\end{array}$ & $\bar{W}_{t}^{g} D Q_{t}^{g}=\Theta^{g} D Q_{t}+\phi \Theta^{g}\left(D P_{t}^{g \prime}-D P_{t}^{\prime}\right)+E_{t}^{g}$ & $\begin{array}{c}\bar{W}^{g}= \\
\sum_{i=1}^{2} \bar{w}_{i}^{g}\end{array}$ & $\Theta_{i=1}^{\Theta^{g}}=$ & $\begin{array}{c}D Q_{t}^{g}= \\
\sum_{i=1}^{2} \frac{\bar{w}_{i t}^{g}}{\bar{w}_{t}^{g}} D q_{i t}^{g}\end{array}$ & $\begin{array}{c}D P_{t}^{g \prime}= \\
\sum_{i=1}^{2} \frac{\theta_{i}^{g}}{\Theta^{g}} D p_{i t}^{g}\end{array}$ & $\frac{\Theta^{g}}{\bar{W}^{g}}$ & $\phi \frac{\Theta^{g}}{\bar{W}^{g}}$ \\
\hline 10. Wood, $g=5$ & \multicolumn{7}{|c|}{ As in row 5} \\
\hline \multicolumn{8}{|c|}{ E. Within 8 Groups of Goods } \\
\hline $\begin{array}{l}\text { 11. Individual goods, } i= \\
1,2, g=1, \cdots, 8, g \neq 5\end{array}$ & $\frac{\bar{w}_{i t}^{g}}{\bar{W}_{t}^{g}} D q_{i t}^{g}=\frac{\theta_{i}^{g}}{\Theta^{g}} D Q_{t}^{g}+\left(\phi \frac{\Theta^{g}}{\bar{W}_{t}^{g}}\right) \frac{\theta_{i}^{g}}{\Theta^{g}}\left(D p_{i t}^{g}-D P_{t}^{g \prime}\right)+\xi_{i t}^{g}$ & $\frac{\bar{w}_{i}^{g}}{\bar{W}^{g}}$ & $\frac{\theta_{i}^{g}}{\Theta^{g}}$ & \multicolumn{2}{|c|}{ As in row 9} & $\frac{\theta_{i}^{g} / \Theta^{g}}{\bar{w}_{i}^{g} / \bar{w}^{g}}$ & $\phi \frac{\theta_{i}^{g}}{\bar{w}_{i}^{g}}$ \\
\hline 12. Wood, $i=1,2$ & \multicolumn{7}{|c|}{ As in row 8} \\
\hline
\end{tabular}




\section{SUPPLEMENTARY MATERIALS}

\section{A-28}

Notes:

1. There are 8 elementary goods with each split according to where it whether it was produced domestically or imported. Thus, there are 16 items identified in panel A. These are aggregated in 2 ways:

(i) Into the 3 varieties: (a) Domestically produced, excluding "Wood” $\left(\boldsymbol{V}_{1}\right)$; (b) Imported excluding "Wood” $\left(\boldsymbol{V}_{2}\right)$ and (c) "Wood” from both domestic and foreign sources $\left(\boldsymbol{V}_{3}\right)$.These groups are represented in panel B.

(ii) Into the 8 groups corresponding to the elementary goods: These groups are represented in panel D.

2. Panels $\mathrm{C}$ and $\mathrm{E}$ refer to budget allocations within aggregations (i) and (ii) above.

3. Column 3: The budget shares are sample means.

4. Column 7: The "income" elasticities represent elasticities with respect to the high-level aggregates.

5. Column 8: The own-price elasticities are of the Frisch variety (which holds marginal utility of income constant).

6. The item "Wood" represents "Wood and Paper Products". 


\section{SUPPLEMENTARY MATERIALS}

\section{A-29}

Table A8.1. Year-on-Year Evaluation of Budget-Share Predictions, Information Inaccuracies

\begin{tabular}{|c|c|c|c|c|c|c|}
\hline \multirow[b]{2}{*}{ Year } & \multicolumn{3}{|c|}{ A. Three varieties } & \multicolumn{3}{|c|}{ B. Eight groups } \\
\hline & $\begin{array}{c}\text { Demand } \\
\text { model } \\
\text { (2) }\end{array}$ & $\begin{array}{c}\text { Naïve } \\
\text { (3) }\end{array}$ & $\begin{array}{c}\text { Demand } \\
\text { model } \\
\text { better? } \\
\text { (4) }\end{array}$ & $\begin{array}{c}\text { Demand } \\
\text { model } \\
\text { (5) }\end{array}$ & $\begin{array}{c}\text { Naïve } \\
\text { (6) }\end{array}$ & $\begin{array}{c}\text { Demand } \\
\text { model } \\
\text { better? } \\
\text { (7) }\end{array}$ \\
\hline 1996 & 0.47 & 0.23 & No & 1.72 & 1.79 & Yes \\
\hline 1997 & 0.51 & 0.40 & No & 1.78 & 1.55 & No \\
\hline 1998 & 1.71 & 12.83 & Yes & 2.73 & 2.85 & Yes \\
\hline 1999 & 0.31 & 0.08 & No & 5.73 & 2.20 & No \\
\hline 2000 & 9.29 & 7.91 & No & 1.27 & 1.91 & Yes \\
\hline 2001 & 0.78 & 4.12 & Yes & 13.22 & 7.08 & No \\
\hline 2002 & 8.38 & 3.42 & No & 9.15 & 1.91 & No \\
\hline 2003 & 2.02 & 4.35 & Yes & 5.08 & 6.04 & Yes \\
\hline 2004 & 0.76 & 1.16 & Yes & 6.45 & 2.24 & No \\
\hline 2005 & 0.29 & 4.58 & Yes & 4.07 & 11.47 & Yes \\
\hline 2006 & 7.32 & 6.52 & No & 3.78 & 7.83 & Yes \\
\hline 2007 & 0.50 & 1.19 & Yes & 5.14 & 14.03 & Yes \\
\hline 2008 & 1.94 & 2.99 & Yes & 10.26 & 6.34 & No \\
\hline 2009 & 0.82 & 5.71 & Yes & 12.43 & 11.06 & No \\
\hline 2010 & 0.95 & 3.74 & Yes & 16.08 & 13.13 & No \\
\hline 2011 & 0.62 & 0.59 & No & 2.32 & 3.74 & Yes \\
\hline 2012 & 8.77 & 12.55 & Yes & 7.41 & 9.07 & Yes \\
\hline 2013 & 4.47 & 0.03 & No & 1.72 & 6.02 & Yes \\
\hline 2014 & 0.31 & 1.31 & Yes & 3.47 & 2.64 & No \\
\hline 2015 & 3.48 & 2.57 & No & 4.26 & 17.02 & Yes \\
\hline 2016 & 0.31 & 0.18 & No & 4.52 & 5.86 & Yes \\
\hline 2017 & 0.75 & 0.14 & No & 5.82 & 1.57 & No \\
\hline Mean & 2.49 & 3.48 & No. of & 5.84 & 6.24 & No. of \\
\hline SD & 3.00 & 3.67 & "Yes": 11/22 & 3.98 & 4.53 & "Yes": 12/22 \\
\hline
\end{tabular}

Notes: All entries are multiplied by $10^{4}$.

Table A9.1. Import Demand Simulations

\begin{tabular}{|c|c|c|c|}
\hline \multirow[b]{2}{*}{$\begin{array}{l}\text { Simulated } \\
\text { variable }\end{array}$} & \multicolumn{3}{|c|}{ Shock to } \\
\hline & $\begin{array}{c}\text { Income } \\
\widetilde{D Q}_{t}=D Q_{t}+r \\
\text { (2) }\end{array}$ & $\begin{array}{l}\text { Spending on group } g \\
\widetilde{D Q}_{t}^{g}=D Q_{t}^{g}+r \\
(g=1, \ldots, 8 ; g \neq 5) \\
\text { (3) }\end{array}$ & $\begin{array}{c}\text { Total imports } \\
\widetilde{D Q}_{2 t}=D Q_{2 t}+r \\
\text { (4) }\end{array}$ \\
\hline $\begin{array}{l}\text { Import } \\
\text { penetration of } g \\
\underset{\left(\frac{w_{2 s}^{g}}{W_{s}^{g}}\right)}{(p)}\end{array}$ & $\begin{array}{c}\frac{w_{2 s}^{g}+\sum_{t=1996}^{s}\left(\theta_{2}^{g}-\bar{w}_{2 t}^{g}\right) r}{W_{s}^{g}+\sum_{t=1996}^{s}\left(\Theta^{g}-\bar{W}_{t}^{g}\right) r} \\
\text { Eq. (A9.9) }\end{array}$ & $\begin{array}{c}\frac{w_{2 s}^{g}}{w_{s}^{g}}+\sum_{t=1996}^{s}\left(\frac{\theta_{2}^{g}}{\Theta^{g}}-\frac{\bar{w}_{2 t}^{g}}{\bar{w}_{t}^{g}}\right) r \\
\text { Eq. (A9.11) }\end{array}$ & $\begin{array}{c}{\left[\frac{w_{2 s}^{g}}{W_{2 s}}+\sum_{t=1996}^{s}\left(\frac{\theta_{2}^{g}}{\Theta_{2}}-\frac{\bar{w}_{2 t}^{g}}{\bar{W}_{2 t}}\right) r\right] \times} \\
{\left[W_{2 s}+\sum_{t=1996}^{s} \bar{W}_{2 t} r\right]\left(W_{s}^{g}\right)^{-1}} \\
\text { Eq. (A9.15) }\end{array}$ \\
\hline $\begin{array}{l}\text { Total imports } \\
\qquad \widetilde{W}_{2 s}^{(p)}\end{array}$ & $\begin{array}{c}W_{2 s}+\sum_{t=1996}^{S}\left(\Theta_{2}-\bar{W}_{2 t}\right) r \\
\text { Eq. (A9.10) }\end{array}$ & - & $\begin{array}{c}W_{2 s}+\sum_{t=1996}^{s} \bar{W}_{2 t} r \\
\text { Eq. (A9.13) }\end{array}$ \\
\hline
\end{tabular}

Note: “Imports” refer to non-Wood commodities only $(g \neq 5)$. 


\section{SUPPLEMENTARY MATERIALS}

A-30

Table A10.1. Domestic and Foreign Demands Under Preference Dependence With Intercepts $\bar{w}_{i t}^{g} D q_{i t}^{g}=\alpha_{i}^{g}+\theta_{i}^{g} D Q_{t}+\sum_{j=1}^{2} v_{i j}^{g}\left(D p_{j t}^{g}-D P_{t}^{\prime}\right)+\varepsilon_{i t}^{g}, \quad i=1,2 ; g=1, \cdots, 8$

\begin{tabular}{|c|c|c|c|c|c|c|c|c|c|}
\hline \multirow{3}{*}{$\begin{array}{l}\text { Commodity } \\
\text { group } g\end{array}$} & \multirow[b]{3}{*}{ Variety $i$} & \multirow{3}{*}{$\begin{array}{c}\text { Budget share } \\
\text { (Sample mean } \\
\times 100) \\
w_{i}^{g}\end{array}$} & \multicolumn{4}{|c|}{ Coefficients $(\times 100)$} & \multicolumn{3}{|c|}{ Elasticities } \\
\hline & & & \multirow[b]{2}{*}{$\begin{array}{c}\text { Intercept } \\
\alpha_{i}^{g}\end{array}$} & \multirow[b]{2}{*}{$\begin{array}{c}\text { Marginal } \\
\text { share } \\
\theta_{i}^{g}\end{array}$} & \multicolumn{2}{|c|}{ Price coefficients } & \multirow{3}{*}{$\begin{array}{l}\text { Income } \\
\eta_{i}^{g}=\frac{\theta_{i}^{g}}{w_{i}^{g}} \\
\text { (8) }\end{array}$} & \multicolumn{2}{|c|}{ Frisch price } \\
\hline & & & & & $\begin{array}{c}\text { Domestic } \\
v_{i 1}^{g}\end{array}$ & $\begin{array}{c}\text { Foreign } \\
v_{i 2}^{g}\end{array}$ & & $\begin{array}{l}\text { Domestic } \\
F_{i 1}^{g}=\frac{v_{i 1}^{g}}{w_{i}^{g}}\end{array}$ & $\begin{array}{l}\text { Foreign } \\
F_{i 2}^{g}=\frac{v_{i 2}^{g}}{w_{i}^{g}}\end{array}$ \\
\hline$(1)$ & $(2)$ & (3) & (4) & (5) & (6) & (7) & & (9) & (10) \\
\hline 1. Food and Agricultural & Domestic, 1 & 20.19 & $0.03(0.13)$ & $3.12(5.14)$ & $-2.42(2.82)$ & $0.67(0.35)$ & $0.15(0.25)$ & $-\mathbf{0 . 1 2}(0.14)$ & $0.03(0.02)$ \\
\hline Commodities & Foreign, 2 & 1.82 & $0.05(0.01)$ & $0.89(0.58)$ & & $-1.17(0.27)$ & $0.49(0.32)$ & $0.37(0.19)$ & $-0.64(0.15)$ \\
\hline \multirow{2}{*}{ 2. Energy and Minerals } & 1 & 22.29 & $-0.24(0.18)$ & $38.06(7.01)$ & $-17.75(4.02)$ & $-3.51(1.63)$ & $1.71(0.31)$ & $\mathbf{- 0 . 8 0}(0.18)$ & $-0.16(0.07)$ \\
\hline & 2 & 6.53 & $0.10(0.09)$ & $14.05(5.13)$ & & $-4.34(2.57)$ & $2.15(0.79)$ & $-0.54(0.25)$ & $\mathbf{- 0 . 6 6}(0.39)$ \\
\hline \multirow{2}{*}{ 3. Chemicals } & 1 & 5.32 & $0.01(0.05)$ & $3.46(2.00)$ & $-1.81(1.13)$ & $-0.12(0.43)$ & $0.65(0.38)$ & $\mathbf{- 0 . 3 4}(0.21)$ & $-0.02(0.08)$ \\
\hline & 2 & 2.91 & $0.07(0.02)$ & $2.82(0.81)$ & & $-1.45(0.41)$ & $0.97(0.28)$ & $-0.04(0.15)$ & $-\mathbf{0 . 5 0}(0.14)$ \\
\hline \multirow{2}{*}{$\begin{array}{l}\text { 4. Textile, Leather, Clothing and } \\
\text { Footwear }\end{array}$} & 1 & 4.56 & $-0.05(0.04)$ & $2.56(1.24)$ & $-2.05(0.80)$ & $0.62(0.29)$ & $0.56(0.27)$ & $-0.45(0.18)$ & $0.14(0.06)$ \\
\hline & 2 & 1.92 & $0.05(0.02)$ & $0.59(0.51)$ & & $-0.94(0.20)$ & $0.31(0.27)$ & $0.32(0.15)$ & $-0.49(0.10)$ \\
\hline \multirow{2}{*}{ 5. Wood and Paper Products } & 1 & 4.81 & $-0.07(0.05)$ & $0.95(1.67)$ & $-1.02(0.99)$ & $0.49(0.23)$ & $0.20(0.35)$ & $\mathbf{- 0 . 2 1}(0.21)$ & $0.10(0.05)$ \\
\hline & 2 & 0.76 & $-0.01(0.01)$ & $0.33(0.34)$ & & $-0.68(0.13)$ & $0.44(0.44)$ & $0.65(0.30)$ & $-\mathbf{0 . 8 9}(0.17)$ \\
\hline \multirow{2}{*}{ 6. Machinery and Equipment } & 1 & 7.41 & $-0.04(0.05)$ & $7.94(1.97)$ & $-4.23(1.56)$ & $-0.21(0.85)$ & $1.07(0.27)$ & $\mathbf{- 0 . 5 7}(0.21)$ & $-0.03(0.11)$ \\
\hline & 2 & 7.75 & $0.12(0.09)$ & $11.30(2.98)$ & & $-6.10(1.10)$ & $1.46(0.38)$ & $-0.03(0.11)$ & $-\mathbf{0 . 7 9}(0.14)$ \\
\hline \multirow{2}{*}{ 7. Motor Vehicles and Transport } & 1 & 5.92 & $-0.12(0.08)$ & $5.96(2.81)$ & $-3.38(2.38)$ & $0.05(1.51)$ & $1.01(0.47)$ & $\mathbf{- 0 . 5 7}(0.40)$ & $0.01(0.25)$ \\
\hline & 2 & 4.45 & $0.07(0.07)$ & $5.76(2.38)$ & & $-3.27(1.30)$ & $1.29(0.53)$ & $0.01(0.34)$ & $-\mathbf{0 . 7 3}(0.29)$ \\
\hline 8. Miscellaneous Manufactured & 1 & 2.48 & $-0.02(0.02)$ & $1.56(0.85)$ & $-0.99(0.57)$ & $0.12(0.22)$ & $0.63(0.34)$ & $\mathbf{- 0 . 4 0}(0.23)$ & $0.05(0.09)$ \\
\hline \multirow[t]{2}{*}{ Goods } & 2 & 0.89 & $0.03(0.01)$ & $0.96(0.45)$ & & $-0.66(0.14)$ & $1.08(0.50)$ & $0.14(0.25)$ & $-\mathbf{0 . 7 4}(0.16)$ \\
\hline & & & & \multicolumn{6}{|c|}{ Income flexibility $(\phi)=-0.559(0.061)$} \\
\hline
\end{tabular}

Notes:

1. Column 6: As the $2 \times 2$ matrices $\left[v_{i j}^{g}\right], g=1, \cdots, 8$, are symmetric, only the upper triangle is presented.

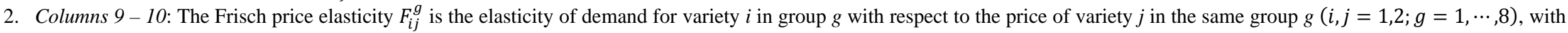
the marginal utility of income constant. The Frisch own-price elasticities, $F_{i i}^{g}$, are emboldened. The across-group Frisch elasticities are zero.

3. Bootstrap standard errors with 10,000 replications in parentheses. 
A-31

Table A10.2. Domestic and Foreign Demands under Preference Independence $\bar{w}_{i t}^{g} D q_{i t}^{g}=\theta_{i}^{g} D Q_{t}+v_{i i}^{g}\left(D p_{j t}^{g}-D P_{t}^{\prime}\right)+\xi_{i t}^{g}, \quad i=1,2 ; g=1, \cdots, 8$

\begin{tabular}{|c|c|c|c|c|c|}
\hline \multirow[b]{2}{*}{$\begin{array}{l}\text { Commodity } \\
\text { group } g\end{array}$} & \multirow[b]{2}{*}{ Variety $i$} & \multicolumn{2}{|c|}{ Coefficients $(\times 100)$} & \multicolumn{2}{|c|}{ Elasticities } \\
\hline & & $\begin{array}{c}\text { Marginal } \\
\text { share } \\
\theta_{i}^{g} \\
(3)\end{array}$ & $\begin{array}{l}\text { Price } \\
v_{i i}^{g} \\
(4)\end{array}$ & $\begin{array}{c}\text { Income } \\
\eta_{i}^{g}=\frac{\theta_{i}^{g}}{w_{i}^{g}} \\
\text { (5) }\end{array}$ & $\begin{array}{c}\text { Price } \\
F_{i i}^{g}=\frac{v_{i i}^{g}}{w_{i}^{g}} \\
\text { (6) }\end{array}$ \\
\hline 1. Food and Agricultural & Domestic, 1 & $3.31(4.23)$ & $-1.20(1.74)$ & $0.16(0.21)$ & $-0.06(0.09)$ \\
\hline Commodities & Foreign, 2 & $1.74(1.27)$ & $-0.63(0.18)$ & $0.96(0.70)$ & $-0.35(0.10)$ \\
\hline 2. Energy and Minerals & $\begin{array}{l}1 \\
2\end{array}$ & $\begin{array}{l}30.77(4.45) \\
17.47(2.52)\end{array}$ & $\begin{array}{l}-11.14(2.20) \\
-6.33(1.62)\end{array}$ & $\begin{array}{l}1.38(0.20) \\
2.67(0.39)\end{array}$ & $\begin{array}{l}-0.50(0.10) \\
-0.97(0.25)\end{array}$ \\
\hline 3. Chemicals & $\begin{array}{l}1 \\
2\end{array}$ & $\begin{array}{l}3.54(2.17) \\
3.70(1.61)\end{array}$ & $\begin{array}{l}-1.28(0.59) \\
-1.34(0.25)\end{array}$ & $\begin{array}{l}0.67(0.41) \\
1.27(0.55)\end{array}$ & $\begin{array}{l}-0.24(0.11) \\
-0.46(0.08)\end{array}$ \\
\hline $\begin{array}{l}\text { 4. Textile, Leather, Clothing } \\
\text { and Footwear }\end{array}$ & $\begin{array}{l}1 \\
2\end{array}$ & $\begin{array}{l}1.77(2.01) \\
1.44(1.31)\end{array}$ & $\begin{array}{l}-0.64(0.41) \\
-0.52(0.19)\end{array}$ & $\begin{array}{l}0.39(0.44) \\
0.75(0.68)\end{array}$ & $\begin{array}{l}-0.14(0.09) \\
-0.27(0.10)\end{array}$ \\
\hline 5. Wood and Paper Products & $\begin{array}{l}1 \\
2\end{array}$ & $\begin{array}{l}-0.20(2.07) \\
0.57(0.82)\end{array}$ & $\begin{array}{c}0.07(0.55) \\
-0.21(0.12)\end{array}$ & $\begin{array}{l}-0.04(0.43) \\
0.74(1.08)\end{array}$ & $\begin{array}{c}0.01(0.11) \\
-0.27(0.16)\end{array}$ \\
\hline 6. Machinery and Equipment & $\begin{array}{l}1 \\
2\end{array}$ & $\begin{array}{l}7.75(2.56) \\
13.70(2.65)\end{array}$ & $\begin{array}{l}-2.81(0.76) \\
-4.96(0.87)\end{array}$ & $\begin{array}{l}1.05(0.35) \\
1.77(0.34)\end{array}$ & $\begin{array}{l}-0.38(0.10) \\
-0.64(0.11)\end{array}$ \\
\hline $\begin{array}{l}\text { 7. Motor Vehicles and } \\
\text { Transport }\end{array}$ & $\begin{array}{l}1 \\
2\end{array}$ & $\begin{array}{l}4.92(2.29) \\
7.17(2.00)\end{array}$ & $\begin{array}{l}-1.78(0.92) \\
-2.60(0.73)\end{array}$ & $\begin{array}{l}0.83(0.39) \\
1.61(0.45)\end{array}$ & $\begin{array}{l}-0.30(0.16) \\
-0.58(0.16)\end{array}$ \\
\hline $\begin{array}{l}\text { 8. Miscellaneous } \\
\text { Manufactured Goods }\end{array}$ & $\begin{array}{l}1 \\
2\end{array}$ & $\begin{array}{l}1.07(1.48) \\
1.50(0.89)\end{array}$ & $\begin{array}{l}-0.39(0.29) \\
-0.54(0.10)\end{array}$ & $\begin{array}{l}0.43(0.60) \\
1.69(1.00)\end{array}$ & $\begin{array}{l}-0.16(0.12) \\
-0.61(0.11)\end{array}$ \\
\hline & & & me flexibility & $=-0.362(0$. & \\
\hline
\end{tabular}

Note: Bootstrap standard errors with 10,000 replications in parentheses.

Table A10.3. Own-Price Elasticities under Preference Independence $\bar{w}_{i t}^{g} D q_{i t}^{g}=\theta_{i}^{g} D Q_{t}+v_{i i}^{g}\left(D p_{i t}^{g}-D P_{t}^{\prime}\right)+\varepsilon_{i t}^{g}, \quad i=1,2 ; g=1, \cdots, 8$

\begin{tabular}{|c|c|c|c|c|}
\hline \multirow[b]{2}{*}{$\begin{array}{l}\text { Commodity } \\
\text { group } g \\
\text { (1) }\end{array}$} & \multirow[b]{2}{*}{ Variety $i$} & \multicolumn{3}{|c|}{ Own-price elasticities } \\
\hline & & $\begin{array}{l}\text { Frisch } \\
F_{i i}^{g}=\frac{v_{i i}^{g}}{w_{i}^{g}} \\
\text { (3) }\end{array}$ & $\begin{array}{c}\text { Slutsky } \\
S_{i i}^{g g}=\frac{\pi_{i i}^{g}}{w_{i}^{g}}\end{array}$ & $\begin{array}{c}\text { Marshallian } \\
M_{i i}^{g g}=S_{i i}^{g g}-w_{i}^{g} \eta_{i}^{g} \\
\text { (5) }\end{array}$ \\
\hline $\begin{array}{l}\text { 1. Food and Agricultural } \\
\text { Commodities }\end{array}$ & $\begin{array}{l}\text { Domestic, } 1 \\
\text { Foreign, } 2\end{array}$ & $\begin{array}{l}-0.059(0.086) \\
-0.347(0.100)\end{array}$ & $\begin{array}{l}-0.057(0.082) \\
-0.340(0.098)\end{array}$ & $\begin{array}{l}-0.091(0.134) \\
-0.358(0.103)\end{array}$ \\
\hline 2. Energy and Minerals & $\begin{array}{l}1 \\
2 \\
\end{array}$ & $\begin{array}{l}-0.500(0.099) \\
-0.968(0.248)\end{array}$ & $\begin{array}{l}-0.346(0.053) \\
-0.799(0.172)\end{array}$ & $\begin{array}{l}-0.654(0.092) \\
-0.974(0.205)\end{array}$ \\
\hline 3. Chemicals & $\begin{array}{l}1 \\
2\end{array}$ & $\begin{array}{l}-0.241(0.111) \\
-0.460(0.085)\end{array}$ & $\begin{array}{l}-0.233(0.104) \\
-0.443(0.081)\end{array}$ & $\begin{array}{l}-0.268(0.120) \\
-0.480(0.086)\end{array}$ \\
\hline $\begin{array}{l}\text { 4. Textile, Leather, Clothing and } \\
\text { Footwear }\end{array}$ & $\begin{array}{l}1 \\
2\end{array}$ & $\begin{array}{l}-0.141(0.090) \\
-0.271(0.099)\end{array}$ & $\begin{array}{l}-0.138(0.086) \\
-0.267(0.097)\end{array}$ & $\begin{array}{l}-0.156(0.098) \\
-0.281(0.102)\end{array}$ \\
\hline 5. Wood and Paper Products & $\begin{array}{l}1 \\
2\end{array}$ & $\begin{array}{r}0.015(0.114) \\
-0.269(0.160)\end{array}$ & $\begin{array}{r}0.015(0.113) \\
-0.268(0.158)\end{array}$ & $\begin{array}{r}0.017(0.129) \\
-0.274(0.162)\end{array}$ \\
\hline 6. Machinery and Equipment & $\begin{array}{l}1 \\
2\end{array}$ & $\begin{array}{l}-0.379(0.102) \\
-0.640(0.113)\end{array}$ & $\begin{array}{l}-0.350(0.089) \\
-0.552(0.091)\end{array}$ & $\begin{array}{l}-0.427(0.104) \\
-0.689(0.105)\end{array}$ \\
\hline 7. Motor Vehicles and Transport & $\begin{array}{l}1 \\
2\end{array}$ & $\begin{array}{l}-0.301(0.156) \\
-0.583(0.164)\end{array}$ & $\begin{array}{l}-0.286(0.138) \\
-0.541(0.144)\end{array}$ & $\begin{array}{l}-0.335(0.163) \\
-0.613(0.162)\end{array}$ \\
\hline $\begin{array}{l}\text { 8. Miscellaneous Manufactured } \\
\text { Goods }\end{array}$ & $\begin{array}{l}1 \\
2\end{array}$ & $\begin{array}{l}-0.157(0.116) \\
-0.611(0.111)\end{array}$ & $\begin{array}{l}-0.155(0.113) \\
-0.601(0.108)\end{array}$ & $\begin{array}{l}-0.166(0.121) \\
-0.616(0.110)\end{array}$ \\
\hline
\end{tabular}

Note: Bootstrap standard errors with 10,000 replications in parentheses. 


\section{SUPPLEMENTARY MATERIALS}

A-32

Table A10.4. Own-Price Elasticities under Partial Preference Independence $\bar{w}_{i t}^{g} D q_{i t}^{g}=\theta_{i}^{g} D Q_{t}+\phi A_{i t}^{g}(\boldsymbol{\theta})+D(g=5)[2 \gamma(i=1)-1] v_{12}^{g} \Delta p_{21, t}^{g}+\varepsilon_{i t}^{g}$; $i=1,2 ; g=1, \ldots 8$

\begin{tabular}{|c|c|c|c|c|}
\hline \multirow[b]{2}{*}{$\begin{array}{l}\text { Commodity } \\
\text { group } g\end{array}$} & \multirow[b]{2}{*}{ Variety $i$} & \multicolumn{3}{|c|}{ Own-price elasticities } \\
\hline & & $\begin{array}{l}\text { Frisch } \\
F_{i i}^{g}=\frac{v_{i i}^{g}}{w_{i}^{g}} \\
\text { (3) }\end{array}$ & $\begin{array}{l}\text { Slutsky } \\
S_{i i}^{g g}=\frac{\pi_{i i}^{g}}{w_{i}^{g}} \\
\text { (4) }\end{array}$ & $\begin{array}{c}\text { Marshallian } \\
M_{i i}^{g g}=S_{i i}^{g g}-w_{i}^{g} \eta_{i}^{g} \\
(5)\end{array}$ \\
\hline $\begin{array}{l}\text { 1. Food and Agricultural } \\
\text { Commodities }\end{array}$ & $\begin{array}{l}\text { Domestic, } 1 \\
\text { Foreign, } 2\end{array}$ & $\begin{array}{l}-0.059(0.086) \\
-0.343(0.111)\end{array}$ & $\begin{array}{l}-0.057(0.079) \\
-0.337(0.107)\end{array}$ & $\begin{array}{l}-0.090(0.132) \\
-0.355(0.111)\end{array}$ \\
\hline 2. Energy and Minerals & $\begin{array}{l}1 \\
2\end{array}$ & $\begin{array}{l}-0.495(0.091) \\
-0.952(0.254)\end{array}$ & $\begin{array}{l}-0.343(0.051) \\
-0.787(0.169)\end{array}$ & $\begin{array}{l}-0.650(0.098) \\
-0.961(0.201)\end{array}$ \\
\hline 3. Chemicals & $\begin{array}{l}1 \\
2\end{array}$ & $\begin{array}{l}-0.239(0.110) \\
-0.455(0.099)\end{array}$ & $\begin{array}{l}-0.230(0.103) \\
-0.439(0.093)\end{array}$ & $\begin{array}{l}-0.266(0.119) \\
-0.475(0.097)\end{array}$ \\
\hline $\begin{array}{l}\text { 4. Textile, Leather, } \\
\text { Clothing and Footwear }\end{array}$ & $\begin{array}{l}1 \\
2\end{array}$ & $\begin{array}{l}-0.139(0.087) \\
-0.269(0.103)\end{array}$ & $\begin{array}{l}-0.137(0.085) \\
-0.265(0.100)\end{array}$ & $\begin{array}{l}-0.154(0.096) \\
-0.279(0.105)\end{array}$ \\
\hline $\begin{array}{l}\text { 5. Wood and Paper } \\
\text { Products }\end{array}$ & $\begin{array}{l}1 \\
2\end{array}$ & $\begin{array}{l}-0.016(0.111) \\
-0.115(0.140)\end{array}$ & $\begin{array}{l}-0.016(0.112) \\
-0.114(0.139)\end{array}$ & $\begin{array}{l}-0.018(0.129) \\
-0.117(0.143)\end{array}$ \\
\hline $\begin{array}{l}\text { 6. Machinery and } \\
\text { Equipment }\end{array}$ & $\begin{array}{l}1 \\
2\end{array}$ & $\begin{array}{l}-0.375(0.097) \\
-0.635(0.117)\end{array}$ & $\begin{array}{l}-0.346(0.085) \\
-0.548(0.091)\end{array}$ & $\begin{array}{l}-0.424(0.101) \\
-0.685(0.104)\end{array}$ \\
\hline $\begin{array}{l}\text { 7. Motor Vehicles and } \\
\text { Transport }\end{array}$ & $\begin{array}{l}1 \\
2\end{array}$ & $\begin{array}{l}-0.298(0.149) \\
-0.578(0.166)\end{array}$ & $\begin{array}{l}-0.283(0.139) \\
-0.537(0.142)\end{array}$ & $\begin{array}{l}-0.332(0.165) \\
-0.608(0.160)\end{array}$ \\
\hline $\begin{array}{l}\text { 8. Miscellaneous } \\
\text { Manufactured Goods }\end{array}$ & $\begin{array}{l}1 \\
2\end{array}$ & $\begin{array}{l}-0.155(0.112) \\
-0.607(0.123)\end{array}$ & $\begin{array}{l}-0.154(0.110) \\
-0.598(0.120)\end{array}$ & $\begin{array}{l}-0.165(0.118) \\
-0.613(0.121)\end{array}$ \\
\hline
\end{tabular}

Notes:

1. Column 3 coincides with columns 8 and 9 of Table 4.4 .

2. Bootstrap standard errors with 10,000 replications in parentheses. 
SUPPLEMENTARY MATERIALS

\section{A-33}

Figure A4.1. Data Construction

\begin{tabular}{|c|}
\hline $\begin{array}{c}\text { Data } 1.0 \\
\text { Imports } \\
(\$ \mathrm{M} / \text { month })\end{array}$ \\
\hline $\begin{array}{c}\text { Data } 2.0 \\
\text { Exports } \\
(\$ \mathrm{M} / \text { month })\end{array}$ \\
\hline
\end{tabular}

60 SITC commodities

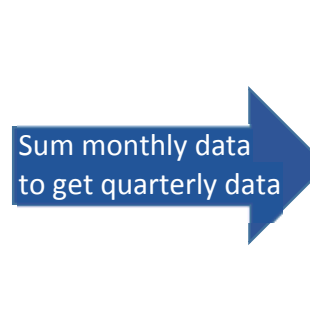

\section{(}

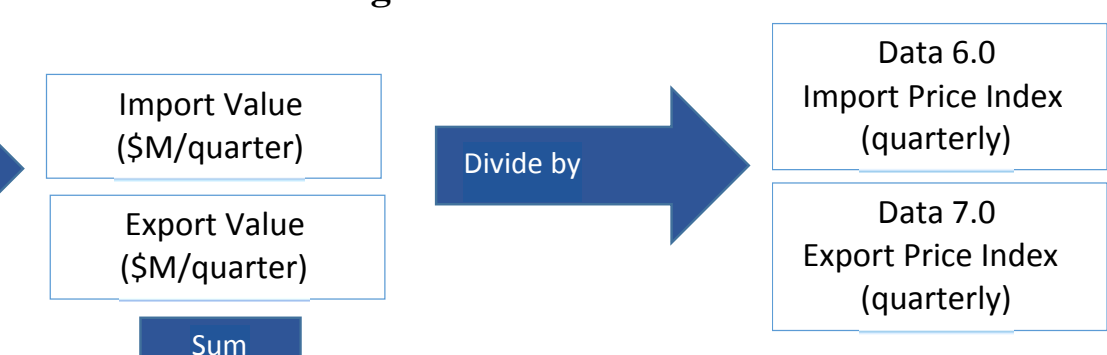

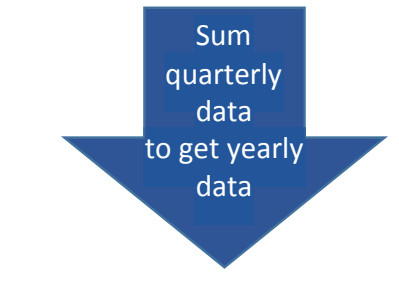
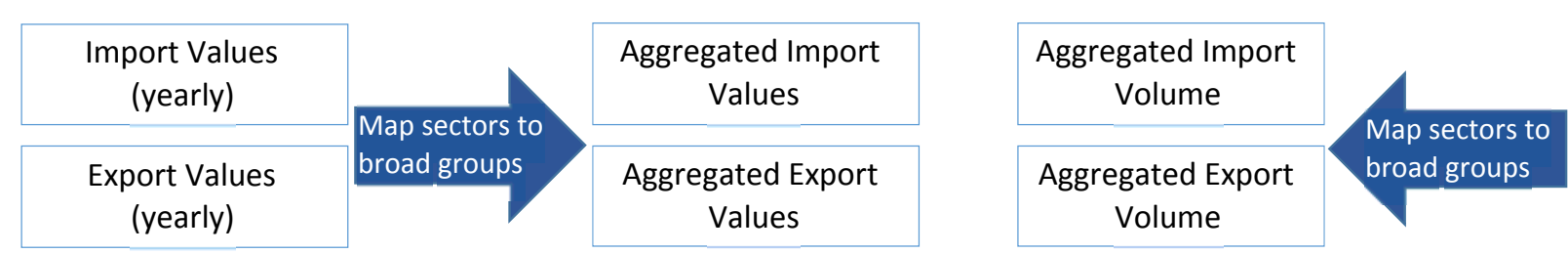

60 SITC commodities

Values

20 broad commodities Volume
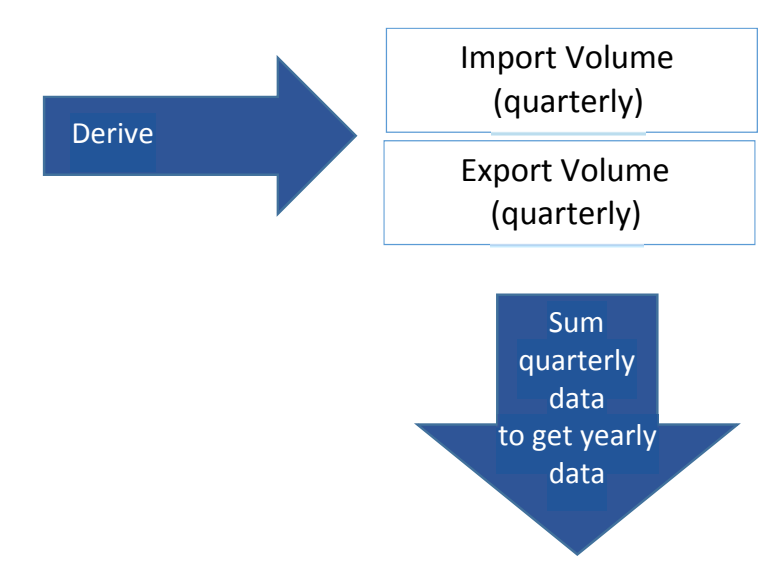

Import Volume (yearly)

Export Volume (yearly)

60 SITC commodities

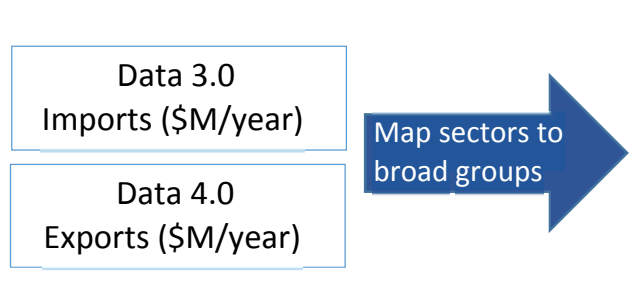

57 SUT commodities

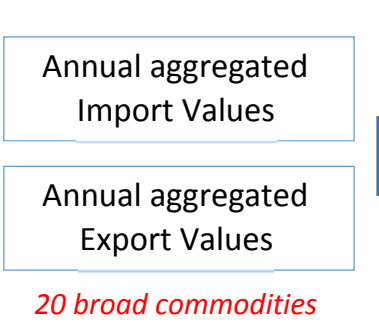

20 broad commodities

Divide values by the quantities

Notes: Database numberings (e.g., “Data 1.0”) are consistent with column 1 of Table A4.1. 
SUPPLEMENTARY MATERIALS

A-34

Figure A4.2. Quantity and Price Dispersion

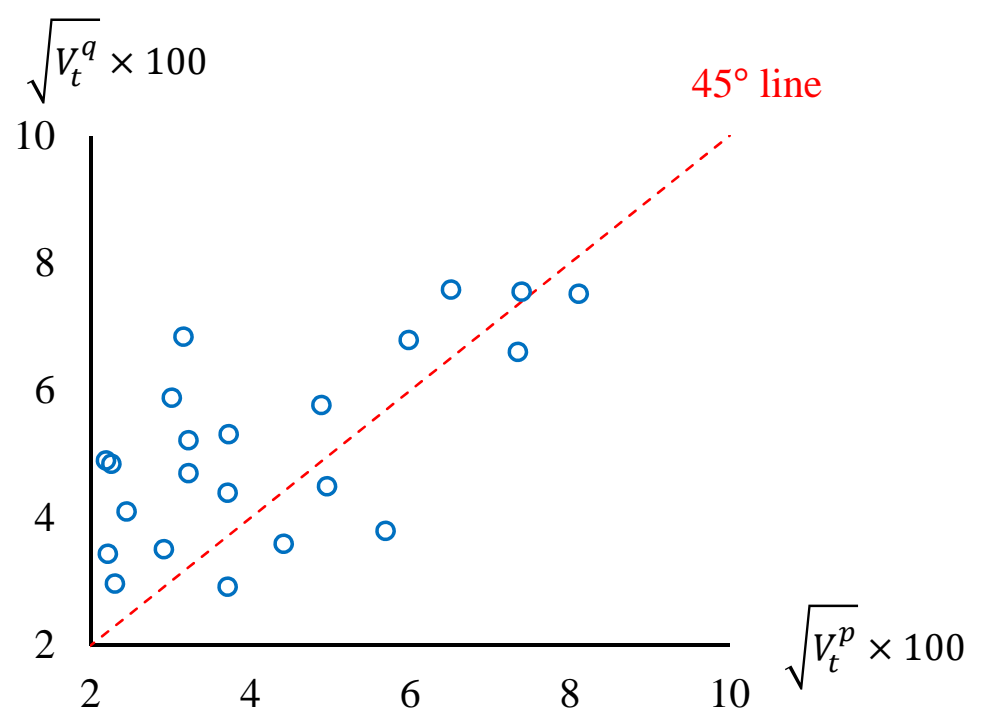




\section{SUPPLEMENTARY MATERIALS}

\section{A-35}

Figure A6.1. Distributions of F-statistics

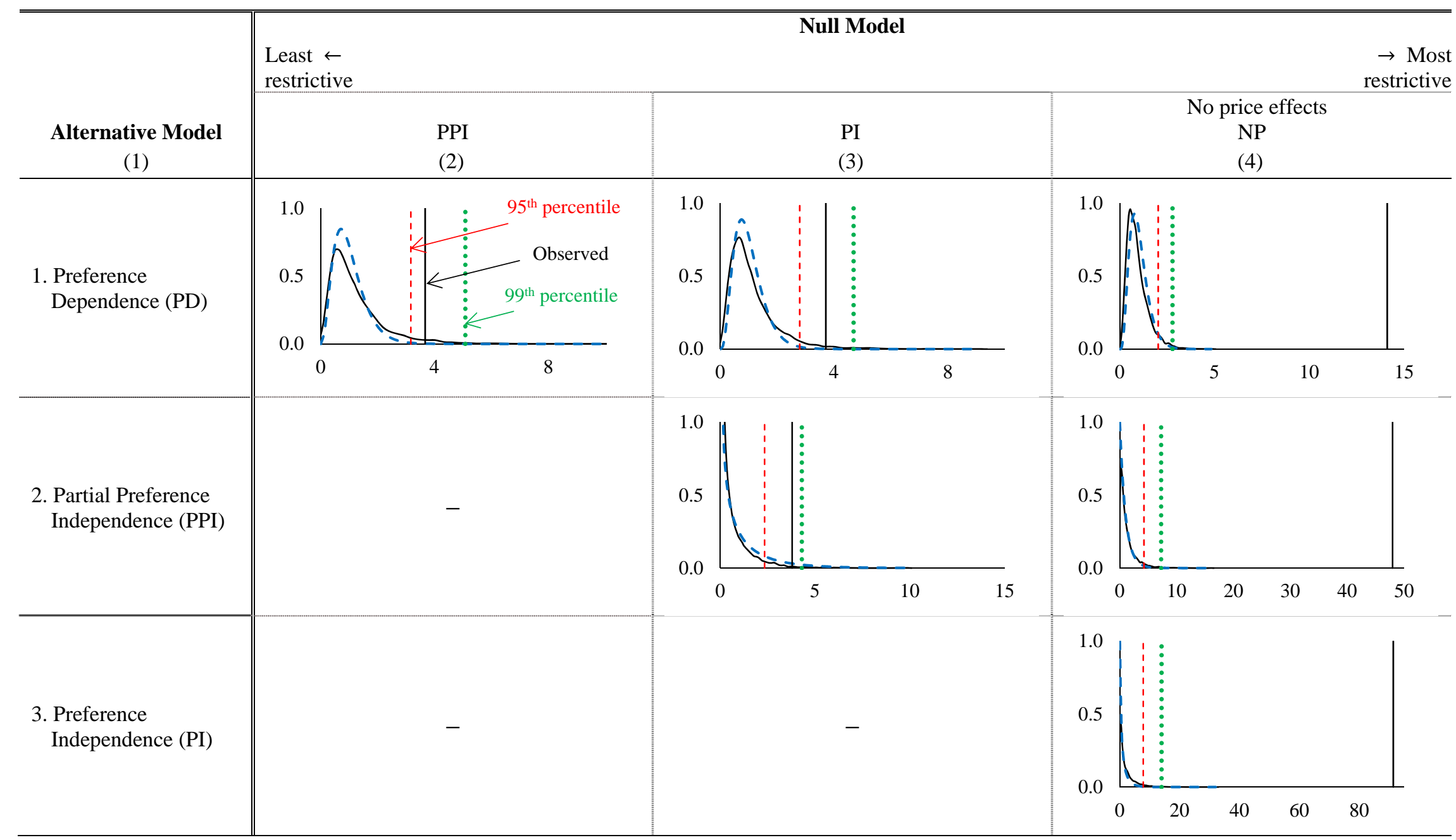

Notes: This figure presents the distributions of bootstrap F-statistics using 10,000 replications. In each plot:

1. The solid black curve indicates the bootstrap density function.

2. The dashed blue curve represents the asymptotic F-distribution density function with appropriate degrees of freedom.

3. The dashed red and dotted green vertical lines indicate the $95^{\text {th }}$ and $99^{\text {th }}$ percentiles of the bootstrap sample.

4. The black solid vertical line represents the observed F-statistic. 
A-36

Figure A8.1. Budget-Share Predictions

\section{A. By Source of Origin}

A1. Domestic Products

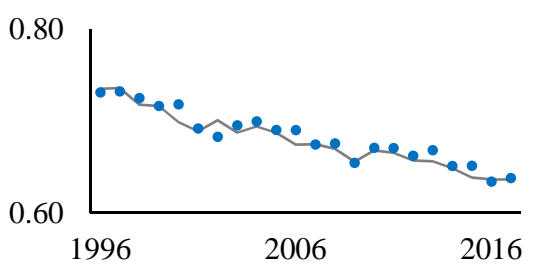

A2. Imports

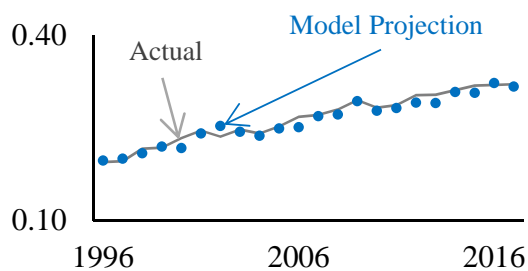

B. By Commodity Group

B1. Food and Agricultural Products

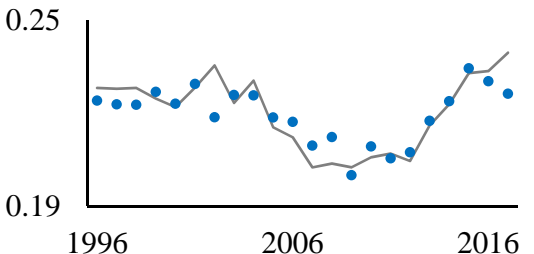

B3. Chemicals

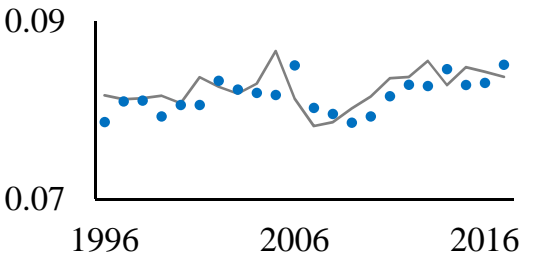

B5. Wood and Paper Products

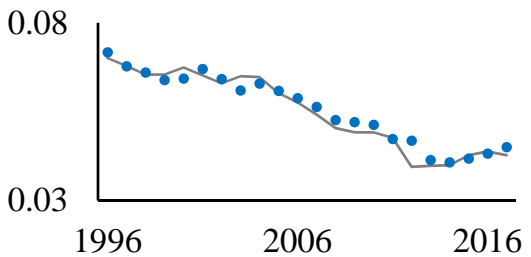

B7. Motor Vehicles and Transport

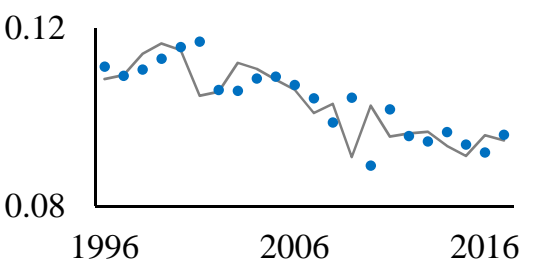

B2. Energy and Minerals

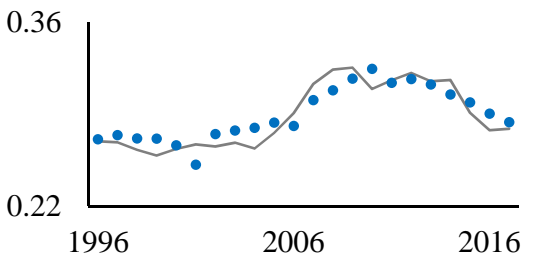

B4. Textile, Leather, Clothing and Footwear

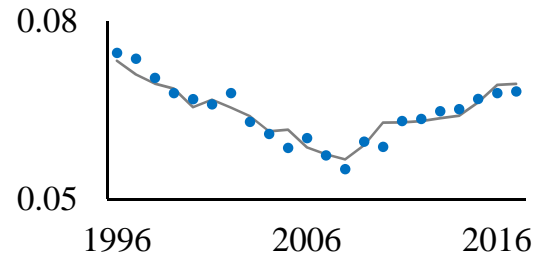

B6. Machinery and Equipment

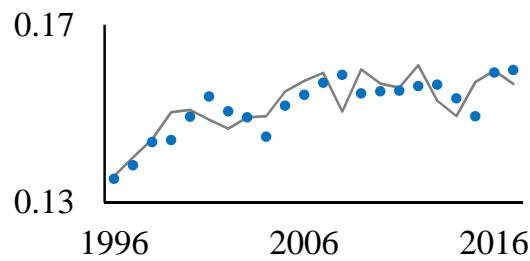

B8. Miscellaneous Manufactured Goods

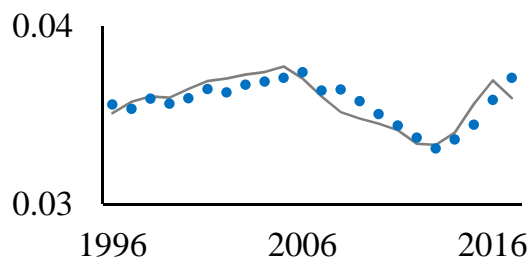

Notes:

1. Panel A: Grey solid lines are the actual shares $W_{k t}=\sum_{g \in V_{k}} w_{k t}^{g}(k=1,2)$; blue dots are the predicted shares $W_{k t}-\widehat{E}_{k t}$, where $\hat{E}_{k t}$ is the residual from the demand equation.

2. Panel B: Grey solid lines are the actual shares $W_{t}^{g}=\sum_{i=1}^{2} w_{i t}^{g}(g=1, \cdots, 8)$; blue dots are the predicted shares $W_{t}^{g}-\hat{E}_{t}^{g}$, where $\hat{E}_{t}^{g}$ is the residual from the demand equation.

3. All values are percentage shares. 